\title{
Bone disease in chronic epilepsy: fit for a fracture
}

Citation for published version (APA):

Beerhorst, K. (2015). Bone disease in chronic epilepsy: fit for a fracture. [Doctoral Thesis, Maastricht University]. Maastricht University. https://doi.org/10.26481/dis.20151113kb

Document status and date:

Published: 01/01/2015

DOI:

10.26481/dis.20151113kb

Document Version:

Publisher's PDF, also known as Version of record

\section{Please check the document version of this publication:}

- A submitted manuscript is the version of the article upon submission and before peer-review. There can be important differences between the submitted version and the official published version of record.

People interested in the research are advised to contact the author for the final version of the publication, or visit the DOI to the publisher's website.

- The final author version and the galley proof are versions of the publication after peer review.

- The final published version features the final layout of the paper including the volume, issue and page numbers.

Link to publication

\footnotetext{
General rights rights.

- You may freely distribute the URL identifying the publication in the public portal. please follow below link for the End User Agreement:

www.umlib.nl/taverne-license

Take down policy

If you believe that this document breaches copyright please contact us at:

repository@maastrichtuniversity.nl

providing details and we will investigate your claim.
}

Copyright and moral rights for the publications made accessible in the public portal are retained by the authors and/or other copyright owners and it is a condition of accessing publications that users recognise and abide by the legal requirements associated with these

- Users may download and print one copy of any publication from the public portal for the purpose of private study or research.

- You may not further distribute the material or use it for any profit-making activity or commercial gain

If the publication is distributed under the terms of Article $25 \mathrm{fa}$ of the Dutch Copyright Act, indicated by the "Taverne" license above, 


\title{
Bone disease in chronic epilepsy:
}

\author{
fit for a fracture
}


${ }^{\circ}$ Copyright Kim Beerhorst, Maastricht 2015

Layout: Tiny Wouters

Cover: Kim Beerhorst

Photograph: view advanced basecamp Cho Oyu, Tibet $(5700 \mathrm{~m})$

Printed by: Ipskamp Drukkers, Nijmegen

ISBN: 978-90-9029298-4

The printing of this thesis was financially supported by Cyberonics Europa BVBA, EISAI B.V., Kempenhaeghe Sector for Research and Development, School for Mental Health and Neuroscience (MHeNS), and UCB Pharma B.V. Breda. 


\section{Bone disease in chronic epilepsy: fit for a fracture}

\section{ACADEMISCH PROEFSCHRIFT}

ter verkrijging van de graad van doctor aan de Universiteit Maastricht, op gezag van de Rector Magnificus, Prof. dr. L.L.G. Soete volgens het besluit van het College van Decanen,

in het openbaar te verdedigen op vrijdag 13 november 2015 om 10.00 uur

door

Kim Beerhorst 


\section{Promotor}

Prof. dr. A.P. Aldenkamp

Prof. dr. R. van Oostenbrugge

\section{Copromotor}

Dr. P. Verschuure (Kempenhaeghe/ Acdemisch Centrum voor Epileptologie)

\section{Beoordelingscommissie}

Prof. dr. J.E. Wildberger (voorzitter)

Prof. dr. ir. W.H. Backes

Prof. dr. O. Bekers

Dr. A. de Louw (Kempenhaeghe/ Academisch Centrum voor Epileptologie)

Prof. dr. K. Vonck (Universiteit van Gent) 


\section{Contents}

$\begin{array}{lll}\text { Chapter } 1 \text { General introduction } & 7\end{array}$

Chapter 2 Bone disease during chronic antiepileptic drug therapy: 17

General versus specific risk factors

Chapter 3 Epilepsy: fractures and the role of cumulative antiepileptic 35

drug load

Chapter $4 \quad$ Antiepileptic drugs and high prevalence of low bone mineral 47 density in a group of inpatients with chronic epilepsy

Chapter 5 Dual-energy X-ray absorptiometry versus quantitative ultrasonography in diagnosing osteoporosis in patients with refractory epilepsy and chronic antiepileptic drug use

Chapter 6 Biochemical markers of bone turnover for the prediction of

fracture risk in patients with chronic epilepsy

$\begin{array}{lll}\text { Chapter } 7 & \text { General discussion } & 87\end{array}$

Summary \& Samenvatting 103

Dankwoord

List of publications

Curriculum Vitae

Valorisation 



\section{Chapter 1}

General introduction 
8 Chapter 1 


\section{Introduction}

Epilepsy, the tendency to have recurrent unprovoked seizures, is one of the most common serious neurological disorders. ${ }^{1}$ Its prevalence ranges from 0.5 to $1 \%$ of the population in the developed countries, and is probably higher in developing countries. ${ }^{1,2}$ Epilepsy is estimated to affect approximately 50 million people worldwide. ${ }^{3,4}$ For the Netherlands it is estimated that about 84.000 patients are suffering from active epilepsy. ${ }^{5}$

The majority of patients diagnosed with epilepsy can expect to achieve good control of seizures with antiepileptic drugs (AEDs). ${ }^{1}$ However, a substantial minority will continue to experience seizures in spite of several AEDs used in adequate doses either in mono- or polytherapy. ${ }^{1}$ Chronic use of antiepileptic drug (AED) therapy is not uncommon, despite the fact that long-term AED therapy is associated with several adverse effects such as cognitive deterioration ${ }^{6}$ and low bone mineral density. ${ }^{7-12}$

Osteoporosis is a systemic skeletal disease, characterised by low bone density (BMD) and microarchitectural deterioration of bone tissue. The consequent increase in bone fragility greatly increases the risk of fractures which represent the major relevant clinical aspects of the disease. ${ }^{13}$ In most patients the development of osteoporosis is asymptomatic, because the condition of low bone mineral density does not have to be accompanied by signs or symptoms. Only when an osteoporotic fracture occurs, osteoporosis becomes clinically overt.

In addition, the World Health Organisation (WHO) has defined osteoporosis based upon dual-energy X-ray absorptiometry (DXA) measurement, the current gold standard. Bone mineral density is expressed as T-score (number of standard deviations (SD) compared to a cohort of age-and sex-matched healthy controls). A T-score of -1.0 and greater is considered normal, low bone mass (osteopenia) is defined as a T-score between -1.0 and -2.5 , and osteoporosis is defined as a T-score of -2.5 and less. ${ }^{14,15}$ The relative risk of fracture increases as BMD decreases. The three major fracture sites in osteoporosis are the hip, the vertebrae and the distal radius. Fractures are associated with increased rates of morbidity and mortality. ${ }^{16}$

Osteoporosis affects mainly post-menopausal women but also men, in either primary or secondary forms. Besides post-menopausal status, there are several other risk factors known for the development of osteoporosis, such as low body mass index, prolonged corticosteroid therapy, previous low-trauma fracture, hypogonadism and a low calcium intake. ${ }^{13}$ However, long-term use of antiepileptic drugs in patients with epilepsy also has been associated with low BMD. In this population the reduction in BMD can be detected as early as 1-5 years after commencing AED treatment, and they have a six times greater risk of fracture. ${ }^{16}$ 


\section{Antiepileptic drugs and bone mineral density}

\section{Historical perspective}

It has been long recognised that antiepileptic drug therapy is associated with alterations in bone mineral metabolism and an increased fracture rate. As early as in 1950 Mackmull described bilateral fractures of the humeral heads due to convulsions. ${ }^{17}$ Later in the $20^{\text {th }}$ century various reports described the occurrence of fractures in patients with epilepsy and alterations in bone density. ${ }^{18-25}$ In the 1960 s and 1970 s the focus was on patients with epilepsy who were institutionalised. Later also ambulant patients otherwise healthy besides epilepsy, were involved in cohortand case-control-studies and were shown to have low BMD during AED treatment.

The strongest association between low BMD and AED therapy is with the older enzyme-inducing AEDs such as phenytoin, ${ }^{26,27}$ phenobarbital, primidone and carbamazepine. ${ }^{8,26,28}$ However, also the non-enzyme inducing AEDs such as valproic acid, $^{7,29-34}$ levetiracetam, ${ }^{35,36}$ and lamotrigine ${ }^{29,33,37,38}$ are associated with low BMD.

\section{Current clinical situation including guidelines}

The evidence for a silent epidemic of bone disease during antiepileptic drug therapy is emerging. However, a study surveying daily practice in neurology ${ }^{39}$ showed a striking lack of screening for bone mineral density and prophylactic treatment with calcium and vitamin D. In this study $41 \%$ of paediatric neurologists and $28 \%$ of adult neurologists routinely screened AED-treated patients for bone disease, and only $7 \%$ prescribed supplements for patients taking AEDs. Compared to this study which was published 14 years ago, nowadays there are several guidelines concerning screening for bone health in patients with AED treatment. According to the NICE guidelines a high level of vigilance for treatment-emergent adverse effects such as bone health issues should be maintained. This includes blood tests for bone metabolism (i.e. serum calcium, alkaline phosphatase, vitamin D levels) every 2-5 years in adults taking enzyme-inducing AEDs. The Medicines and Healthcare Regulatory Authority (MHRA) recommends considering vitamin $D$ supplementation for at risk patients treated with enzyme-inducing AEDs CBZ, PHT, primidone, and also VPA. The Scottish Intercollegiate Guidelines Network (SIGN) guidelines recommend that patients taking both enzymeinducing and non-enzyme inducing AEDs should receive dietary and lifestyle advice to reduce osteoporosis risk. ${ }^{40}$ Guidance from the USA has suggested that for newly diagnosed patients with epilepsy over the age of 60 years, use of enzyme-inducing AEDs should not be started unless at least two other AEDs have been unsuccessful in reducing seizures or have caused severe adverse effects. ${ }^{41}$ The Dutch Guidelines on Epilepsy recommend in patients older than 50 years treated with $\mathrm{PHT}, \mathrm{PB}$, primidone, CBZ and VPA adequate nutrition and appropriate calcium and vitamin D intake, and regular physical exercise. ${ }^{5}$ Based on expert-opinion when reviewing the literature on 
AEDs and bone health, the clinician should take into consideration the following points:

- All patients with epilepsy and AED treatment should be given lifestyle advices regarding prevention of osteoporosis such as regular weight-bearing exercise, nonsmoking, mild alcohol intake and sufficient/regular exposure to sunlight. ${ }^{42}$

- Baseline measurement of serum calcium, phosphate, alkaline phosphatase, parathormone and vitamin D levels in patients starting on AED treatment, but also patients already on AED treatment and repeat these measurements every 6-12 months. ${ }^{43,44}$

- Advise sufficient daily intake of calcium (1200 mg) and vitamin D (400 IU) or start supplementation. $^{38,45}$

- Consider fracture risk analysis with WHO FRAX ${ }^{\circledR}$ tool. $^{43}$

- Consider a DXA scan in patients treated with AED(s) for 2-5 year. ${ }^{42}$

- If low BMD is confirmed by DXA scan, consider referral of the patient to an internist-endocrinologist for further differential diagnosis and treatment. ${ }^{44}$

- Consider a baseline DXA scan for baseline BMD measurement in postmenopausal women who are going to start with an AED. ${ }^{42,44}$

- Other secondary causes of osteoporosis need to be excluded. ${ }^{44}$ 


\section{Aim and outline of this thesis}

Following the occurrence of fractures during minimal impact trauma in several relatively young (male) residents of Providentia (long-stay department for people with refractory epilepsy), these residents were referred to a consultant internal medicineendocrinology. Besides long-term use of anti-epileptic drugs and in some residents impaired ambulation, no other risk factors for osteoporosis were identified. The majority of these residents were diagnosed with osteoporosis. The idea for screening for osteoporosis in all the residents of the long-stay department for patients with refractory epilepsy and AED therapy was born.

The aim of this thesis was to explore the prevalence of osteoporosis in a high risk cohort of patients with epilepsy, long-term AEDs use at the long-stay department of a tertiary referral centre for epilepsy.

In chapter 2 we reviewed the literature on epilepsy and low BMD. We looked at the general and specific risk factors for the development of low BMD during antiepileptic drug treatment.

In chapter 3 we introduced the 'cumulative antiepileptic drug load' (defined as the number of current antiepileptic medication multiplied by the years of antiepileptic drug use) and we investigated the association between fractures and the cumulative antiepileptic drug load.

In chapter 4 the prevalence of low bone mineral density in the residents of the longstay department of a tertiary referral centre is investigated. We tried to identify risk factors for the development of low BMD in this high-risk population.

In chapter 5 we investigated if quantitative ultrasound of the calcaneus can be used in diagnosing osteoporosis in patients with refractory epilepsy and chronic AED use.

In chapter 6 we investigated the role of biochemical bone turnover markers for the prediction of fracture risk and low BMD in patients with chronic epilepsy.

Chapter 7 provides a general discussion and summary of the conclusions of this thesis. 


\section{References}

1. Mohanraj R, Brodie MJ. Early predictors of outcome in newly diagnosed epilepsy. Seizure 2013;22:333-344.

2. Banerjee PN, Filippi D, Allen Hauser W. The descriptive epidemiology of epilepsy-a review. Epilepsy research 2009;85:31-45.

3. Brodie MJ, Shorvon SD, Canger R, Halász P, Johannessen S, Thompson P, Wieser HG, Wolf P. Commission on European Affairs: appropriate standards of epilepsy care across Europe.ILEA. Epilepsia 1997;38:1245-1250.

4. Kwan P, Brodie MJ. Early identification of refractory epilepsy. The New England journal of medicine 2000;342:314-319.

5. 'Epilepsie' Wr. Richtlijn Epilepsie NVN. 2013; Available from: http://epilepsie.neurologie.nl. 2013.

6. Bootsma HP, Aldenkamp AP, Diepman L, Hulsman J, Lambrechts D, Leenen L, Majoie M, Schellekens A, de Krom M. The Effect of Antiepileptic Drugs on Cognition: Patient Perceived Cognitive Problems of Topiramate versus Levetiracetam in Clinical Practice. Epilepsia 2006;47 Suppl 2:24-27.

7. Stephen LJ, McLellan AR, Harrison JH, Shapiro D, Dominiczak MH, Sills GJ, Brodie MJ. Bone density and antiepileptic drugs: a case-controlled study. Seizure 1999;8:339-342.

8. Feldkamp J, Becker A, Witte OW, Scharff D, Scherbaum WA. Long-term anticonvulsant therapy leads to low bone mineral density--evidence for direct drug effects of phenytoin and carbamazepine on human osteoblast-like cells. Exp Clin Endocrinol Diabetes 2000;108:37-43.

9. Lyngstad-Brechan MA, Taubøll E, Nakken KO, Gjerstad L, Godang K, Jemtland R, Bollerslev J. Reduced bone mass and increased bone turnover in postmenopausal women with epilepsy using antiepileptic drug monotherapy. Scand J Clin Lab Invest 2008;68:759-766.

10. Lado F, Spiegel R, Masur JH, Boro A, Haut SR. Value of routine screening for bone demineralization in an urban population of patients with epilepsy. Epilepsy research 2008;78:155-160.

11. Rauchenzauner M, Griesmacher A, Tatarczyk T, Haberlandt E, Strasak A, Zimmerhackl LB, Falkensammer G, Luef G, Högler W. Chronic antiepileptic monotherapy, bone metabolism, and body composition in non-institutionalized children. Dev Med Child Neurol 2010;52:283-288.

12. Kulak CA, Borba VZ, Bilezikian JP, Silvado CE, Paola L, Boguszewski CL. Bone mineral density and serum levels of $25 \mathrm{OH}$ vitamin $\mathrm{D}$ in chronic users of antiepileptic drugs. Arq Neuropsiquiatr 2004;62:940-948.

13. Genant HK, Cooper C, Poor G, Reid I, Ehrlich G, Kanis J, Nordin BE, Barrett-Connor E, Black D, Bonjour JP, Dawson-Hughes B, Delmas PD, Dequeker J, Ragi Eis S, Gennari C, Johnell O, Johnston CC Jr, Lau EM, Liberman UA, Lindsay R, Martin TJ, Masri B, Mautalen CA, Meunier PJ, Khaltaev N, et al. Interim report and recommendations of the World Health Organization Task-Force for Osteoporosis. Osteoporos Int 1999;10:259-264.

14. Kanis JA. Assessment of fracture risk and its application to screening for postmenopausal osteoporosis: synopsis of a WHO report. WHO Study Group. Osteoporosis international : a journal established as result of cooperation between the European Foundation for Osteoporosis and the National Osteoporosis Foundation of the USA 1994;4:368-381.

15. Xu W, Perera S, Medich D, Fiorito G, Wagner J, Berger LK, Greenspan SL. Height loss, vertebral fractures, and the misclassification of osteoporosis. Bone 2011;48:307-311.

16. Phabphal K, Geater A, Limapichart K, Sathirapanya P, Setthawatcharawanich S, Witeerungrot N, Thammakumpee $\mathrm{N}$, Leelawattana $\mathrm{R}$. The association between Bsml polymorphism and bone mineral density in young patients with epilepsy who are taking phenytoin. Epilepsia 2013;54:249-255.

17. Mackmull G, Weeder SD. Bilateral fracture of the humeral heads; case with fractures of the anatomical and surgical necks of the humeri due to convulsion. Radiology 1950;55:736-739.

18. Dent CE, Richens A, Rowe DJ, Stamp TC. Osteomalacia with long-term anticonvulsant therapy in epilepsy. BMJ 1970;1970:69-72.

19. Linde J, Molholm Hansen J, Siersbaek-Nielsen K, Frederiksen VF. Bone density and long-term anticonvulsant therapy. Br Med J 1971;3:433.

20. Nilsson OS, Lindholm TS, Elmstedt E, Lindback A, Lindholm TC. Fracture incidence and bone disease in epileptics receiving long-term anticonvulsant drug treatment. Arch Orthop Trauma Surg 1986;105:146-149. 
21. Nishiyama S, Kuwahara T, Matsuda I. Decreased bone density in severely handicapped children and adults, with reference to the influence of limited mobility and anticonvulsant medication. European journal of pediatrics 1986;144:457-463.

22. Barden HS, Smith E. Bone mineral in mentally retarded patients receiving long-term anticonvulsive therapy. Growth 1975;39:371-388.

23. Lidgren L, Walloe A. Incidence of fracture in epileptics. Acta Orthop Scand 1977;48:356-361.

24. Hoikka V, Savolainen K, Alhava EM, Sivenius J, Karjalainen P, Repo A. Osteomalacia in institutionalized epileptic patients on long-term anticonvulsant therapy. Acta neurologica Scandinavica 1981;64: 122-131.

25. Hoikka V, Savolainen K, Alhava EM, Sivenius J, Karjalainen P, Parvianinen M. Anticonvulsant osteomalacia in epileptic outpatients. Ann Clin Res 1982;14:129-132.

26. Andress DL, Ozuna J, Tirschwell D, Grande L, Johnson M, Jacobson AF, Spain W. Antiepileptic druginduced bone loss in young male patients who have seizures. Arch Neurol 2002;59:781-786.

27. Pack AM, Morrell MJ, Randall A, McMahon DJ, Shane E. Bone health in young women with epilepsy after one year of antiepileptic drug monotherapy. Neurology 2008;70:1586-1593.

28. Kim SH, Lee JW, Choi KG, Chung HW, Lee HW. A 6-month longitudinal study of bone mineral density with antiepileptic drug monotherapy. Epilepsy \& behavior : E\&B 2007;10:291-295.

29. Farhat G, Yamout B, Mikati MA, Demirjian S, Sawaya R, El-Hajj Fuleihan G. Effect of antiepileptic drugs on bone density in ambulatory patients. Neurology 2002;58:1348-1353.

30. Sato Y, Kondo I, Ishida S, Motooka H, Takayama K, Tomita Y, Maeda H, Satoh K. Decreased bone mass and increased bone turnover with valproate therapy in adults with epilepsy. Neurology 2001;57: 445-449.

31. Boluk A, Guzelipek M, Savli H, Temel I, Ozisik HI, Kaygusuz A. The effect of valproate on bone mineral density in adult epileptic patients. Pharmacological research : the official journal of the Italian Pharmacological Society 2004;50:93-97.

32. Oner N, Kaya M, Karasalihoglu S, Karaca H, Celtik C, Tutunculer F. Bone mineral metabolism changes in epileptic children receiving valproic acid. J Paediatr Child Health 2004;40:470-473.

33. Guo CY, Ronen GM, Atkinson SA. Long-term valproate and lamotrigine treatment may be a marker for reduced growth and bone mass in children with epilepsy. Epilepsia 2001;42:1141-1147.

34. Ecevit C, Aydogan A, Kavakli T, Altinoz S. Effect of carbamazepine and valproate on bone mineral density. Pediatr Neurol 2004;31:279-282.

35. Nissen-Meyer LS, Svalheim S, Taubøll E, Reppe S, Lekva T, Solberg LB, Melhus G, Reinholt FP, Gjerstad $\mathrm{L}$, Jemtland R. Levetiracetam, phenytoin, and valproate act differently on rat bone mass, structure, and metabolism. Epilepsia 2007;48:1850-1860.

36. Koo DL, Joo EY, Kim D, Hong SB. Effects of levetiracetam as a monotherapy on bone mineral density and biochemical markers of bone metabolism in patients with epilepsy. Epilepsy research 2013;104:134-139.

37. Elliott JO, Jacobson MP, Haneef Z. Homocysteine and bone loss in epilepsy. Seizure 2007;16:22-34.

38. Pack AM, Morrell MJ, Marcus R, Holloway L, Flaster E, Doñe S, Randall A, Seale C, Shane E. Bone mass and turnover in women with epilepsy on antiepileptic drug monotherapy. Ann Neurol 2005;57: 252-257.

39. Valmadrid C, Voorhees C, Litt B, Schneyer CR. Practice patterns of neurologists regarding bone and mineral effects of antiepileptic drug therapy. Arch Neurol 2001;58:1369-1374.

40. Nicholas JM, Ridsdale L, Richardson MP, Grieve AP, Gulliford MC. Fracture risk with use of liver enzyme inducing antiepileptic drugs in people with active epilepsy: cohort study using the general practice research database. Seizure 2013;22:37-42.

41. Pugh MJ, Berlowitz DR, Rao JK, Shapiro G, Avetisyan R, Hanchate A, Jarrett K, Tabares J, Kazis LE. The quality of care for adults with epilepsy: an initial glimpse using the QUIET measure. BMCHealth Serv Res 2011;11:1.

42. Pack AM, Morrell MJ. Epilepsy and bone health in adults. Epilepsy \& behavior : E\&B 2004;5 Suppl 2:S24-29.

43. Panday K, Gona A, Humphrey MB. Medication-induced osteoporosis: screening and treatment strategies. Therapeutic advances in musculoskeletal disease 2014;6:185-202.

44. Valsamis HA, Arora SK, Labban B, McFarlane SI. Antiepileptic drugs and bone metabolism. Nutr Metab (Lond) 2006;3:36. 
45. Mattson RH, Gidal BE. Fractures, epilepsy, and antiepileptic drugs. Epilepsy \& behavior : E\&B 2004;5 Suppl 2:S36-40. 


\section{Chapter 2}

\section{Bone disease during chronic antiepileptic drug therapy: General versus specific risk factors}

K Beerhorst*, SJM van der Kruijs*, P Verschuure, IY Tan, AP Aldenkamp

* Both authors contributed equally Journal of Neurological Sciences 2013;331:19-25 


\section{Summary}

An increasing number of studies suggest a direct effect of antiepileptic drug (AED) therapy on bone health: Patients on chronic AED therapy may have an increased risk of fractures, reduced bone mineral density, osteopenia, and osteoporosis. In an attempt to distinguish general and specific risk factors, this review examines the available empirical research. The pathophysiology is discussed and guidelines for early detection and treatment options are proposed. 


\section{Introduction}

Epilepsy is a disease characterised by recurrent seizures and affects about 4 to 10 per 1000 persons in the general population. Antiepileptic drug (AED) therapy is the most common type of treatment, with nearly $70 \%$ of the patients eventually successfully achieving seizure remission. ${ }^{1}$ Nonetheless, treatment with AEDs is generally chronic, if not lifelong, and has been associated with serious side effects on bone health, e.g. increased fracture risk, ${ }^{2-10}$ rickets in children, ${ }^{11,12}$ decreased bone mineral density, ${ }^{9,13-16}$ osteopenia, $^{9,10,16-23}$ and osteoporosis. ${ }^{10,11,16,17,19-22}$

Although the association between AED therapy and bone health has been recurrently reported, it appears difficult to confirm causality, since other major factors may lead to increased fracture risk and altered bone health in AED-treated patients. First of all, the increased fracture rate in patients on AED therapy may result from seizure-related trauma. ${ }^{24,25}$ Also, antiepileptic drugs affect central nervous system (CNS) functions, possibly producing drowsiness, slowing of protective reflexes and incoordination, which often leads to falls and fractures, especially in the elderly. ${ }^{26-29}$ Furthermore, hospitalisation or institutionalisation of patients with epilepsy may make them susceptible to many factors for low bone mineral density (BMD), e.g. lack of exposure to sunlight, limited physical activity and poor nutrition.

Many literature reviews have focused on the relationship between AED therapy and bone disease, with a focus on enzyme-inducing AEDs. However, conclusive evidence has not been reported. This article reviews the available empirical data on the prevalence of bone disease in AED-treated patients, to explore the relative risk of several factors. In a further attempt to clarify the relationship between AED therapy and bone health, a survey of postulated mechanisms is offered. We conclude with suggestions for early identification and intervention of altered bone health in patients treated with AED therapy.

\section{Methods}

\section{Literature search}

Relevant studies were identified by searching the electronic databases Cochrane, PubMed and ScienceDirect. Articles included in this review were identified by searching the following combination of MeSH terms: ("anticonvulsants" or "epilepsy") and ("fractures, bone", or "bone diseases"). This search resulted in 1826 publications. Titles of articles and abstracts extracted during the search were reviewed for relevance, and if found to be applicable, the full-text article was retrieved. For determination of incidence and risk ratios, only articles with experimental data were included. Articles obtained via citation tracking were also considered. Articles were included when published after 1960 up till 2012. 


\section{Results}

\section{Incidence and relative risk of bone disease during AED treatment}

\section{Fractures}

Multiple empirical studies have evaluated the incidence of fractures during treatment with antiepileptic drugs, of which the results are summarised in Table 2.1. The risk of fractures is undoubtedly increased in AED-treated patients with epilepsy, with relative risk factors ranging from $1.3-6.1 .^{4-8}$ Desai et al. ${ }^{4}$ and Vestergaard et al. ${ }^{7}$ eliminated seizure-related fractures from their relative risk analysis, and still found the risk of fractures to be increased in patients with epilepsy. Their results indicate that AED treatment contributes to the increased fracture risk, independent from the influence of the epilepsy itself.

Table 2.1 Event rates and relative risk values of the occurrence of fractures in patients with epilepsy.

\begin{tabular}{|c|c|c|c|c|}
\hline & & EER & CER & $\mathrm{RR}$ \\
\hline Pedersen et al. $^{2}$ & Patients with epilepsy & $(14 / 87) 0.16$ & & \\
\hline Lidgren and Walloe ${ }^{3}$ & Patients with epilepsy & $(34 / 87) 0.39$ & & \\
\hline Annegers et al. ${ }^{30}$ & Epilepsy vs. expected CER & & & 2.3 \\
\hline Desai et al. ${ }^{4}$ & Epilepsy vs. controls & & & $4.2 / 3.4^{*}$ \\
\hline Jancar and Jancar ${ }^{5}$ & Epilepsy vs. controls & $(18 / 68) 0.26$ & 0.15 & 1.7 \\
\hline Scane et al. ${ }^{6}$ & Epilepsy vs. controls & & & 6.1 \\
\hline Vestergaard et al. ${ }^{7}$ & Epilepsy vs. controls & & & $2.0 / 1.3^{*}$ \\
\hline Persson et al. ${ }^{8}$ & Patients with epilepsy & (20/177) 0.11 & & 2.4 \\
\hline Souverein et al. ${ }^{31}$ & Epilepsy vs. controls & (3478/40485) 0.09 & (3940/80970) 0.05 & 1.9 \\
\hline Swanton et al. ${ }^{9}$ & Patients with epilepsy & (112/208) 0.54 & & \\
\hline \multirow{2}{*}{$\begin{array}{l}\text { Gniatkowska- } \\
\text { Nowakowska }^{10}\end{array}$} & Epilepsy vs. controls & $(43 / 126) 0.34$ & $(19 / 132) 0.14$ & 2.4 \\
\hline & $\begin{array}{l}\text { Polytherapy AED vs. } \\
\text { monotherapy }\end{array}$ & 0.49 (33/67) & 0.17 (10/59) & 2.9 \\
\hline Jefferson et al. $^{32}$ & Patients with Rett syndrome & $(26 / 97) 0.32$ & & \\
\hline
\end{tabular}

$\mathrm{EER}=$ Experimental Event Rate, $\mathrm{CER}=$ Control Event Rate, $\mathrm{RR}=$ Relative Risk $(\mathrm{EER} / \mathrm{CER}) .{ }^{*}$ Relative risk ratio after elimination of seizure-related fractures.

\section{Rickets}

Rickets is a childhood condition which is characterised by insufficient amounts of vitamin $\mathrm{D}$, calcium or phosphate in the bone matrix. The accumulation of unmineralised osteoid disturbs the mineralisation of the growth plate of the bone. As a result, the bone does not become rigid and bends more easily. The mineral deficiency in the bones eventually causes destruction of the supportive matrix, resulting in progressive softening and weakening of the bones' structure. Symptoms can include bone pain and tenderness, dental problems, muscle weakness and severe skeletal deformities. 
The incidence of rickets has greatly decreased after improved nutrition. It is now considered a rare disease, affecting less than 200,000 in the US population (National Institutes of Health). Although often the result of malnutrition- e.g. lack of vitamin $D$, calcium or phosphate- rickets has also been associated with AED treatment in children (Table 2.2). The two investigations identified by our literature search merely assessed institutionalised children with coexisting neurological or mental disease. ${ }^{11,12}$ These children are more prone to confounding factors as malnutrition and lack of physical activity as well as sunlight exposure, making it difficult to demonstrate an effect of AED treatment. However, since rickets only occurred in children who were on add-on therapy and not able to walk, polytherapy and immobility emerge as candidate specific risk factors.

Later studies handling ambulatory children did not focus on the occurrence of rickets, but investigated bone mineral density (BMD), with which more subtle changes related to AED therapy may also be detected (see below).

Table 2.2 Event rates and relative risk values of the occurrence of rickets in children with epilepsy.

\begin{tabular}{lcc}
\hline & EER & CER \\
\hline Lifshitz and Maclaren $^{11}$ & & \\
Epilepsy vs. controls & $(9 / 134) 0.07$ & $(0 / 154) 0$ \\
Polytherapy AED vs. monotherapy & $(9 / 68) 0.13$ & $(0 / 66) 0$ \\
Immobile vs. ambulatory & $(9 / 159) 0.06$ & $(9 / 159) 0.06$ \\
Morijiri and Sato & & \\
Epilepsy vs. Controls & $(9 / 144) 0.06$ & $(0 / 84) 0$ \\
Polytherapy AED vs. monotherapy & $(9 / 94) 0.10$ & $(0 / 46) 0$ \\
Immobile vs. ambulatory & $(9 / 114) 0.08$ & $(0 / 114) 0$ \\
\hline
\end{tabular}

$\mathrm{EER}=$ Experimental Event Rate, $\mathrm{CER}=$ Control Event Rate.

\section{Reduced bone mineral density (BMD)}

The higher incidence of bone disease in patients with epilepsy suggests softening of the bones caused by defective bone mineralisation (a condition often referred to as osteomalacia) to be a result of AED therapy. Indeed, investigations of Sheth and Hermann, ${ }^{14}$ Kim et al., ${ }^{13}$ and Phabphal et al. ${ }^{16}$ suggest bone mineral density to be reduced in patients on AED therapy compared to healthy controls (Table 2.3). Especially treatment with carbamazepine ${ }^{13}$ and other enzyme-inducing AEDs ${ }^{16}$ appear to have a significant effect on bone mineral status in addition to the risk of polytherapy. However, Heo et al. ${ }^{33}$ found no significant differences in bone mineral density between patients on AED therapy and healthy controls, and between patients on carbamazepine, valproate or topiramate. 
Table 2.3 Average bone mineral density z-scores* in AED-treated patients with epilepsy.

\begin{tabular}{|c|c|c|c|}
\hline & Group 1 & Group 2 & p-value \\
\hline \multicolumn{4}{|l|}{ Kim et al. $^{13}$} \\
\hline Before/After 6 months of Lamotrigine $(\mathrm{N}=8)$ & $0.60(0.17)$ & $0.48(0.18)$ & NS \\
\hline Before/After 6 months of Valproic Acid ( $N=15)$ & $0.61(0.41)$ & $0.06(0.30)$ & NS \\
\hline Before/After 6 months of Carbamazepine $(N=10)$ & $0.42(0.26)$ & $-0.34(0.35)$ & 0.043 \\
\hline \multicolumn{4}{|l|}{ Sheth and Hermann ${ }^{14}$} \\
\hline Lamotrigine monother. $(\mathrm{N}=13)$ vs. controls $(\mathrm{N}=36)$ & $0.49(0.7)$ & $0.52(0.76)$ & NS \\
\hline Polytherapy $1-5$ yrs $(\mathrm{N}=21)$ vs. controls $(\mathrm{N}=36)$ & $0.14(0.8)$ & $0.52(0.76)$ & NS \\
\hline Polytherapy >6 yrs $(\mathrm{N}=19)$ vs. controls $(\mathrm{N}=36)$ & $0.24(1.15)$ & $0.52(0.76)$ & $<0.003$ \\
\hline \multicolumn{4}{|l|}{ Swanton et al. ${ }^{9}$} \\
\hline Patients with epilepsy ( $N=208$ ) & $1.10(1.43)$ & & - \\
\hline \multicolumn{4}{|l|}{ Sheth and Hermann ${ }^{15}$} \\
\hline Epilepsy ( $N=116)$ vs. controls ( $N=36)$ & $0.31(1.1)$ & $0.54(0.75)$ & - \\
\hline Idiopathic $(\mathrm{N}=79)$ vs. symptomatic $(\mathrm{N}=37)$ & $0.38(1)$ & $0.17(1)$ & - \\
\hline Generalised ( $N=52)$ vs. partial $(N=64)$ & $0.12(1.1)$ & $0.47(1.1)$ & - \\
\hline \multicolumn{4}{|l|}{ Phabphal et al. ${ }^{16}$} \\
\hline Patients with epilepsy ( $N=123$ ) & $-0.45(1.12)$ & & - \\
\hline EIAED ( $N=97)$ vs. Non-EIAED $(\mathrm{N}=26)$ & $-0.53(1.05)$ & $-0.15(1.32)$ & 0.024 \\
\hline Polytherapy $(\mathrm{N}=52)$ vs. monotherapy $(\mathrm{N}=71)$ & $-0.51(1.06)$ & $-0.41(1.17)$ & NS \\
\hline \multicolumn{4}{|l|}{ Heo et al. ${ }^{33}$} \\
\hline Topiramate $(\mathrm{N}=36)$ vs. controls $(\mathrm{N}=36)$ & $0.17(0.98)$ & $-0.06(0.85)$ & NS \\
\hline Carbamazepine ( $\mathrm{N}=36)$ vs. controls $(\mathrm{N}=36)$ & $0.01(0.96)$ & $-0.06(0.85)$ & NS \\
\hline Valproate $(\mathrm{N}=32)$ vs controls $(\mathrm{N}=36)$ & $0.12(0.95)$ & $-0.06(0.85)$ & NS \\
\hline \multicolumn{4}{|l|}{ 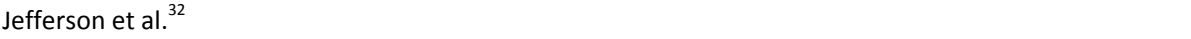 } \\
\hline Patients with Rett syndrome & $-1.10(2.43)$ & & - \\
\hline
\end{tabular}

BMD z-scores are reported as mean (SD); EIAED=Enzyme-inducing AEDs; NS=Non-significant. * Because most empirical studies that examined bone mineral density have reported BMD $z$-scores, only studies using $z$-scores are included in this report for uniformity of comparison.

\section{Osteopenia}

Osteopenia is a bone disease characterised by a reduction in bone mineral density. It is considered to be a precursor to osteoporosis, but not every person with osteopenia develops osteoporosis. Osteopenia and osteoporosis can be diagnosed with dualenergy X-ray absorptiometry (DXA) scanning, distinguishing osteopenia ( $T$-score -1 to -2.5 SD) and osteoporosis ( $T$-score <-2.5 SD) according to the World Health Organisation (WHO) definition. ${ }^{34}$

Table 2.4 shows that epilepsy has been associated with increased risk of osteopenia in multiple studies. The event rate is around $30 \%$ in most studies and the relative risk varies from 1.3 to 3.8. Based on these investigations, no definite conclusions can be drawn about the distinct effects of the factors involved and specifically of the effect of the different AEDs. 
Table 2.4 Event rates and relative risk values of the osteopenic measurements in patients with epilepsy.

\begin{tabular}{|c|c|c|c|}
\hline & EER & CER & $\mathrm{RR}$ \\
\hline \multicolumn{4}{|l|}{ Pack et al. ${ }^{17}$} \\
\hline Epilepsy vs. controls (<50 yrs) & (39/97) 0.40 & $0.15^{*}$ & 2.7 \\
\hline Epilepsy vs. controls (>50 yrs) & $(19 / 53) 0.35$ & $0.15^{*}$ & 2.3 \\
\hline \multicolumn{4}{|l|}{ Lohiya et al. $^{19}$} \\
\hline Epilepsy vs. other residents & $(93 / 300) 0.31$ & $(63 / 262) 0.24$ & 1.3 \\
\hline \multicolumn{4}{|l|}{ Oner et al. ${ }^{18}$} \\
\hline Epilepsy vs. controls & $(7 / 33) 0.21$ & $(0 / 33) 0$ & - \\
\hline \multicolumn{4}{|l|}{ Elliot et al. $^{20}$} \\
\hline Patients with epilepsy & $(59 / 137) 0.43$ & & \\
\hline \multicolumn{4}{|l|}{ Swanton et al. ${ }^{9}$} \\
\hline Patients with epilepsy & $(65 / 208) 0.31$ & & \\
\hline \multicolumn{4}{|l|}{ Cansu et al. ${ }^{21}$} \\
\hline Patients with epilepsy & $(3 / 34) 0.09$ & & \\
\hline \multicolumn{4}{|l|}{ Lado et al. $^{22}$} \\
\hline Patients with epilepsy & $(51 / 130) 0.39$ & & \\
\hline \multicolumn{4}{|l|}{ Phabphal et al. ${ }^{16}$} \\
\hline Patients with epilepsy & $(45 / 123) 0.36$ & & \\
\hline \multicolumn{4}{|l|}{ Gniatkowska-Nowakowska ${ }^{10}$} \\
\hline Epilepsy vs. controls & $(29 / 126) 0.23$ & $(8 / 132) 0.06$ & 3.8 \\
\hline \multicolumn{4}{|l|}{ Triantafyllou et al. ${ }^{23}$} \\
\hline Patients with epilepsy & $(10 / 41) 0.24$ & & \\
\hline
\end{tabular}

EER=Experimental Event Rate, CER=Control Event Rate, RR=Relative Risk (EER/CER). * Expected by WHO norms in medically healthy population.

\section{Osteoporosis}

Osteoporosis is defined as a systemic disorder of the skeleton, characterised by low bone mass and deterioration of bone microarchitecture, resulting in increased fracture risk. As demonstrated in Table 2.5, epilepsy and the use of AEDs have been associated with osteoporosis. The relative risk varies from 1.7 to 3.8. As suggested by Lifshitz and Maclaren, ${ }^{11}$ polytherapy and immobility may be specific risk factors for osteoporosis. These results suggest a specific effect of epilepsy or AED therapy on bone health. 
Table 2.5 Event rates and relative risk values of osteoporotic measurements in patients with epilepsy.

\begin{tabular}{|c|c|c|c|}
\hline & EER & CER & $\mathrm{RR}$ \\
\hline \multicolumn{4}{|l|}{ Lifshitz and Maclaren $^{11}$} \\
\hline Epilepsy vs. controls & $(20 / 134) 0.15$ & $(0 / 154) 0$ & - \\
\hline Polytherapy AED vs. monotherapy & $(20 / 68) 0.29$ & $(0 / 66) 0$ & - \\
\hline Immobile vs. ambulatory & $(20 / 159) 0.14$ & $(0 / 129) 0$ & - \\
\hline \multicolumn{4}{|l|}{ Pack et al. ${ }^{17}$} \\
\hline Epilepsy vs. controls (<50 yrs) & (10/97) 0.10 & $0.06^{*}$ & 1.7 \\
\hline Epilepsy vs. controls (>50 yrs) & $(12 / 53) 0.23$ & $0.06^{*}$ & 3.8 \\
\hline \multicolumn{4}{|l|}{ Lohiya et al. $^{19}$} \\
\hline Epilepsy vs. other residents & $(71 / 300) 0.24$ & $(27 / 262) 0.10$ & 2.4 \\
\hline \multicolumn{4}{|l|}{ Elliot et al. $^{20}$} \\
\hline Patients with epilepsy & $(40 / 137) 0.29$ & & \\
\hline \multicolumn{4}{|l|}{ Swanton et al. ${ }^{9}$} \\
\hline Patients with epilepsy & $(76 / 208) 0.37$ & & \\
\hline \multicolumn{4}{|l|}{ Lado et al. ${ }^{22}$} \\
\hline Patients with epilepsy & $(21 / 130) 0.16$ & & \\
\hline \multicolumn{4}{|l|}{ Phabphal et al. ${ }^{16}$} \\
\hline Patients with epilepsy & $(5 / 123) 0.04$ & & \\
\hline \multicolumn{4}{|l|}{ Gniatkowska-Nowakowska ${ }^{10}$} \\
\hline Epilepsy vs. controls & $(9 / 126) 0.07$ & $(0 / 132) 0$ & - \\
\hline
\end{tabular}

EER=Experimental Event Rate, CER=Control Event Rate, RR=Relative Risk (EER/CER). * Expected by WHO norms in medically normal population.

\section{General and specific risk factors for bone disease during AED treatment}

\section{General risk factors}

Several risk factors have long been identified for the development of bone diseases such as osteopenia and osteoporosis in the general population. These general risk factors include malnutrition (low calcium, vitamin D, phosphorus, overall poor nutrition), decreased exposure to sunlight, low body weight, race (i.e. Caucasian), female gender, and family history of bone disease. ${ }^{35}$ Risk factors which are especially important in a chronic epilepsy population are impaired physical mobility and institutionalisation (because of the increased risk of malnutrition and decreased exposure to sunlight). However, the increased fracture risk of institutionalised patients with epilepsy may also be related to refractoriness of the epilepsy. ${ }^{4}$

However, next to these general risk factors, some specific risk factors have been identified for patients under AED-treatment: Type of AED, amount of AEDs, and duration of AED therapy are variables which may influence the incidence of bone disease during AED treatment. ${ }^{11-13,16}$ The following section provides some explanations regarding these specific risk factors.

\section{Type of AED}

Because of the variability in pharmacodynamics of the different AEDs, several AEDs have been associated with bone disease. The majority of published reports describe 
AEDs that induce the hepatic cytochrome P450 system. Enzyme-inducers (i.e. phenytoin, phenobarbital, carbamazepine and primidone) may have a more deteriorative effect on bone than non-inducers. ${ }^{17,36}$ However, non-inducing or even inhibiting AEDs have also been associated with altered bone health.

\section{Phenytoin}

Treatment with phenytoin is associated with higher bone turnover, as demonstrated by an increase in serum markers of bone formation and resorption. Decreased levels of calcium and vitamin D have also been observed, as well as increased PTH levels. ${ }^{37-46}$ An increase in calcium has also been reported, probably resulting from increased resorption of bone. ${ }^{47}$

Välimäki et al. ${ }^{48}$ observed reduced serum concentrations of 25-hydroxy vitamin D and 1,25-dihydroxy vitamin $D$ in 38 female patients on phenytoin and carbamazepine. Bone mineral density was only reduced in females using phenytoin. These results suggest other mechanisms than the cytochrome P450 enzyme system to be involved, since phenytoin and carbamazepine have the same potency of enzyme induction.

\section{Carbamazepine}

Carbamazepine is another inducer of hepatic enzymes. There are conflicting results in evaluating the effect of carbamazepine on bone mineral content. Several studies have been performed by Tjellesen et al. ${ }^{45,49}$ In one of their first studies, ${ }^{45}$ they found decreased serum 25-(OH)D levels, serum alkaline phosphatase levels to be increased $(p<0.05)$, and hypocalcaemia to be present $(p<0.001)$ in patients on carbamazepine. These results were not as pronounced as those found in patients on phenytoin. However, they only included 9 patients on carbamazepine. In a later study ${ }^{49}$ they included 30 patients on carbamazepine monotherapy. These patients had a normal bone mass, normal serum $25-(\mathrm{OH}) \mathrm{D}$ levels, increased serum alkaline phosphatase levels $(p<0.001)$, and reduced serum calcium levels $(p<0.001)$. Because these results were similar to what was found in the previous study, the authors question the connection between liver enzyme induction and anticonvulsant osteomalacia, since carbamazepine possesses the same potency of liver enzyme induction as phenytoin.

Similar results were found by Hoikka et al., ${ }^{41}$ who found lower serum $25-(\mathrm{OH}) \mathrm{D}$ levels in patients using carbamazepine. Other outcomes were not significant. Verrotti et al. ${ }^{50,51}$ demonstrated increased alkaline phosphatase levels in carbamazepine using patients of different ages, alongside with other markers that suggest elevated bone formation and resorption. However, vitamin D levels remained normal.

In addition, Sheth et al. ${ }^{52}$ used DXA scanning to investigate bone health in patients on carbamazepine, and found no significant reduction in bone mineral density. Similarly, Brämswig and colleagues ${ }^{53}$ found no significant changes in bone formation and resorption markers. However, they used different markers, and their subjects were only treated for 10 weeks with carbamazepine. 


\section{Valproate}

Although valproate inhibits the P450 system, it may also have negative effects on bone health. Early studies in patients using valproate found no significant abnormalities in calcium or $(25-\mathrm{OH}) \mathrm{D}$ levels, ${ }^{40}$ but a recent investigation in 40 patients using valproate therapy demonstrated increased serum concentrations of calcium (which may be due to increased bone resorption) and decreased level of vitamin D metabolites. ${ }^{54}$ Results in children taking valproate are also conflicting: decreases in BMD as well as normal BMD have been reported. ${ }^{52,55-57}$ The mechanism by which valproate may affect bone health is not understood.

\section{Newer drugs}

There are a few studies evaluating newer AEDs such as lamotrigine, gabapentin, topiramate and tiagabine. Kim et al. ${ }^{13}$ found bone mineral density and vitamin D not to be affected by 6 months of lamotrigine therapy. Sheth and Hermann ${ }^{14}$ also found no differences in BMD between patients on lamotrigine monotherapy and healthy controls.

Zhang et al. ${ }^{58}$ demonstrated altered serum contents of calcium and phosphorus as well as BMD reduction in topiramate treated children.

Stephen et al. ${ }^{59}$ investigated the effect of a few of these newer AEDs (lamotrigine, topiramate and gabapentin) and found no significant abnormalities. However, as in many studies, most of the subjects were on anticonvulsant polytherapy. As a consequence, the effect of a single drug is difficult to establish.

A report in young women treated with lamotrigine monotherapy found no significant differences in bone markers for formation or resorption of bone. ${ }^{52}$ In a study in epileptic children, Guo et al. ${ }^{55}$ found short stature, low BMD and reduced bone formation to be associated with long-term valproate and lamotrigine therapy, particularly when combined. However, they concluded that these changes were probably due to lack of physical activity rather than to the medication itself.

\section{Polytherapy}

Treatment with more than one AED is thought to have an increased bone-destructing influence compared with monotherapy. No specific combinations of AEDs appeared to be more devastating than others, but all studies involving polytherapy included at least one enzyme-inducing AED. However, results are conflicting. For example, Gniatkowska-Nowakowska ${ }^{10}$ demonstrated the incidence of fractures to be higher in patients on polytherapy compared to patients on monotherapy, suggesting add-on therapy also to be a specific risk factor. Gough et al. ${ }^{40}$ found the most severe biochemical changes in biochemical markers in the polytherapy group. Similarly, Farhat et al. ${ }^{60}$ reported multiple AED use as a possible risk factor for bone disease, but their results were not significant and could be confounded by inconcordance of therapy duration. Persson et al. ${ }^{8}$ reported an increase in fractures in patients receiving 
polytherapy in contrast to monotherapy, but their results were also not significant. Tekgul et al. ${ }^{61}$ investigated children on mono- and polytherapy and also found no significant differences between the two groups. Research addressing confounding variables that might explain any relationship between AED polytherapy and bone disease could provide more clarity. For example, patients on polytherapy might have reduced balance, leading to increased fracture rates, ${ }^{28,29,62}$ or exercise and mobility may be decreased due to the failure to reach seizure freedom in these patients.

\section{Treatment duration}

Souverein et al. ${ }^{63}$ investigated the duration of AED therapy as a possible risk factor for fractures. They concluded that fracture risk increased with cumulative duration of AED exposure, with a strong association for exposure duration of 12 years and more. Their results indicate treatment duration to be a specific risk factor for anticonvulsantrelated bone disease.

\section{Pathophysiology of antiepileptic drug-induced bone disease}

Bone undergoes continuous remodelling, a process in which calcium and phosphorus are required for bone formation and bone resorption. These processes occur in tandem by osteoblasts and osteoclasts, coupled together via paracrine cell signalling. As bone formation actively fixes circulating calcium in its mineral form, removing it from the bloodstream, it is crucial that systemic calcium levels are satisfactory. The main system to maintain calcium homeostasis is the vitamin D - parathyroid hormone (PTH) axis.

It is hypothesised that AED therapy influences the vitamin D - PTH axis, which results in altered bone mineral density. The principal mechanism reported is hepatic induction of the cytochrome P450 enzyme system which leads to accelerated catabolism of vitamin D into its inert metabolites. ${ }^{64,65}$ This in turn leads to a decline in intestinal absorption of calcium, which causes a depression of calcium concentration in the serum. The parathyroid gland is thereby stimulated to release PTH. The net result is mobilisation of calcium and phosphorus from the bone, causing demineralised bone, more susceptible to fracture. ${ }^{66,67}$

Most AEDs associated with bone loss are cytochrome P450 enzyme-inducing AEDs, e.g. phenytoin, phenobarbital, carbamazepine and primidone. However, there is also evidence of reduced $B M D$ in patients who are treated with non-enzyme inducing AEDs, and even enzyme-inhibitors such as valproate. ${ }^{52,54,68}$ Also, studies measuring general bone turnover markers, such as cross-linked-N-telopeptides of type 1 collagen, osteocalcine and alkaline phosphatase showed an increase of bone turnover in patients with epilepsy, despite normal levels of vitamin D. ${ }^{50,51}$ These observations lead to the idea that treatment with non-enzyme-inducing AEDs can also result in bone disease, and other mechanisms than the vitamin D - PTH axis are involved. 
Other mechanisms have been proposed such as a direct effect of AED therapy on the bone including an obstruction of calcium uptake. AEDs may also directly inhibit the calcium uptake from the intestine, leading to low serum calcium levels. AED therapy might also result in hyperparathyroidism, causing high levels of PTH which trigger the bone to release calcium, thereby increasing bone turnover. Paradoxically, as demonstrated in rats, another effect of AED may be an inhibition of cellular response to PTH. This diminished sensitivity to PTH could also lead to hypocalcaemia.

Calcitonin deficiency has also been associated with AED treatment. Calcitonin, a hormone produced by the thyroid gland, is believed to inhibit osteoclast mediated bone resorption. Deficiency of this hormone can therefore cause higher rate of bone turnover. ${ }^{69}$

One explanation of decreased calcium found in some studies could be the impaired response to PTH. Normally, PTH acts as a stimulator of bone resorption, leading to a higher level of calcium in the blood. When there is an impairment of response to PTH, resorption will decline which could lead to hypocalcaemia.

\section{Importance and realisation of early identification and intervention of bone disease during AED treatment}

Although the evidence for a silent epidemic of bone disease among patients using AEDs is emerging, a large study surveying daily practice in neurology by Valmadrid et al. $^{70}$ showed a striking lack of screening for mineral defects and prophylactic treatment with calcium and vitamin D: $41 \%$ of paediatric neurologists and $28 \%$ of adult neurologists routinely evaluated AED-treated patients for bone health, and only $7 \%$ prescribed supplements for patients taking AEDs.

\section{Recommendations for prevention and treatment of bone disease during AED} treatment

\section{a). Screening}

Determination of serum calcium, alkaline phosphatase, and 25-hydroxyvitamin D and DXA-baseline scans have been recommended for epilepsy patients with AEDs use at risk. DXA is the accepted "gold standard" (World Health Organisation) for detecting and diagnosing osteoporosis. However, DXA measurement requires a substantial patient cooperation for reliable readings, some radiation load is involved and the machine is not portable. In patients who have limitations in mobility or with anatomical restrictions (joint contractures, scoliosis etc.) DXA scan of lumbar spine and hip is not always possible. Quantitative Ultrasound (QUS) of the heel appears to be a good alternative in situations where central DXA is unavailable. ${ }^{71}$ Heel QUS is inexpensive, transportable, ionizing radiation-free, and like central DXA, proven to predict hip fractures and all osteoporotic fractures in elderly women. It could 
therefore be a more practical method for screening under the condition that its sensitivity and specificity are comparable with DXA.

\section{b). Prevention/prophylaxis}

Adequate nutrition, avoidance of alcohol and smoking, appropriate calcium and vitamin D intake, regular menstrual cycles and normal physical exercise are essential elements in preventing osteoporosis. ${ }^{72,73}$ In patients with chronic epilepsy, these factors must therefore be carefully monitored. The supplementation of vitamin $D$ is often recommended, although the optimal moment of initiation and the exact doses remain unclear. Drezner ${ }^{74}$ advises an immediate start with vitamin D 2.000 IU daily at the beginning of AED treatment. Tested doses of vitamin D supplementation vary from $4.000 \mathrm{IU}$ in children ${ }^{75}$ to $120.000 \mathrm{IU}$ in adults. ${ }^{76}$ In a prospective study by Collins et al. $^{77}$ in both institutionalised- and outpatients on AED therapy, a dose of vitamin D ranging from 400-4000 IU/day was needed to retain normal serum 25-hydroxy vitamin D levels.

Additional supplementation of calcium has also been recommended. For example, Ali et al. ${ }^{66}$ propose daily supplementation of $1000-1500 \mathrm{mg}$ of calcium for patients who are on AEDs for more than 6 months and have no documented osteoporosis. Drezner $^{74}$ recommends a calcium intake of $600-1000 \mathrm{mg} /$ day. Important to note is that calcium carbonate may interfere with the effects of AEDs, and for that reason should not be taken at the same time of day. ${ }^{78,79}$

Specific interventions need to be proposed for patients at high risk, including polypharmacy and hospitalisation.

\section{c). Treatment}

When bone disease has already been established, vitamin $\mathrm{D}$ can be given for curative reasons and a dose of $120.000 \mathrm{IU} /$ day for one month has proven effects on serum levels and BMD markers. ${ }^{76}$ Other therapies have been proposed, for example calcitriol, a synthetic vitamin D analogue. The needed dose of calcitriol varies from 0.25 to 0.75 microgram daily. However, complications of calcitriol therapy have been described, such as hypocalcaemia. ${ }^{80}$

Bisphosphonates are frequently used in treatment of osteoporosis, especially in postmenopausal women. Published research in postmenopausal women concludes that BMD increases after treatment with alendronate, etidronate and risedronate. ${ }^{81-83}$ It is likely that these medications will improve the bone mineral content also in patients with antiepileptic drug-induced osteoporosis. However, for these patients there are no international evidence-based medicine guidelines concerning treatment, duration of treatment and follow-up. This is important since these patients are on average much younger than postmenopausal women. The effects of these substances on bone growth and bone remodelling are unknown, as are the adverse effects of very long-term use. Also teratogenity is a factor which has to be taken into account in younger persons. ${ }^{74}$ 
Hormone replacement therapy is another form of therapy which may be helpful in women with bone disease, but there are multiple reported serious side effects to this treatment, including breast cancer, cardiovascular events and increase in seizure activity. $^{84}$

\section{Discussion}

Epilepsy increases the risk of bone disease. The relative risk for osteopenia varies from 1.3 to 3.8 ; for osteoporosis from 1.7 to 3.8 , and for fractures from 1.7 to 6.1 . These findings suggest that patients receiving chronic anticonvulsant drug therapy should be carefully evaluated for the presence of drug-induced bone disease and treated appropriately. This is especially important in those patients in whom the presence of multiple risk factors indicates an increased likelihood of deranged mineral metabolism. It is generally assumed that treatment with enzyme-inducing AEDs belongs to these risk factors, but the evidence for this association is modest to poor. In contrast, non-inducing or even inhibiting AEDs have also been associated with altered bone health. Rather more general factors, such as polytherapy and possibly therapy duration, seem to have an effect.

The increased risk implies that screening for early signs of bone disease is necessary in patients on chronic antiepileptic drug therapy. However, guidelines concerning the time of screening start and 'minimal signs' requiring prophylaxis or treatment have not been well-defined. Two factors further complicate the decision making about screening: the pathophysiology of bone disease during AED treatment is largely unclear, and no clear risk factors in terms of type of antiepileptic drug and duration of treatment have been identified. Prevention is needed and should be focused on life style (mobility, nutrition) and vitamin D supplementation. How early the latter prophylaxis should start and with what dose is unclear. Finally, treatment should start at least after diagnosis of osteoporosis. However, the long-term effects of osteoporosis treatment are not known, which is especially important in young patients.

We suggest that all patients receiving chronic anticonvulsant drug therapy should be carefully evaluated for the presence of drug-induced bone disease and treated appropriately with vitamin D. This is especially important in those patients in whom the presence of multiple risk factors indicates an increased likelihood of deranged mineral metabolism. 


\section{References}

1. Kwan P, Brodie MJ. Early identification of refractory epilepsy. N Engl J Med 2000;342:314-9.

2. Pedersen KK, Christiansen $C$, Ahlgren $P$, Lund $M$. Incidence of fractures of the vertebral spine in epileptic patients. Acta Neurol Scand 1976;54:200-3.

3. Lidgren L, Walloe A. Incidence of fracture in epileptics. Acta Orthop Scand 1977;48:356-61.

4. Desai KB, Ribbans WJ, Taylor GJ. Incidence of five common fracture types in an institutional epileptic population. Injury 1996;27:97-100.

5. Jancar J, Jancar MP. Age-related fractures in people with intellectual disability and epilepsy. J Intellect Disabil Res 1998;42:429-33.

6. Scane AC, Francis RM, Sutcliffe AM, Francis MJ, Rawlings DJ, Chapple CL. Case-control study of the pathogenesis and sequelae of symptomatic vertebral fractures in men. Osteoporosis Int 1999;9:91-7.

7. Vestergaard P, Tigaran S, Rejnmark L, Tigaran C, Dam M, Mosekilde L. Fracture risk is increased in epilepsy. Acta Neurol Scand 1999;99:269-75.

8. Persson HB, Alberts KA, Farahmand BY, Tomson T. Risk of extremity fractures in adult outpatients with epilepsy. Epilepsia 2002;43:768-72.

9. Swanton J, Simister R, Altmann D, Watts H, Keen R, Duncan JS, et al. Bone mineral density in institutionalised patients with refractory epilepsy. Seizure 2007;16:538-41.

10. Gniatkowska-Nowakowska A. Fractures in epilepsy children. Seizure 2010;19:324-5.

11. Lifshitz F, Maclaren NK. Vitamin D-dependent rickets in institutionalized, mentally retarded children receiving long-term anticonvulsant therapy. I. A survey of 288 patients. J Pediatr 1973;83:612-20.

12. Morijiri Y, Sato T. Factors causing rickets in institutionalised handicapped children on anticonvulsant therapy. Arch Dis Child 1981;56:446-9.

13. Kim SH, Lee JW, Choi KG, Chung HW, Lee HW. A 6-month longitudinal study of bone mineral density with antiepileptic drug monotherapy. Epilepsy Behav 2007;10:291-5.

14. Sheth RD, Hermann BP. Bone mineral density with lamotrigine monotherapy for epilepsy. Pediatr Neurol 2007;37:250-4.

15. Sheth RD, Hermann BP. Bone in idiopathic and symptomatic epilepsy. Epilepsy Res 2008;78:71-6.

16. Phabphal K, Geater A, Leelawattana R, Sathirapunya P, Sattawatcharawanich S, Limapichat K. Prevalence and risk factors of low bone mineral density and 25-hydroxyvitamin $D$ status in young healthy epileptic adult patients in a tropical Asian country taking antiepileptic drug. Bone 2009;45:232-7.

17. Pack AM, Olarte LS, Morrell MJ, Flaster E, Resor SR, Shane E. Bone mineral density in an outpatient population receiving enzyme-inducing antiepileptic drugs. Epilepsy Behav 2003;4:169-74.

18. Oner N, Kaya M, Karasalihoglu S, Karaca H, Celtik C, Tutunculer F. Bone mineral metabolism changes in epileptic children receiving valproic acid. J Paediatr Child Health 2004;40:470-3.

19. Lohiya GS, Tan-Figueroa L, lannucci A. Identification of low bone mass in a developmental center: finger bone mineral density measurement in 562 residents. J Am Med Dir Assoc 2004;5:371-6.

20. Elliott JO, Jacobson MP, Haneef Z. Homocysteine and bone loss in epilepsy. Seizure 2007;16:22-34.

21. Cansu A, Yesilkaya E, Serdaroglu A, Hirfanoglu TL, Camurdan O, Gulbahar O, et al. Evaluation of bone turnover in epileptic children using oxcarbazepine. Pediatr Neurol 2008;39:266-71.

22. Lado F, Spiegel R, Masur JH, Boro A, Haut SR. Value of routine screening for bone demineralization in an urban population of patients with epilepsy. Epilepsy Res 2008;78:155-60.

23. Triantafyllou N, Lambrinoudaki I, Armeni E, Evangelopoulos EM, Boufidou F, Antoniou A, et al. Effect of long-term valproate monotherapy on bone mineral density in adults with epilepsy. J Neurol Sci 2010;290:131-4.

24. Tomson T, Beghi E, Sundqvist A, Johannessen SI. Medical risks in epilepsy: a review with focus on physical injuries, mortality, traffic accidents and their prevention. Epilepsy Res 2004;60:1-16.

25. Beghi E. Accidents and injuries in patients with epilepsy. Expert Rev Neurother 2009;9:291-8.

26. Ensrud KE, Blackwell TL, Mangione CM, Bowman PJ, Whooley MA, Bauer DC, et al. Central nervous system-active medications and risk for falls in older women. J Am Geriatr Soc 2002;50:1629-37.

27. Fife TD, Blum D, Fisher RS. Measuring the effects of antiepileptic medications on balance in older people. Epilepsy Res 2006;70:103-9. 
28. Gandelman-Marton R, Arlazoroff A, Dvir Z. Balance performance in adult epilepsy patients. Seizure 2006;15:582-9.

29. Petty SJ, Hill KD, Haber NE, Paton LM, Lawrence KM, Berkovic SF, et al. Balance impairment in chronic antiepileptic drug users: a twin and sibling study. Epilepsia 2010;51:280-8.

30. Annegers JF, Melton $\amalg, 3 r d$, Sun CA, Hauser WA. Risk of age-related fractures in patients with unprovoked seizures. Epilepsia 1989;30:348-55.

31. Souverein PC, Webb DJ, Petri H, Weil J, Van Staa TP, Egberts T. Incidence of fractures among epilepsy patients: a population-based retrospective cohort study in the General Practice Research Database. Epilepsia 2005;46:304-10.

32. Jefferson AL, Woodhead HJ, Fyfe S, Briody J, Bebbington A, Strauss BJ, et al. Bone mineral content and density in Rett syndrome and their contributing factors. Pediatr Res 2011;69:293-8.

33. Heo K, Rhee Y, Lee HW, Lee SA, Shin DJ, Kim WJ, et al. The effect of topiramate monotherapy on bone mineral density and markers of bone and mineral metabolism in premenopausal women with epilepsy. Epilepsia 2011;52:1884-9.

34. Assessment of fracture risk and its application to screening for postmenopausal osteoporosis. Report of a WHO Study Group. World Health Organ Tech Rep Ser 1994;843:1-129.

35. Wasserman SH, Barzel US. Osteoporosis: the state of the art in 1987: a review. Semin Nucl Med 1987; 17:283-92.

36. Petty SJ, Paton LM, O'Brien TJ, Makovey J, Erbas B, Sambrook P, et al. Effect of antiepileptic medication on bone mineral measures. Neurology 2005;65:1358-65.

37. Richens A, Rowe DJ. Disturbance of calcium metabolism by anticonvulsant drugs. BMJ 1970;4:73-6.

38. Hahn TJ, Birge SJ, Scharp CR, Avioli LV. Phenobarbital-induced alterations in vitamin D metabolism. J Clin Invest 1972;51:741-8.

39. Bouillon R, Reynaert J, Claes JH, Lissens W, De Moor P. The effect of anticonvulsant therapy on serum levels of 25-hydroxy-vitamin D, calcium, and parathyroid hormone. J Clin Endocrinol Metab 1975;41:1130-5.

40. Gough H, Goggin T, Bissessar A, Baker M, Crowley M, Callaghan N. A comparative study of the relative influence of different anticonvulsant drugs, UV exposure and diet on vitamin $D$ and calcium metabolism in out-patients with epilepsy. Q J Med 1986;59:569-77.

41. Hoikka V, Savolainen K, Alhava EM, Sivenius J, Karjalainen P, Repo A. Osteomalacia in institutionalized epileptic patients on long-term anticonvulsant therapy. Acta Neurol Scand 1981;64:122-31.

42. Skillen AW, Pierides AM. Serum gamma glutamyl transferase and alkaline phosphatase activities in epileptics receiving anticonvulsant therapy. Clin Chim Acta 1976;72:245-51.

43. Davie MW, Emberson CE, Lawson DE, Roberts GE, Barnes JL, Barnes ND, et al. Low plasma 25hydroxyvitamin $D$ and serum calcium levels in institutionalized epileptic subjects: associated risk factors, consequences and response to treatment with vitamin D. Q J Med 1983;52:79-91.

44. Stamp TC, Round JM, Rowe DJ, Haddad JG. Plasma levels and therapeutic effect of 25hydroxycholecalciferol in epileptic patients taking anticonvulsant drugs. BMJ 1972;4:9-12.

45. Tjellesen L, Christiansen C. Serum vitamin D metabolites in epileptic patients treated with 2 different anti-convulsants. Acta Neurol Scand 1982;66:335-41.

46. Weinstein RS, Bryce GF, Sappington L, King DW, Gallagher BB. Decreased serum ionized calcium and normal vitamin D metabolite levels with anticonvulsant drug treatment. J Clin Endocrinol Metab 1984;58:1003-9.

47. Takahashi A, Onodera K, Shinoda H, Mayanagi H. Phenytoin and its metabolite, 5-(4-hydroxyphenyl)5-phenylhydantoin, show bone resorption in cultured neonatal mouse calvaria. Jpn J Pharmacol 2000;82:82-4.

48. Valimaki MJ, Tiihonen M, Laitinen K, Tahtela R, Karkkainen M, Lamberg-Allardt C, et al. Bone mineral density measured by dual-energy $x$-ray absorptiometry and novel markers of bone formation and resorption in patients on antiepileptic drugs. J Bone Miner Res 1994;9:631-7.

49. Tjellesen L, Nilas L, Christiansen C. Does carbamazepine cause disturbances in calcium metabolism in epileptic patients? Acta Neurol Scand 1983;68:13-9.

50. Verrotti A, Greco R, Latini G, Morgese G, Chiarelli F. Increased bone turnover in prepubertal, pubertal, and postpubertal patients receiving carbamazepine. Epilepsia 2002;43:1488-92.

51. Verrotti A, Greco R, Morgese G, Chiarelli F. Increased bone turnover in epileptic patients treated with carbamazepine. Ann Neurol 2000;47:385-8. 
52. Sheth RD, Wesolowski CA, Jacob JC, Penney S, Hobbs GR, Riggs JE, et al. Effect of carbamazepine and valproate on bone mineral density. J Pediatr 1995;127:256-62.

53. Bramswig S, Zittermann A, Berthold HK. Carbamazepine does not alter biochemical parameters of bone turnover in healthy male adults. Calcif Tissue Int 2003;73:356-60.

54. Sato $\mathrm{Y}$, Kondo I, Ishida S, Motooka H, Takayama K, Tomita $\mathrm{Y}$, et al. Decreased bone mass and increased bone turnover with valproate therapy in adults with epilepsy. Neurology 2001;57:445-9.

55. Guo CY, Ronen GM, Atkinson SA. Long-term valproate and lamotrigine treatment may be a marker for reduced growth and bone mass in children with epilepsy. Epilepsia 2001;42:1141-7.

56. Kafali G, Erselcan T, Tanzer F. Effect of antiepileptic drugs on bone mineral density in children between ages 6 and 12 years. Clin Pediatr (Phila) 1999;38:93-8.

57. Akin R, Okutan V, Sarici U, Altunbas A, Gokcay E. Evaluation of bone mineral density in children receiving antiepileptic drugs. Pediatr Neurol 1998;19:129-31.

58. Zhang J, Wang KX, Wei Y, Xu MH, Su JM, Bao YG, et al. [Effect of topiramate and carbamazepine on bone metabolism in children with epilepsy]. Zhongguo Dang Dai Er Ke Za Zhi 2010;12:96-8.

59. Stephen LJ, McLellan AR, Harrison JH, Shapiro D, Dominiczak MH, Sills GJ, et al. Bone density and antiepileptic drugs: a case-controlled study. Seizure 1999;8:339-42.

60. Farhat G, Yamout B, Mikati MA, Demirjian S, Sawaya R, El-Hajj Fuleihan G. Effect of antiepileptic drugs on bone density in ambulatory patients. Neurology 2002;58:1348-53.

61. Tekgul H, Dizdarer G, Demir N, Ozturk C, Tutuncuoglu S. Antiepileptic drug-induced osteopenia in ambulatory epileptic children receiving a standard vitamin D3 supplement. J Pediatr Endocrinol Metab 2005;18:585-8.

62. Arima K, Kitamura J, Onuma T, Hirose H, Yamadera H, Yamaguchi A. Analysis of the swaying of center of gravity in standing posture of patients with antiepileptic drugs. Jpn J Psychiatry Neurol 1990;44:371-3.

63. Souverein PC, Webb DJ, Weil JG, Van Staa TP, Egberts AC. Use of antiepileptic drugs and risk of fractures: case-control study among patients with epilepsy. Neurology 2006;66:1318-24.

64. Pack AM, Morrell MJ. Adverse effects of antiepileptic drugs on bone structure: epidemiology, mechanisms and therapeutic implications. CNS Drugs 2001;15:633-42.

65. Mintzer S, Boppana P, Toguri J, DeSantis A. Vitamin D levels and bone turnover in epilepsy patients taking carbamazepine or oxcarbazepine. Epilepsia 2006;47:510-5.

66. Ali, II, Schuh L, Barkley GL, Gates JR. Antiepileptic drugs and reduced bone mineral density. Epilepsy Behav 2004;5:296-300.

67. Fitzpatrick LA. Pathophysiology of bone loss in patients receiving anticonvulsant therapy. Epilepsy Behav 2004;5 Suppl 2:S3-15.

68. Boluk A, Guzelipek M, Savli H, Temel I, Ozisik HI, Kaygusuz A. The effect of valproate on bone mineral density in adult epileptic patients. Pharmacol Res 2004;50:93-7.

69. Rasmussen H, Tenenhouse A. Thyrocalcitonin, osteoporosis and osteolysis. Am J Med 1967;43: 711-26.

70. Valmadrid C, Voorhees C, Litt B, Schneyer CR. Practice patterns of neurologists regarding bone and mineral effects of antiepileptic drug therapy. Arch Neurol 2001;58:1369-74.

71. Krieg MA, Barkmann R, Gonnelli S, Stewart A, Bauer DC, Del Rio Barquero L, et al. Quantitative ultrasound in the management of osteoporosis: the 2007 ISCD Official Positions. J Clin Densitom 2008;11:163-87.

72. Lane JM, Russell L, Khan SN. Osteoporosis. Clin Orthop Relat Res 2000(372):139-50.

73. Lloyd ME, Spector TD, Howard R. Osteoporosis in neurological disorders. J Neurol Neurosurg Psychiatry 2000;68:543-7.

74. Drezner MK. Treatment of anticonvulsant drug-induced bone disease. Epilepsy Behav 2004;5 Suppl 2:S41-7.

75. Liakakos D, Papadopoulos Z, Vlachos P, Boviatsi E, Varonos DD. Serum alkaline phosphatase and urinary hydroxyproline values in children receiving phenobarbital with and without vitamin D. J Pediatr 1975;87:291-6.

76. Pedrera JD, Canal ML, Carvajal J, Postigo S, Villa LF, Hernandez ER, et al. Influence of vitamin D administration on bone ultrasound measurements in patients on anticonvulsant therapy. Eur J Clin Invest 2000;30:895-9. 
77. Collins N, Maher J, Cole M, Baker M, Callaghan N. A prospective study to evaluate the dose of vitamin $D$ required to correct low 25-hydroxyvitamin D levels, calcium, and alkaline phosphatase in patients at risk of developing antiepileptic drug-induced osteomalacia. Q J Med 1991;78:113-22.

78. Carter BL, Garnett WR, Pellock JM, Stratton MA, Howell JR. Effect of antacids on phenytoin bioavailability. Ther Drug Monit 1981;3:333-40.

79. McElnay JC, Uprichard G, Collier PS. The effect of activated dimethicone and a proprietary antacid preparation containing this agent on the absorption of phenytoin. Br J Clin Pharmacol 1982;13:501-5.

80. Hunt PA, Wu-Chen ML, Handal NJ, Chang CT, Gomez M, Howell TR, et al. Bone disease induced by anticonvulsant therapy and treatment with calcitriol (1,25-dihydroxyvitamin D3). Am J Dis Child 1986;140:715-8.

81. Storm T, Thamsborg G, Steiniche T, Genant HK, Sorensen OH. Effect of intermittent cyclical etidronate therapy on bone mass and fracture rate in women with postmenopausal osteoporosis. N Engl J Med 1990;322:1265-71.

82. Harris ST, Watts NB, Genant HK, McKeever CD, Hangartner T, Keller M, et al. Effects of risedronate treatment on vertebral and nonvertebral fractures in women with postmenopausal osteoporosis: a randomized controlled trial. Vertebral Efficacy With Risedronate Therapy (VERT) Study Group. JAMA. 1999;282:1344-52.

83. Pols HA, Felsenberg D, Hanley DA, Stepan J, Munoz-Torres M, Wilkin TJ, et al. Multinational, placebocontrolled, randomized trial of the effects of alendronate on bone density and fracture risk in postmenopausal women with low bone mass: results of the FOSIT study. Fosamax International Trial Study Group. Osteoporosis international : a journal established as result of cooperation between the European Foundation for Osteoporosis and the National Osteoporosis Foundation of the USA. 1999;9:461-8.

84. Pack AM. The Association Between Antiepileptic Drugs and Bone Disease. Epilepsy Curr 2003;3:91-5. 


\section{Chapter}

\section{Epilepsy: fractures and the role of cumulative antiepileptic drug load}

K Beerhorst, FM Schouwenaars, IY Tan, AP Aldenkamp Acta Neurologica Scandinavica 2012;125:54-59 


\section{Summary}

\section{Background}

An association between antiepileptic drugs (AEDs), low bone mineral density, fractures and abnormalities in bone metabolism has been suggested for a longer period although conclusive evidence has not been reported. We aimed at studying patient characteristics in a high risk population.

\section{Methods}

All adult patients from a residential unit of a tertiary epilepsy centre who were diagnosed with osteoporosis and consequently treated with a bisphosphonate at that moment were included. Correlations between reported fractures and patient characteristics were explored.

\section{Results}

54 patients of the total population of 261 adult patients were included resulting in a high prevalence rate of $21 \%$ osteoporosis in this population. The number of fractures correlated significantly with ambulatory status $(r=-0.269, p=0.05)$, drug load $[r=0.286, p=0.04])$ and current number of AEDs ( $r=0.283, p=0.04)$.

Correlations could not be provided for individual drugs in our population as only a minority was on monotherapy and even less patients had always been on monotherapy of the same antiepileptic drug. Linear regression analysis showed that cumulative drug load (defined by a surrogate parameter: the total duration of epilepsy multiplied by the number of AEDs) was the dominant factor explaining the occurrence of fractures.

\section{Conclusion}

In this high risk population we obtained a positive and strong correlation between the occurrence of fractures in a diagnosed population with osteoporosis and the cumulative drug load of antiepileptic drugs. This effect seems general, independent of the type of AEDs that were used. 


\section{Introduction}

An association between anti-epileptic drugs (AEDs), low bone mineral density (BMD), fractures and abnormalities in bone metabolism has been suggested during a longer period. In the 1960's and 1970's initially phenobarbital (PB), phenytoin (PHT) and primidone were studied and associated with hypocalcaemia, osteomalacia, ${ }^{1,2}$ and increased incidence of fractures. ${ }^{3}$ Later on the second generation AEDs carbamazepine $(\mathrm{CBZ})^{4}$ and valproic acid $(\mathrm{VPA})^{5-8}$ were associated with low BMD. Nowadays also the newer AEDs such as lamotrigine (LTG), ${ }^{5,9}$ oxcarbazepine (OXC), ${ }^{10}$ and in animal studies also levetiracetam (LVT) ${ }^{11}$ are associated with negative effects on bone mineral metabolism and bone quality. Although few of the studies present conclusive evidence most studies have found some association between the use of specific AEDs and low BMD. In addition the following factors are mentioned in patients on AED treatment: polytherapy, ${ }^{5,12}$ age older than 50 years, ${ }^{13,14}$ postmenopausal status, ${ }^{13}$ use of AEDs for longer than 2 years, ${ }^{12,14}$ and use of enzymeinducing AEDs. ${ }^{13,14}$ Nowadays, screening for osteoporosis is recommended in patients using AEDs. ${ }^{15}$ Clinically the most important consequence of low BMD is an increased fracture risk. In patients with epilepsy and AEDs the incidence of fractures is 2-6 times higher compared to the general population. ${ }^{16}$

Providentia is the long-stay department of a tertiary referral centre for patients with epilepsy in the Netherlands. As such this is a high risk population as most patients are on chronic treatment with (mostly polytherapy) AED treatment. In this population we evaluated the patient characteristics of those patients already diagnosed with osteoporosis and treated with a bisphosphonate, an inhibitor of bone resorption.

\section{Materials and methods}

\section{Study population}

The study population are residents living in Providentia, a long-stay care facility for patients with (refractory) epilepsy. The total number of adult residents living in Providentia is 261 . Almost all residents have a history of refractory epilepsy for which in most patients chronic treatment with several AEDs is necessary. Most of the residents also have some degree of intellectual disability.

\section{Study design}

In December 2008 a search in the database of the hospital pharmacy was performed to identify all adult patients who were diagnosed with osteoporosis and treated with a bisphosphonate at that moment. This search resulted in 54 residents. This is $21 \%$ of the total population. The patient record files of each of these 54 residents were 
reviewed for information regarding demography (age, sex, length, weight, menopausal status, current smoker, history of smoking, alcohol consumption, ambulatory status), epilepsy characteristics (type of epilepsy, age onset epilepsy, duration of epilepsy), fracture history (number of fractures), current medication use history of AEDs use, and presence of secondary causes of osteoporosis.

Antiepileptic drug amount was semi-quantified by defining 'cumulative drug load' as total duration of epilepsy multiplied by the current number of AEDs. This surrogate measure of cumulative antiepileptic drug load was used because no standard measure for chronic treatment with multiple drugs during many years is available. Because of the refractory nature of the epilepsy in most patients treatment with multiple AEDs is necessary. Most patients were on stable AED numbers over the years.

Epilepsy load was determined by the number of years patients are suffering from epilepsy.

\section{Statistical analysis}

For statistical evaluation, SPSS for windows version 16.0 software statistics packet was used (SPSS, Chicago, IL).

For correlational analysis, the Pearson correlation coefficient or for nonparametric data the Spearman correlation was used. A $p$ value less than 0.05 was defined as statistically significant. Linear regression analysis was used to evaluate the impact of the risk factors (smoking, alcohol, ambulatory status, etc.) in combination on the occurrence of fractures.

\section{Results}

\section{Group characteristics}

Table 3.1 shows that 54 residents of the in total 261 adult residents were treated with a bisphosphonate (alendronic acid or risedronic acid) because of osteoporosis, resulting in a prevalence of $21 \%$. This group of 54 residents consisted of 33 men (61\%) and 21 women (39\%). The mean age was 58,2 years (range 20,5 years-89,9 years). 10 residents (18,5\%) ( 8 men and 2 women) were younger than 48 years.

The mean duration of epilepsy was $53.7 \pm 14.2$ years. Therefore the majority of the patients suffered from epilepsy and were on AED treatment during almost their entire life.

All the residents had a symptomatic or probable symptomatic localisation related (former cryptogenic) epilepsy.

Of the 54 patients only three patients (6\%) did not use enzyme-inducing AEDs: two patients did not use any AED, one was on VPA monotherapy. 
Of the enzyme-inducing AEDs, CBZ was the most frequent used (67\%): $11 \%$ of these patients were on CBZ monotherapy, $67 \%$ used CBZ in combination with one or more other enzyme-inducing AEDs, $16 \%$ used CBZ in combination with VPA and 6\% used CBZ in combination with LVT (see Table 3.2).

Table 3.1 Characteristics of the study population $(n=54)$.

\begin{tabular}{lc}
\hline Age (years) (SD) & $58.2 \pm 14$ \\
Sex (female) (n, \%) & $21(39)$ \\
Weight (kg) & $73.3 \pm 12.0$ \\
Mean & $52-105$ \\
Range & $1,69 \pm 0.10$ \\
Height (m) & $25,4 \pm 3.68$ \\
Body mass index (BMI) & $19 / 21(90)$ \\
Postmenopausal women (n, \%) & $5(9.8)$ \\
Current smoking (n, \%) & $14(27)$ \\
Alcohol consumption (n, \%) & $50(98)$ \\
Caffeine consumption (n, \%) & \\
Intellectual disability (n, \%) & $1(1.9)$ \\
None & $16(29.6)$ \\
Mild (70-55) & $16(29.6)$ \\
Moderate (55-40) & $8(14.8)$ \\
Severe (40-25) & $3(5.6)$ \\
Profound (<25) & $10(18.5)$ \\
$\quad$ Unknown & \\
\hline
\end{tabular}

Table 3.2 Current antiepileptic drugs study population $(n=54)$.

\begin{tabular}{ll}
\hline Current number of AEDs (n, \%) & $2(3,7 \%)$ \\
0 & $7(13,0 \%)$ \\
1 & $14(25,9 \%)$ \\
2 & $20(37.0 \%)$ \\
3 & $10(18,5 \%)$ \\
4 & $1(1,9 \%)$ \\
5 & \\
Strong enzyme-inducing AEDs (n, \%) & $36(67)$ \\
Carbamazepine & $5(9)$ \\
Oxcarbazepine & $6(11)$ \\
Phenobarbital & $15(28)$ \\
Phenytoin & \\
Moderate enzyme-inducing AEDs (n, \%) & $21(39)$ \\
Lamotrigine & \\
Enzyme-inhibiting AEDs (n, \%) & $22(41)$ \\
Valproic acid & $6(11)$ \\
Topiramate & \\
Others (n, \%) & $1(2)$ \\
Gabapentin & $6(11)$ \\
Levetiracetam &
\end{tabular}

AEDs, antiepileptic drugs 
The results of the bone mineral studies are summarised in Table 3.3. 32 patients had a quantitative computed tomography of the spine (QCT), 10 patients had a dual-energy X-ray absorptiometry (DXA) scan of the lumbar spine and hip. 12 patients had only conventional X-rays.

The mean total bone mineral density with QCT was $86.8 \mathrm{mg} / \mathrm{cm}^{3}$ (SD $\left.37.6 \mathrm{mg} / \mathrm{cm}^{3}\right)$. A total BMD spine $<80 \mathrm{mg} / \mathrm{cm}^{3}$ is considered compatible with osteoporosis, a total BMD spine between 80 and $120 \mathrm{mg} / \mathrm{cm}^{3}$ is compatible with osteopenia. ${ }^{17}$ The mean QCT spine T- and Z-scores were -3.6 and -2.3 , respectively. For the diagnosis osteoporosis of the spine a cut-off value of QCT T-score of <-3.1 was used ${ }^{17}$ and/or a Z-score of $<-1.5$. $^{18}$ The mean DXA T- and Z-score of the lumbar spine were -1.5 and -1.0 , and at the hip they were -2.1 and -1.6 , respectively. For the diagnosis osteoporosis the DXA T-score threshold defined by the WHO were used. ${ }^{19}$ The mean number of fractures was 4.7, with a range from 0 till 18.

Table 3.3 Results bone mineral density studies and fractures study population $(n=54)$.

\begin{tabular}{lcc}
\hline & Mean \pm SD & $\mathrm{N}(\%)$ \\
\hline BMS QCT & & $32(59.3)$ \\
Total BMD g/cm & $86.8 \pm 37.6$ & \\
$T$-score & $-3.6 \pm 1.0$ & \\
$Z$-score & $-2.3 \pm 0.94$ & $10(18.5)$ \\
DXA & & \\
$T$-score lumbar spine & $-1.5 \pm 1.7$ & \\
$Z$-scores lumbar spine & $-1.0 \pm 1.8$ & \\
$T$-score hip & $-2.1 \pm 0.5$ & $-1.6 \pm 0.6$ \\
$Z$-score hip & $4.7 \pm 3.7$ (range 0-18) \\
Number of fractures & & \\
\hline
\end{tabular}

Values are mean \pm SD unless otherwise indicated. BMD, bone mineral density; BMS QCT, bone mineral study quantitative computed tomography; DXA, dual-energy X-ray absorptiometry; SD, standard deviation.

\section{Correlations}

The number of fractures correlated significantly with ambulatory status $(r=-0.269$, $p=0.05)$, cumulative drug load $[r=0.286, p=0.04])$, and current number of AEDs $(r=0.283, p=0.04)$.

There was a negative correlation between the cumulative drug load and T-score of QCT ( $r=-.456, p=0.04)$. The determination coefficient was 0.137 (see Figure 3.1).

Correlations could not be provided for individual drugs in our population as only a minority was on monotherapy and even less patients had always been on monotherapy of the same antiepileptic drug. 


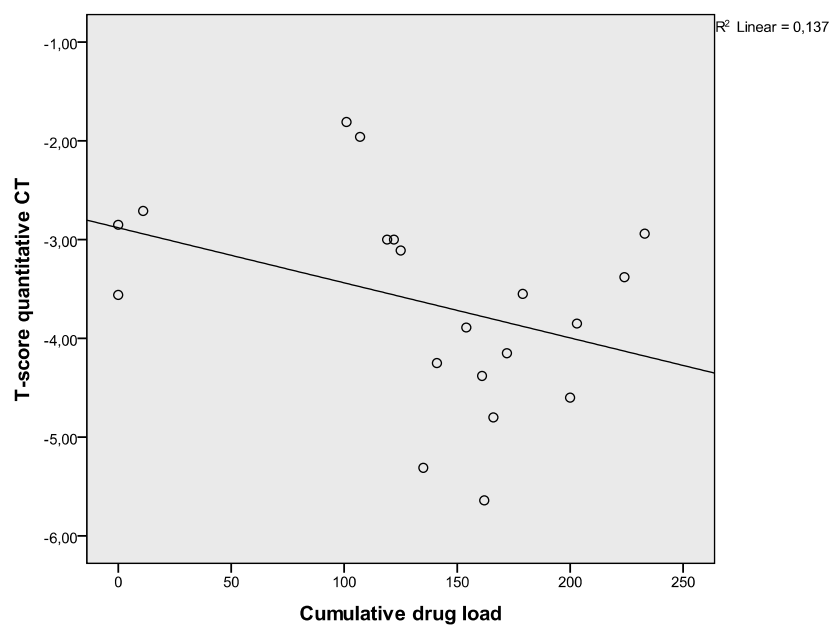

Figure 3.1 Correlation between cumulative drug load and T-score $(n=20)$.

\section{Linear regression analysis}

Linear regression analysis was performed to analyse the effect of several potential predictors for the risk of fractures combined.

In a first step of the analysis, number of fractures is included as criterion variable and duration of epilepsy and cumulative drug load as predictors. These two variables combined do not predict the number of fractures on a statistically significant level, although a trend is visible $(p=0.07)$. This is caused by the low predictive value of duration of epilepsy $(p=0.20)$, whereas cumulative drug load is a powerful predictor $(p=0.03)$. In a second step also age, body mass index and ambulatory status are included as predictors (in addition to the factors in step 1). This analysis shows that cumulative drug load and duration of epilepsy in combination (and taken into account the three aforementioned factors) still predicted a significant portion of the number of fractures $(p=0.047)$ with again only cumulative drug load being statistically significant as isolated factor $(p=0.021)$.

Finally in a third step the confounders alcohol consumption, caffeine intake and smoking were included (in addition to the factors in step 1 and step 2), drug load still was the only significant variable predicting the number of fractures $(p=0.029)$.

\section{Discussion}

Osteoporosis is a significant problem is the population of patients with a chronic epilepsy. $21 \%$ of a population of residents in a tertiary centre for epilepsy appeared to 
have a confirmed diagnosis of osteoporosis and were treated for this. On average they had suffered almost 5 (4.7) fractures. This is in line with studies that have estimated that patients with epilepsy have a 2 to 6 times higher hip or vertebral fracture rate compared to the general population. ${ }^{20}$

Our prevalence rate is in agreement with another study, which found $16 \%{ }^{13}$ but relatively low compared to another study which found a prevalence of osteoporosis of $62 \% .^{21}$

For our study we only analysed the data of the residents who were documented with the diagnosis osteoporosis and were treated with a bisphosphonate at that particular moment. Osteopenia is not an indication for treatment with a bisphosphonate and thus residents with osteopenia were not included in our study. Also asymptomatic residents with still undetected osteoporosis without any clinical indication for measuring BMD were not included in our study. Therefore it is very likely that the found prevalence in our population of $21 \%$ is an underestimation of the true prevalence of osteoporosis and osteopenia.

In this high risk population we obtained a positive and strong correlation between the occurrence of fractures in a diagnosed population with osteoporosis and the cumulative drug load of antiepileptic drugs. Cumulative drug load was defined here using a surrogate parameter that in our opinion is an acceptable reflection of clinical practice in this chronic patient group: the total duration of epilepsy multiplied by the number of AEDs. This does not provide concluding evidence for a causal relationship, but is at least 'a smoking gun' illustrating a strong association between 'chronic'. i.e. long-term treatment with multiple AEDs and osteoporosis. This effect seems general, independent of the type of AEDs that were used.

Our finding is not new. The first cases of the association between bone disorders and AED therapy were reported around the 1960s to 1970s. The prevalence varied between 4 to $30 \%$ depending on the population studied. ${ }^{3-6}$ Since the 1990 s there is a renewed interest in the association between use of AEDs and bone disease. Our focus was on patients with refractory epilepsy and chronic treatment. Therefore this population may be considered 'a worst case scenario' offering a 'pressure cooker model' in which possible risk factors for development of low BMD are maximalised, especially the cumulative drug load. In the regression analysis we entered potential confounders and the association between our cumulative drug load parameter and fractures was preserved.

There are many factors influencing the BMD, e.g. physical exercise, sun exposure, diet and smoking, which were presumably also present in our study population. It is probably the presence of these multiple risk factors that makes this population particularly vulnerable for development of low BMD and the occurrence of fractures. However, clearly chronic use of antiepileptic medication is a specific risk factor for bone disease and fractures and warrants special attention. This high risk profile also justifies active screening for osteoporosis. 
Intellectual disability is a risk factor present in most of our residents, that could not be controlled in the regression analysis, as the vast majority of the residents are known with a mild to moderate intellectual disability. More ideally our study design would have been a case control study with a control group consisting of residents with an intellectual disability without epilepsy and AEDs use. Because no such control group was available in our tertiary epilepsy centre we had to abandon this design. People with an intellectual disability are reported to have high rates of osteoporosis and osteopenia, ${ }^{22,23}$ possibly as an effect of reduced mobility. It is possible therefore that the effect of chronic medication interacts with intellectual disability. However, when entering mobility into the linear regression analysis, the association between drug load and fractures was preserved, suggesting again the independent effect of cumulative drug load. Our findings have been confirmed by others. Vestergaard et al. conducted a population-based pharmacoepidemiologic case-control study with any fracture as outcome and use of AEDs as exposure variables. ${ }^{24}$ They found a trend towards more fractures with increasing numbers of AEDs and thus higher drug load. This was also confirmed by Persson et al. in a patient control study ${ }^{25}$ and by Tsiropoulos et al. who conducted a case-control study in which polytherapy was associated with a higher fracture risk than monotherapy. ${ }^{26}$ Other investigators have corroborated our finding that fracture rate seemed to increase with the duration of treatment. ${ }^{4,14,16,21}$ However, a minority of studies could not confirm such association. $^{6,27}$

The diagnosis osteoporosis in our study population was made on clinical grounds as well as the results of bone mineral studies. In the nineties of the last century bone mineral density was measured with quantitative computed tomography (QCT). The current gold standard for measurement of BMD is dual-energy X-ray absorptiometry. Ideally all our patients should have had a BMD measurement by the same method: the DXA scan. However, we were dependent of the county hospital where our residents were sent to for their bone mineral studies. In this hospital, DXA scan has become more available in the last 10 years, whereas our patients were examined in earlier periods. As a consequence most residents had a bone mineral study with quantitative CT $(59.3 \%)$, only $18.5 \%$ of the residents had a DXA scan. In the remaining 12 residents $(22.2 \%)$ the diagnosis osteoporosis was made on clinical grounds (one or multiple low-energy fractures) in combination with radiographic signs of osteoporosis on conventional radiographs.

The most important sequela of low BMD is the increased fracture risk. It is estimated that every 1 SD decrease in DXA T-score $<-1$ is associated with a 1.5 to 3 fold increase in fracture risk. ${ }^{20,28}$ In our population the number of fractures ranged from zero to even eighteen in one patient. Fractures represented a heterogeneous group, including vertebral as well as non-vertebral fractures. We did not know the cause of all the fractures nor all the circumstances in which the fractures occurred. However, it is known that not all the fractures in patients with epilepsy are explained by the number 
of seizures or seizure related-falls. Indeed, it is even suggested that there is a possible class effect of anticonvulsants on fracture risk. ${ }^{29}$

From the literature it is known that enzyme-inducing AEDs are more associated with low bone mineral density than non-enzyme inducing AEDs. ${ }^{12,13}$ Because of the characteristics of the patient population and the refractory nature of their epilepsy all patients have used several AEDs in the past and most are still now on polytherapy. $83 \%$ of the residents used 2 or more AEDs. Nonetheless, $67 \%$ of the patients used the strong enzyme-inducing drug CBZ, the majority of them in combination with other enzyme inducing drugs. We therefore cannot exclude the possibility that not simply cumulative drug load is the crucial factor, but cumulative use of enzyme-inducing antiepileptic drugs. Our population did not allow to analyse this.

In conclusion in this high risk population we obtained a positive and strong correlation between the occurrence of fractures in a diagnosed epilepsy population with osteoporosis and the cumulative drug load of antiepileptic drugs. This effect seems general, independent of the type of AEDs that were used. Although more research is necessary, this finding underlines the importance of good bone health practices in patients with chronic AEDs use. 


\section{References}

1. Kruse R. Osteopathies in antiepileptic long-term therapy (preliminary report). Monatsschr Kinderheilkd 1968;116:378-381.

2. Ashworth B, Horn DB. Evidence of osteomalacia in an outpatient group of adult epileptics. Epilepsia 1977;18:37-43.

3. Lidgren L, Walloe A. Incidence of fracture in epileptics. Acta Orthop Scand 1977;48:356-361.

4. Andress DL, Ozuna J, Tirschwell D, Grande L, Johnson M, Jacobson AF, Spain W. Antiepileptic druginduced bone loss in young male patients who have seizures. Arch Neurol 2002;59:781-786.

5. Farhat G, Yamout B, Mikati MA, Demirjian S, Sawaya R, El-Hajj Fuleihan G. Effect of antiepileptic drugs on bone density in ambulatory patients. Neurology 2002;58:1348-1353.

6. Stephen LJ, McLellan AR, Harrison JH, Shapiro D, Dominiczak MH, Sills GJ, Brodie MJ. Bone density and antiepileptic drugs: a case-controlled study. Seizure 1999;8:339-342.

7. Sato Y, Kondo I, Ishida S, Motooka H, Takayama K, Tomita Y, Maeda H, Satoh K. Decreased bone mass and increased bone turnover with valproate therapy in adults with epilepsy. Neurology 2001;57: 445-449.

8. Boluk A, Guzelipek M, Savli H, Temel I, Ozisik HI, Kaygusuz A. The effect of valproate on bone mineral density in adult epileptic patients. Pharmacol Res 2004;50:93-7.

9. Pack AM, Morrell MJ, Marcus R, Holloway L, Flaster E, Doñe S, Randall A, Seale C, Shane E. Bone mass and turnover in women with epilepsy on antiepileptic drug monotherapy. Ann Neurol 2005;57: 252-257.

10. Mintzer S, Boppana P, Toguri J, DeSantis A. Vitamin D levels and bone turnover in epilepsy patients taking carbamazepine or oxcarbazepine. Epilepsia 2006;47:510-515.

11. Nissen-Meyer LS, Svalheim S, Taubøll E, Reppe S, Lekva T, Solberg LB, Melhus G, Reinholt FP, Gjerstad $L$, Jemtland R. Levetiracetam, phenytoin, and valproate act differently on rat bone mass, structure, and metabolism. Epilepsia 2007;48:1850-1860.

12. El-Hajj Fuleihan G, Dib L, Yamout B, Sawaya R, Mikati MA. Predictors of bone density in ambulatory patients on antiepileptic drugs. Bone 2008;43:149-155.

13. Lado F, Spiegel R, Masur JH, Boro A, Haut SR. Value of routine screening for bone demineralization in an urban population of patients with epilepsy. Epilepsy Res 2008;78:155-160.

14. Petty SJ, Paton LM, O'Brien TJ, Makovey J, Erbas B, Sambrook P, Berkovic SF, Wark JD. Effect of antiepileptic medication on bone mineral measures. Neurology 2005;65:1358-1365.

15. Valsamis HA, Arora SK, Labban B, McFarlane SI. Antiepileptic drugs and bone metabolism. Nutr Metab (Lond) 2006;3:36.

16. Souverein PC, Webb DJ, Weil JG, Van Staa TP, Egberts AC. Use of antiepileptic drugs and risk of fractures: case-control study among patients with epilepsy. Neurology 2006;66:1318-1324.

17. Adams JE. Quantitative computed tomography. Eur J Radiol 2009;71:415-424.

18. Bergot C, Laval-Jeantet AM, Hutchinson K, Dautraix I, Caulin F, Genant HK. A comparison of spinal quantitative computed tomography with dual energy X-ray absorptiometry in European women with vertebral and nonvertebral fractures. Calcif Tissue Int 2001;68:74-82.

19. Kanis JA. Assessment of fracture risk and its application to screening for postmenopausal osteoporosis: synopsis of a WHO report. WHO Study Group. Osteoporos Int 1994;4:368-381.

20. Vestergaard P. Epilepsy, osteoporosis and fracture risk - a meta-analysis. Acta Neurol Scand 2005;112: 277-286.

21. Lyngstad-Brechan MA(1), Taubøll E, Nakken KO, Gjerstad L, Godang K, Jemtland R, Bollerslev J. Reduced bone mass and increased bone turnover in postmenopausal women with epilepsy using antiepileptic drug monotherapy. Scand J Clin Lab Invest 2008;68:759-766.

22. Schrager S. Osteoporosis in women with disabilities. J Womens Health (Larchmt) 2004;13:431-437.

23. Jaffe JS, Timell AM, Elolia R, Thatcher SS. Risk factors for low bone mineral density in individuals residing in a facility for the people with intellectual disability. J Intellect Disabil Res 2005;49:457-462.

24. Vestergaard P, Rejnmark L, Mosekilde L. Fracture risk associated with use of antiepileptic drugs. Epilepsia 2004;45:1330-1337.

25. Persson HB, Alberts KA, Farahmand BY, Tomson T. Risk of extremity fractures in adult outpatients with epilepsy. Epilepsia 2002;43:768-772. 
26. Tsiropoulos I, Andersen M, Nymark T, Lauritsen J, Gaist D, Hallas J. Exposure to antiepileptic drugs and the risk of hip fracture: A case-control study. Epilepsia 2008;49:2092-2099.

27. Kulak CA, Borba VZ, Bilezikian JP, Silvado CE, Paola L, Boguszewski CL. Bone mineral density and serum levels of $25 \mathrm{OH}$ vitamin $\mathrm{D}$ in chronic users of antiepileptic drugs. Arq Neuropsiquiatr. 2004;62:940-948.

28. Pack AM, Gidal B, Vazquez B. Bone disease associated with antiepileptic drugs. Cleve Clin J Med 2004;71 Suppl 2:S42-48.

29. Lee RH, Lyles KW, Colon-Emeric C. A review of the effect of anticonvulsant medications on bone mineral density and fracture risk. Am J Geriatr Pharmacother 2010;8:34-46. 


\section{Chapter 4}

Antiepileptic drugs and high prevalence of low bone mineral density in a group of inpatients with chronic epilepsy

K Beerhorst, IY Tan, MCFTM de Krom, P Verschuure, AP Aldenkamp Acta Neurologica Scandinavica 2013;128:273-280 


\section{Abstract}

\section{Purpose}

Long-term antiepileptic drug use is associated with low bone mineral density (BMD), fractures, and abnormalities in bone metabolism. We aimed at determining the prevalence of bone mineral disorders in patients with refractory epilepsy treated with antiepileptic drugs.

\section{Methods}

A cross-sectional survey was conducted in adult patients $(n=205)$ from a residential unit of a tertiary epilepsy centre. Screening for bone mineral disorders was performed with dual-energy X-ray absorptiometry (DXA) scan of spine and hip (including bone mineral density and vertebral fracture assessment) and laboratory measurements. Patient information regarding demography, epilepsy characteristics and medication use were recorded. Based on DXA T-scores prevalences of bone mineral disorders (osteopenia and osteoporosis) were calculated. Correlations between DXA T-scores and epilepsy parameters were explored.

\section{Results}

Of the 205 patients, there were 10 drop outs. 80\% ( $n=156 / 195)$ of the patients had low BMD: $48.2 \%$ had osteopenia and $31.8 \%$ had osteoporosis. Of those having low BMD 51.9\% ( $n=81 / 195)$ was between $18-50$ years. The T-score of the femoral neck correlated significantly with total duration of epilepsy, cumulative drug load and history of fractures. Linear regression analysis showed that of the epilepsy-related parameters only cumulative drug load significantly predicted low femoral neck T-score $(p=0.001)$.

\section{Conclusion}

In this high risk population we obtained a very high prevalence of $80 \%$ of low BMD. Both men and women were affected as well as patients $<50$ years of age. This study illustrates the magnitude of the problem of bone mineral disorders in chronic epilepsy. 


\section{Introduction}

Osteoporosis is a skeletal disorder characterised by compromised bone strength predisposing persons to an increased fracture risk. ${ }^{1}$ The use of antiepileptic drugs (AEDs) associated with biochemical abnormalities such as hypocalcemia, ${ }^{2-4}$ hypovitaminosis $D^{2,3,5-7}$ and secondary hyperparathyroidism ${ }^{2,6}$ is a risk factor for the development of low bone mineral density (BMD) $)^{8,9}$ leading to osteoporosis ${ }^{10-14}$ and an increased fracture risk. ${ }^{15-19}$ Not only the older AEDs (phenobarbital (PB), ${ }^{5}$ phenytoin $(\mathrm{PHT})^{20}$ ), but also the 'newer' AEDs (carbamazepine (CBZ), ${ }^{8,21}$ valproic acid (VPA), ${ }^{22-26}$ lamotrigine (LTG), ${ }^{12,22,27}$ oxcarbazepine (OXC), ${ }^{6}$ and levetiracetam (LVT) ${ }^{28}$ ) are associated with negative effects on bone metabolism.

Several risk factors have been suggested to contribute to low BMD in patients with epilepsy: polytherapy, ${ }^{7,22}$ age above 50 years, ${ }^{14,29}$ use of AEDs for more than 2 years, ${ }^{29}$ and use of enzyme-inducing AEDs. ${ }^{7,14,29}$ As yet, international guidelines concerning screening for osteoporosis in people with epilepsy have not been established due to the lack of convincing studies. This is even true for the high-risk populations. Among chronic epilepsy patients there is an accumulation of the above mentioned risk factors. The aim of our study was to systematically screen a high risk population (pressure cooker model) of a long stay department at a tertiary referral centre for epilepsy in The Netherlands in order to definitely resolve the question on the prevalence of bone mineral disorders and to gain insight in the most important risk factors. This is a typical high risk population for osteoporosis: most patients have some degree of intellectual disability, some patients have an impaired ambulation, almost all patients are on polytherapy with long-term AEDs use, often also with current or a history of enzyme-inducing AEDs use. In this cross-sectional study we evaluated the prevalence of bone mineral disorders in adult people with epilepsy using the gold standard for BMD measurement i.e. dual-energy X-ray absorptiometry (DXA) scan, and using laboratory measurements to evaluate the presence of biochemical abnormalities in bone metabolism.

\section{Materials and methods}

\section{Study design}

All in-patients of 18 years and older and/or their legal representatives were asked to participate in this cross-sectional study. Written informed consent was obtained. The study was approved by the local medical ethical committee and the regional Medical Ethical Committee of Maastricht University Medical Centre. 


\section{Study population}

The population under study were all adult people living in a long-stay care facility for patients with chronic epilepsy. 261 patients are adults of 18 years and older. Almost all patients have some degree of intellectual disability and a history of refractory epilepsy for which in most patients treatment with several AEDs is necessary.

\section{Methods: BMD measurements}

BMD of the lumbar spine (L1-L4) and left hip was measured by DXA scan $\left(\mathrm{g} / \mathrm{cm}^{2}\right)$. All DXA measurements were performed by the same densitometer (Hologic, Discovery W) between 30 August and 29 September 2009. T-scores (number of standard deviations [SD] below peak bone mass) and Z-scores (number of SD below age- and sex-matched controls) were calculated for total lumbar spine, femoral neck and total hip using the manufacturers' reference database. World Health Organisation (WHO) criteria were used to classify bone mineral density and osteoporosis. ${ }^{30} \mathrm{~A}$ T-score of -1.0 and above is considered normal, a T-score between -1.0 and -2.5 is considered low bone mass (osteopenia), and a T-score of -2.5 and below is considered osteoporosis. $^{31}$ In patients aged 70 years and older also a Z-score of <-1.0 was considered osteoporosis. The site with the lowest T-score was included in the diagnosis osteoporosis. ${ }^{31}$

Vertebral fracture assessment (VFA) was performed through lateral spine imaging of T4-L4 using manufacturer's standard protocols for detection of vertebral fractures.

\section{Methods: biochemical measurements}

For all subjects peripheral venous blood samples were collected in a non-fasting state between 8 and 11 a.m. for estimation of serum calcium, phosphate, alkaline phosphatase, creatinine, albumin and thyroid stimulating hormone (TSH) using commercial kits. All samples were collected between 12 September and 20 October 2009. Samples were collected on ice for 25-hydroxy vitamin D3 and parathyroid hormone (PTH). The serum was separated in a refrigerated centrifuge and stored until estimation of 25-hydroxy vitamin D3 and PTH. All serum concentrations were measured by standard auto analyser techniques.

\section{Methods: general}

Data regarding age, sex, length, weight, body mass index (BMI), menopausal status, current smoker, history of smoking, alcohol consumption, Barthel index, ambulatory status, and reproductive history, epilepsy characteristics (symptomatic, cryptogenic or idiopathic epilepsy, age at onset epilepsy, duration of epilepsy), fracture history (number, location and cause of fractures), current medication and medication history, and presence of secondary causes of osteoporosis were collected through the 
electronic patient file. Dietary intake of calcium was assessed using a validated calcium food frequency questionnaire (FFQ). ${ }^{32}$ To evaluate fracture risk of patients, the WHO Fracture Risk Assessment Tool $\left(\mathrm{FRAX}^{\circledR}\right)$ was calculated for all patients aged $>40$ years. For patients below the age of 40 years the programme computed probabilities at age 40 year. The $\mathrm{FRAX}^{\circledR}$ algorithms give the 10 -year probability of fractures, both hip fracture as well as major osteoporotic fractures.

The PDD/DDD is the ratio of the actual prescribed daily doses divided by the recommended therapeutic dose of each drug. ${ }^{33}$ However, this ratio does not take into account the cumulative effect of antiepileptic drug load over the years. Therefore we calculated cumulative antiepileptic drug load by defining a surrogate measure in which the total duration of epilepsy (years) is multiplied by the current number of AEDs. Epilepsy load was defined as the number of years a patient suffered from epilepsy.

\section{Statistical analysis}

Data are presented as means (SD) or as percentages. Spearman's rank correlation coefficients $(r)$ or Pearson's correlations $(r)$ were calculated to determine the relationship between total BMD expressed as $\mathrm{g} / \mathrm{cm}^{2}$ and $\mathrm{T}$ - and Z-scores and other variables including duration and dosage of AED therapy and biochemical parameters. Significance was set at a two-paired tailed $p<0.05$.

Linear regression analysis was used to evaluate the impact of risk factors on bone density. All analyses were performed using SPSS (Statistical Package of Social Sciences) version 18, 2010 (SPSS, Chicago, IL).

\section{Results}

\section{a). Group characteristics}

In total all 261 adult patients were invited, 56 patients (21.5\%) declined. The remaining 205 patients (78.5\%) gave informed consent and all were enrolled in the study. The study group consisted of 124 men (60.5 \%) and 81 women (39.5\%). Mean age was 47.0 (16.8) years. 81 patients $(51.9 \%)$ were younger than 50 years. The characteristics are presented in Table 4.1.

\section{Epilepsy characteristics}

Almost all patients had a symptomatic localisation related epilepsy ( $n=114,55.6 \%)$ or a probably symptomatic localisation related epilepsy ( $n=90,43.9 \%)$. One patient suffered from idiopathic generalised epilepsy. The mean duration of epilepsy was 41.3 (16.1) years (range $9-81$ years). 25 patients (12.2\%) were at least three years or longer seizure free, 180 patients $(87.8 \%)$ still had seizures the last $2-3$ years. The mean 
current number of AEDs was 2.9 (1.1). The mean cumulative drug load was 112.4 (55.2).

Table 4.1 Demographic characteristics of study population $(n=195)$.

\begin{tabular}{|c|c|c|}
\hline & $\mathrm{n}$ & Mean (SD) or \% \\
\hline Age at screening, years, mean (SD) & 195 & \\
\hline $18-39$ & 64 & 32.8 \\
\hline $40-49$ & 42 & 21.5 \\
\hline $50-59$ & 38 & 19.5 \\
\hline $60-69$ & 34 & 17.4 \\
\hline $70-79$ & 14 & 7.2 \\
\hline $80-89$ & 3 & 1.5 \\
\hline Male/ female & $119 / 76$ & $61 \% / 39 \%$ \\
\hline \multicolumn{3}{|l|}{ Ethnicity } \\
\hline Caucasian & 192 & 98.5 \\
\hline Asian & 2 & 1.0 \\
\hline African-American & 1 & 0.5 \\
\hline Length, $\mathrm{m}$ & 195 & $1.69(0.12)$ \\
\hline Weight, kg & 195 & $72.6(15.6)$ \\
\hline Body mass index, $\mathrm{kg} / \mathrm{m}^{2}$ & 195 & $24.9(4.4)$ \\
\hline Barthel index & 195 & $11.7(6.6)$ \\
\hline \multicolumn{3}{|l|}{ Ambulatory status } \\
\hline Wheelchair-bound & 48 & 24.6 \\
\hline Walk with aid & 26 & 13.3 \\
\hline Walk without aid & 121 & 62.1 \\
\hline \multicolumn{3}{|l|}{ Intellectual disability } \\
\hline None & 2 & 1.0 \\
\hline Mild & 55 & 28.2 \\
\hline Moderate & 71 & 36.4 \\
\hline Severe & 58 & 29.7 \\
\hline Profound & 9 & 4.6 \\
\hline Exposure sunlight, hours & 184 & $1.8(1.7)$ \\
\hline \multicolumn{3}{|l|}{ Smoking } \\
\hline Never smoked & 147 & 75.4 \\
\hline Past smoker & 25 & 12.8 \\
\hline Current smoker & 23 & 11.8 \\
\hline \multicolumn{3}{|l|}{ Alcohol use } \\
\hline Nondrinker & 156 & 80.0 \\
\hline Current drinker & 39 & 20.0 \\
\hline \multicolumn{3}{|l|}{ Caffeine consumption } \\
\hline None & 42 & 21.5 \\
\hline Current drinker & 153 & 78.5 \\
\hline Number of pregnancies & 1 & 0.5 \\
\hline \multicolumn{3}{|l|}{ Menopausal status } \\
\hline Female fertile & 31 & 15.9 \\
\hline Female perimenopausal & 4 & 2.1 \\
\hline Female postmenopausal & 41 & 21.0 \\
\hline \multicolumn{3}{|c|}{ Total calcium intake FFQ calcium (mg/day) } \\
\hline Calcium use & 36 & 18.5 \\
\hline Vitamin D use & 8 & 4.1 \\
\hline Bisphosphonate use & 40 & 20.5 \\
\hline Anti-androgen $\left(\right.$ Androcur $\left.{ }^{\circledR}\right)$ & 6 & 3.1 \\
\hline
\end{tabular}


Table $4.1 \quad$ (continued).

\begin{tabular}{lcc}
\hline & $\mathrm{n}$ & Mean (SD) or \% \\
\hline Secondary causes osteoporosis & 1 & 0.5 \\
Osteogenesis imperfecta & 2 & 1.0 \\
Klinefelter syndrome & 2 & 1.0 \\
Premature ovarian failure & 8 & 4.1 \\
Hypogonadism & 2 & 1.0 \\
Down syndrome & 2 & 1.0 \\
Diabetes mellitus & & \\
Current medication & 8 & 4.1 \\
Levothyroxine & 2 & 1.0 \\
Glucocorticoid use & & \\
Diuretics & 3 & 1.5 \\
$\quad$ Thiazid & 16 & 8.2 \\
$\quad$ Loop & 1 & 0.5 \\
Tamoxifen & & \\
Previous fractures & 124 & 63.6 \\
Yes & 52 & 26.7 \\
No & 6 & 3.1 \\
Unknown & & \\
Falls & 164 & $1.7(7.3)$ \\
Number of falls/month related to seizure & 155 & $0.9(3.0$ \\
Number of falls/month not related to seizure & & \\
WHO FRAX & & \\
Major osteoporotic fracture & 195 & $8.6(9.1)$ \\
Hip fracture & 194 & $3.4(6.9)$ \\
\hline
\end{tabular}

\section{BMD measurements}

Of the 205 participants it was possible to perform a DXA scan of either lumbar spine and/or femur in 195 patients (95.1\%): 186 patients (90.7\%) had a DXA scan of both locations, 9 patients (4.4\%) had a DXA scan of either lumbar spine or femur. In 10 patients $(4.9 \%)$ a DXA scan could not be performed because of anatomical restrictions (severe joint contractures, scoliosis, or osteosynthesis material) and/or lack of patient cooperation.

39 of the 195 patients (20\%) had a normal BMD: 20 men (51.3\%) and 19 women (48.7\%). 25 patients (64.1\%) with a normal BMD were younger than 50 years. 156 of the 195 patients studied (80\%) had low BMD of which $48.2 \%(n=94)$ had osteopenia (61.7\% men; $59.6 \%$ age $<50$ years) and $31.8 \%(n=62)$ had osteoporosis (66.1\% men; $40.3 \%$ age $<50$ years). Of those having low BMD 51.9\% $(n=81)$ were between $18-50$ years (Table 4.2 ).

In 185 of the 205 patients (90.2\%) it was possible to perform a good quality lateral spine imaging for VFA. In 20 patients $(9.8 \%)$ this could not be performed because of anatomical restrictions or lack of patient cooperation. 52 patients $(28.1 \%)$ had signs of one of more vertebral fractures. 
Table 4.2 Results DXA scan and vertebral fracture assessment.

\begin{tabular}{|c|c|c|c|}
\hline & $\mathrm{N}$ & Mean (SD) or \% & Range \\
\hline DXA femur and/or lumbar spine possible & 195 & 95.1 & \\
\hline $\mathrm{BMD}$ lumbar spine, $\mathrm{g} / \mathrm{cm}^{2}$ & 190 & $0.951(0.206)$ & $0.102-1.824$ \\
\hline BMD femur neck, $\mathrm{g} / \mathrm{cm}^{2}$ & 191 & $0.687(0.137)$ & $0.340-1.042$ \\
\hline BMD femur Total, $\mathrm{g} / \mathrm{cm}^{2}$ & 191 & $0.810(0.168)$ & $0.411-1.272$ \\
\hline T-score lumbar spine & 190 & $-0.991(1,61)$ & $-5.1-6.7$ \\
\hline T-score femur neck & 191 & $-1.71(1.07)$ & $-4.6-1.1$ \\
\hline T-score femur total & 191 & $-1.38(1.18)$ & $-4.4-1.6$ \\
\hline Z-score lumbar spine & 189 & $-0.419(1.69)$ & $-5.1-7.5$ \\
\hline Z-score femur neck & 190 & $-1.02(1.08)$ & $-4.1-2.5$ \\
\hline Z-score femur total & 190 & $-0.978(1.15)$ & $-3.7-2.2$ \\
\hline Diagnosis lumbar spine & 195 & & \\
\hline Normal & 90 & 46.2 & \\
\hline Osteopenia & 70 & 35.9 & \\
\hline Osteoporosis & 30 & 15.4 & \\
\hline No diagnosis & 5 & 2.5 & \\
\hline Diagnosis femur neck & 195 & & \\
\hline Normal & 50 & 25.6 & \\
\hline Osteopenia & 102 & 52.3 & \\
\hline Osteoporosis & 39 & 20.0 & \\
\hline No diagnosis & 4 & 2.1 & \\
\hline Diagnosis femur Total & 195 & & \\
\hline Normal & 75 & 38.4 & \\
\hline Osteopenia & 82 & 42.1 & \\
\hline Osteoporosis & 34 & 17.4 & \\
\hline No diagnosis & 4 & 2.1 & \\
\hline Vertebral fracture assessment & 185 & & \\
\hline None & 133 & 71.9 & \\
\hline Signs of fracture & 52 & 28.1 & \\
\hline History of previous fracture & 205 & & \\
\hline No & 59 & 28.8 & \\
\hline Yes & 127 & 62.0 & \\
\hline Unknown & 19 & 9.2 & \\
\hline \multicolumn{4}{|c|}{ Definite diagnosis based on DXA site with lowest } \\
\hline T-score & 195 & & \\
\hline Normal & 39 & 20.0 & \\
\hline Osteopenia & 94 & 48.2 & \\
\hline Osteoporosis & 62 & 31.8 & \\
\hline
\end{tabular}

$\mathrm{BMD}=$ bone mineral density; DXA=dual energy $\mathrm{X}$-ray absorptiometry.

\section{Laboratory measurements}

Table 4.3 shows the results of the blood analyses. Only 19 patients had normal serum 25-hydroxy vitamin D3 levels (9.3\%), 50 patients (24.4\%) had an insufficient vitamin D level and the majority of the patients (65.4\%) had a deficient serum vitamin $D$ level. $12.2 \%$ of the patients had an increased PTH. 
Table 4.3 Laboratory measurements study populations $(n=203)$.

\begin{tabular}{|c|c|c|}
\hline & Mean (SD) & $\mathrm{n}(\%)$ \\
\hline Serum calcium (normal $2.20-2.65 \mathrm{mmol} / \mathrm{l}$ ) & $2.38(0.09)$ & \\
\hline Serum phosphate (normal $0.80-1.80 \mathrm{mmol} / \mathrm{l}$ ) & $1.12(0.16)$ & \\
\hline Serum creatinine (normal men $60-100$, women $45-85 \mu \mathrm{mol} / \mathrm{l}$ ) & $63.7(14.8)$ & \\
\hline Serum alkaline phosphatase (normal 40-120 U/I) & $88.4(35.2)$ & \\
\hline Thyroid-stimulating hormone (normal 0.30-5.20 mU/I) & $1.60(1.02)$ & \\
\hline Intact parathyroid hormone (normal 1.0-5.5 pmol/I) & $3.35(2.47)$ & \\
\hline 25-hydroxy vitamin D3 (nmol/l) & $44.4(22.4)$ & \\
\hline Serum albumin $(35-55 \mathrm{~g} / \mathrm{l})$ & $42.9(3.5)$ & \\
\hline 25-hydroxy vitamin D3 & $44.4(22.4)$ & 203 \\
\hline Normal $>80 \mathrm{nmol} / \mathrm{l}$ & & $19(9.3)$ \\
\hline Insufficient $<80$ and $>50 \mathrm{nmol} / \mathrm{I}$ & & $50(24.4)$ \\
\hline Deficient $<50 \mathrm{nmol} / \mathrm{l}$ & & $134(65.4)$ \\
\hline Missing & & $2(1.0)$ \\
\hline
\end{tabular}

\section{b) Correlation}

A correlation analysis was performed. Spearman's rank and Pearson's correlation coefficients were calculated to determine the relationship between the BMD expressed as T- and Z-scores of DXA and nonparametric and parametric variables, respectively. Significance was set at two-paired tailed $p<0.05$. The results are shown in Table 4.4.

The T-score of the total femur and femur neck correlated significantly with age, intellectual disability, BMI, Barthel index, ambulatory status, total duration of the epilepsy, cumulative drug load, history of fractures, number of fractures, serum alkaline phosphatase, $F R A X^{\circledR}$ major osteoporotic fracture and FRAX ${ }^{\circledR}$ hip fracture.

The T-score of the lumbar spine correlated significantly with BMI, Barthel index, ambulatory status, alkaline phosphatase, and WHO FRAX ${ }^{\circledR}$ major osteoporotic fracture and WHO FRAX ${ }^{\circledR}$ hip fracture.

DXA T-scores did not correlated with alcohol consumption, current smoking and caffeine consumption (data not shown). Also number of falls with and without seizure did not correlate with the results of DXA measurements (data not shown).

No statistically significant correlation was found between serum calcium, serum phosphate and serum 25-hydroxy vitamin D3 levels and T-scores of DXA (data not shown).

The WHO FRAX ${ }^{\circledR}$ for major osteoporotic fracture correlated significantly with age $(r=.228, p=.001)$, number of fractures $(r=.278, p<.001)$, total duration of epilepsy $(r=.194, p=.006)$, Barthel index ( $r=-.190, p=.007)$, serum calcium $(r=-.149, p=.033)$ and parathormone $(r=.155, p=.027)$. 
Table 4.4 Correlations BMD measurements.

\begin{tabular}{|c|c|c|c|c|c|c|}
\hline \multirow[t]{2}{*}{ Variable } & \multicolumn{2}{|c|}{$\begin{array}{c}\text { Total femur } \\
\text { T-score }\end{array}$} & \multicolumn{2}{|c|}{$\begin{array}{c}\text { Lumbar spine } \\
\text { T-score }\end{array}$} & \multicolumn{2}{|c|}{$\begin{array}{c}\text { Femur neck } \\
\text { T-score }\end{array}$} \\
\hline & $r$ & $p$ & $r$ & $p$ & $r$ & $p$ \\
\hline $\mathrm{Age}^{\mathrm{b}}$ & ns & $\mathrm{ns}$ & ns & $\mathrm{ns}$ & -.219 & .002 \\
\hline Gender $^{a}$ & ns & ns & ns & ns & ns & ns \\
\hline Intellectual disability ${ }^{a}$ & -.257 & $<.001$ & ns & ns & -.235 & .001 \\
\hline Body mass index ${ }^{b}$ & .173 & .017 & .195 & .007 & .177 & .014 \\
\hline Barthel index ${ }^{b}$ & .482 & $<.001$ & .257 & $<.001$ & .422 & $<.001$ \\
\hline Ambulatory status $^{a}$ & .446 & $<.001$ & .265 & $<.001$ & .431 & $<.001$ \\
\hline Sunlight exposure ${ }^{b}$ & ns & ns & ns & ns & .246 & .001 \\
\hline Total duration epilepsy ${ }^{b}$ & -.179 & .016 & ns & ns & -.213 & .004 \\
\hline Cumulative drug load ${ }^{\mathrm{b}}$ & -.221 & .003 & ns & ns & -.257 & $<.001$ \\
\hline Current number AEDs ${ }^{b}$ & ns & ns & ns & ns & ns & ns \\
\hline History of fracture ${ }^{a}$ & -.148 & .049 & ns & ns & -.159 & .034 \\
\hline Number of fractures ${ }^{b}$ & -.389 & $<.001$ & -.206 & .007 & -.350 & $<.001$ \\
\hline Presence of vertebral fracture VFA DXA ${ }^{a}$ & -.368 & $<.001$ & -.192 & .008 & -.354 & $<.001$ \\
\hline Alkaline phosphatase $^{\mathrm{b}}$ & -.240 & .001 & ns & ns & -.177 & .015 \\
\hline FRAX major osteoporotic fracture & -.529 & $<.001$ & -.328 & $<.001$ & -.589 & $<.001$ \\
\hline FRAX hip fracture & -.466 & $<.001$ & -.285 & $<.001$ & -.567 & $<.001$ \\
\hline
\end{tabular}

${ }^{a}$ Spearman correlation coefficient; ${ }^{b}$ Pearson's correlation coefficient. AEDs=antiepileptic drugs; BMD=bone mineral density; DXA=dual -energy X-ray absorptiometry; ns=not statistically significant; VFA=vertebral fracture assessment.

\section{c) Regression analysis}

A linear regression analysis was performed with T-score of the femur neck as dependent variable and 1) age, 2) BMI, 3) FFQ calcium, 4) exposure to sunlight, 5) current number AEDs, 6) total duration of epilepsy, and 7) cumulative drug load. These seven variables were selected based on the results of the correlation analysis and its clinical relevance (in case of AEDs). Three drug factors were included (i.e. current number of AEDs, total duration epilepsy and cumulative drug load). The femur neck was chosen because this location had the highest prevalence of osteoporotic T-scores. A backward procedure was used. Although all seven factors contributed significantly (F-value $5.247 ; p<.001$ ) the procedure identified a three-factor solution as the strongest predictor of the T-score of the femur neck: age, BMI and cumulative drug load (F-value $=11.627 ; p=<.001$ ), of which cumulative drug load was the only significant epilepsy parameter. Of these three factors BMI had the strongest effect $(p<0.001)$, followed by cumulative drug load and age (both $p=0.001)$.

\section{Discussion}

In our adult study population we found a $80 \%$ prevalence of low BMD of which $31.8 \%$ was osteoporosis and $48.2 \%$ osteopenia. Other studies in ambulant patients without 
intellectual disability found prevalence rates of low BMD in epileptic patients up to $55 \%$ and $62 \% .{ }^{14,34}$ The very high prevalence we found in our study population probably reflects the 'pressure-cooker model' of our study population in which multiple risk factors for the development of osteoporosis are present. Our analysis showed that although in this population general risk factors (such as sunlight exposure and ambulatory status) may have had an influence, AED use and especially cumulative drug load appeared to be the dominant factor. The PDD/DDD is the ratio of the actual prescribed daily doses divided by the recommended therapeutic dose of each drug. ${ }^{33}$ However, this ratio does not take into account the cumulative effect of antiepileptic drug load over the years. Therefore cumulative drug load was defined here using a surrogate parameter that in our opinion is an acceptable reflection of clinical practice in this chronic patient group: the total duration of epilepsy multiplied by the number of AEDs. Total AED load of multiple drug regimen and the duration of exposure rather than the number of AEDs alone may accumulate to chronic toxicity. ${ }^{33}$ With regression analysis cumulative drug load was confirmed as the dominant factor correlating with the T-score of the femur neck $(p=0.001)$. This does not provide concluding evidence for a causal relationship, but is at least 'a smoking gun' illustrating the effect of longterm treatment with AEDs and osteoporosis.

Furthermore our results are supported by other studies in which duration of epilepsy $^{7,29}$ and polytherapy ${ }^{7,22}$ were identified as risk factors for the development of osteoporosis. In another study cumulative antiepileptic drug load was found to be dominant predictor of the occurrence of fractures. ${ }^{35}$

Novel and to our knowledge not earlier reported was the correlation between DXA T-scores and the WHO FRAX ${ }^{\circledR}$ for major osteoporotic fracture and hip fracture, and the correlation between WHO FRAX ${ }^{\circledR}$ major osteoporotic fracture and duration of epilepsy and number of fractures in this specific population with epilepsy and chronic AED use.

The pathophysiologic mechanism of AEDs-induced osteoporosis is presumably multifactorial. The mechanism most frequently mentioned particularly in relation to enzyme-inducing AEDs is the increased catabolism of active vitamin $D$ resulting in a vitamin D deficiency, which in turn leads to hypocalcaemia and secondary hyperparathyroidism eventually resulting in increased bone turnover. ${ }^{36}$ Of striking notice was the very high prevalence of hypovitaminosis D in our patients: $24.4 \%$ had an insufficient vitamin D level and even $65.4 \%$ had a vitamin D deficiency. However, only $12.2 \%$ of our patients had increased parathormone levels compatible with secondary hyperparathyroidism. Secondary hyperparathyroidism therefore seems not the only mechanism explaining low BMD. Hypovitaminosus $D$ is a problem which is encountered frequently in the elderly and less ambulant patients and is not only a health issue specific for epileptic patients. The prevalence of hypovitaminosus $D$ (serum calcidiol $<30 \mathrm{nmol} / \mathrm{l}$ ) among the Dutch Caucasian general adult population is estimated at $5-10 \%$. Among Dutch independent elderly a serum level of $<50 \mathrm{nmol} / \mathrm{I}$ was found in up to $50 \%$ and in residents of nursery homes a prevalence of up to $85 \%$ 
was reported. ${ }^{37}$ The high prevalence of hypovitaminosis $D$ in our patients could partly be the result of institutionalisation. The role of older age was presumably of less significance considering that over $50 \%$ of the patients was below the age of 50 years. Independent of institutionalisation, supplementation of 800 IU vitamin D in combination with calcium has proven to be effective in the reduction of fracture risk, especially hip fractures. ${ }^{38}$

As shown in our regression analysis, besides cumulative drug load also the already established risk factor for the development of osteoporosis age and ambulation contributed significantly to the low BMD. Of course these are amplifying factors in chronic epilepsy, as over time the cumulative drug load and older age and decrease in ambulation may converge. Nonetheless one of the most important striking findings in this study is that of those patients diagnosed with osteoporosis or osteopenia $52 \%$ was below the age of 50 years. This again illustrates that not only the 'normal risk factors' (that are mostly associated with old age) are important in our study group.

For patients below the age of 50 years sometimes separate criteria for diagnosing low BMD based on DXA measurements are used; ${ }^{39} \mathrm{Z}$-scores are preferred instead of the T-scores. A Z-score of $\mathbf{- 2 . 0}$ or lower is defined as 'below the expected range for age'. When applying these criteria $57.1 \%$ of those below the age of 20 years had a BMD below the expected range for age, 33.3\% of those between 20-49 years and in the patients $\geq 50$ years even $84.2 \%$ had a low BMD of which $43.8 \%$ osteopenia and $40.4 \%$ osteoporosis (Table 4.5 ).

Table 4.5 Diagnosis based on DXA measurements according to new criteria.

\begin{tabular}{|c|c|c|c|c|c|}
\hline \multirow[b]{2}{*}{ Age (year) } & \multicolumn{4}{|c|}{ Diagnosis based on DXA new criteria for age $<50$ years } & \multirow[b]{2}{*}{ Total } \\
\hline & Normal & Osteopenia & Osteoporosis & $\begin{array}{l}\text { Below expected } \\
\text { range for age }\end{array}$ & \\
\hline$<20$ & $3(42.9 \%)$ & - & - & $4(57.1 \%)$ & $7(3.6 \%)$ \\
\hline $20-49$ & $66(66.7 \%)$ & 0 & 0 & $33(33.3 \%)$ & $99(50.8 \%)$ \\
\hline$\geq 50$ & $14(15.7 \%)$ & $39(43.8 \%)$ & $36(40.4 \%)$ & - & $89(45.6 \%)$ \\
\hline Total (\%) & $83 / 195(42.6 \%)$ & $39 / 195(20 \%)$ & $36 / 195(18.4 \%)$ & $37 / 195(19.0 \%)$ & $195(100 \%)$ \\
\hline
\end{tabular}

DXA = dual-energy $\mathrm{X}$-ray absorptiometry.

\section{Limitations}

This study has some limitations. Firstly, the design of our study was cross-sectional without a control group. A more convincing longitudinal design was not an option due to the necessary long follow-up period and the ethical considerations involved. However a strong aspect of our design is that almost all institutionalised patients were included.

Secondly, because most of the patients were on polytherapy or had polytherapy with antiepileptic drugs in the past, no specific conclusions between the individual antiepileptic drugs or type of antiepileptic drugs (enzyme-inducing vs. non-enzyme inducing) and bone mineral density results could be drawn. 
Thirdly, our patient group is a very specific patient group with an accumulation of all possible risk factors.

\section{Conclusions}

The present study results strongly suggest that long-term AED use is associated with an extreme high prevalence of osteoporosis and osteopenia. In our study population we found a prevalence of osteoporosis and osteopenia of $32 \%$ and $48 \%$, respectively. Of the epilepsy-related parameters cumulative drug load was the only significant predictor of low BMD. Hypovitaminosis D was very common in our population and may be one of the underlying pathophysiological mechanisms for the development of low BMD. Supplementation with calcium and vitamin D in high risk populations should be considered

The prevalence rate of low BMD of $80 \%$ in our study population underscores the need for more bone health awareness in patients with refractory epilepsy and long-term AED use and in our opinion justifies early screening, careful guidance of life-style factors (physical weight bearing exercise, smoking etc), supplementation of vitamin D and calcium and a critical or even restrictive attitude towards long-term treatment with a high drug load of antiepileptic drugs.

Our results can contribute to the development of guidelines for the screening and treatment of BMD in this vulnerable patient group. 


\section{References}

1. Genant HK, Cooper C, Poor G, Reid I, Ehrlich G, Kanis J, Nordin BE, Barrett-Connor E, Black D, Bonjour JP, Dawson-Hughes B, Delmas PD, Dequeker J, Ragi Eis S, Gennari C, Johnell O, Johnston CC Jr, Lau EM, Liberman UA, Lindsay R, Martin TJ, Masri B, Mautalen CA, Meunier PJ, Khaltaev N, et al. Interim report and recommendations of the World Health Organization Task-Force for Osteoporosis. Osteoporos Int 1999;10:259-264.

2. Bouillon R, Reynaert J, Claes JH, Lissens W, De Moor P. The effect of anticonvulsant therapy on serum levels of 25-hydroxy-vitamin D, calcium, and parathyroid hormone. J Clin Endocrinol Metab 1975;41: 1130-1135.

3. Hahn TJ, Hendin BA, Scharp CR, Haddad JG, Jr. Effect of chronic anticonvulsant therapy on serum 25hydroxycalciferol levels in adults. N Engl J Med 1972;287:900-904.

4. Hunter J, Maxwell JD, Stewart DA, Parsons V, Williams R. Altered calcium metabolism in epileptic children on anticonvulsants. Br Med J 1971;4:202-204.

5. Hahn TJ, Birge SJ, Scharp CR, Avioli LV. Phenobarbital-induced alterations in vitamin D metabolism. J Clin Invest 1972;51:741-748.

6. Mintzer S, Boppana P, Toguri J, DeSantis A. Vitamin D levels and bone turnover in epilepsy patients taking carbamazepine or oxcarbazepine. Epilepsia 2006;47:510-515.

7. El-Hajj Fuleihan G, Dib L, Yamout B, Sawaya R, Mikati MA. Predictors of bone density in ambulatory patients on antiepileptic drugs. Bone 2008;43:149-155.

8. Kim SH, Lee JW, Choi KG, Chung HW, Lee HW. A 6-month longitudinal study of bone mineral density with antiepileptic drug monotherapy. Epilepsy Behav 2007;10:291-295.

9. Phabphal K, Geater A, Leelawattana R, Sathirapunya P, Sattawatcharawanich S, Limapichat K. Prevalence and risk factors of low bone mineral density and 25-hydroxyvitamin $D$ status in young healthy epileptic adult patients in a tropical Asian country taking antiepileptic drug. Bone 2009;45:232-237.

10. Lifshitz F, Maclaren NK. Vitamin D-dependent rickets in institutionalized, mentally retarded children receiving long-term anticonvulsant therapy. I. A survey of 288 patients. J Pediatr. 1973;83(4):612-20. Epub 1973/10/01.

11. Pack AM, Olarte LS, Morrell MJ, Flaster E, Resor SR, Shane E. Bone mineral density in an outpatient population receiving enzyme-inducing antiepileptic drugs. Epilepsy Behav 2003;4:169-174.

12. Elliott JO, Jacobson MP, Haneef Z. Homocysteine and bone loss in epilepsy. Seizure. 2007;16:22-34.

13. Swanton J, Simister R, Altmann D, Watts H, Keen R, Duncan JS, Koepp MJ. Bone mineral density in institutionalised patients with refractory epilepsy. Seizure 2007;16:538-541.

14. Lado F, Spiegel R, Masur JH, Boro A, Haut SR. Value of routine screening for bone demineralization in an urban population of patients with epilepsy. Epilepsy Res 2008;78:155-160.

15. Pedersen KK, Christiansen $C$, Ahlgren $P$, Lund $M$. Incidence of fractures of the vertebral spine in epileptic patients. Acta Neurol Scand 1976;54:200-203.

16. Persson HB, Alberts KA, Farahmand BY, Tomson T. Risk of extremity fractures in adult outpatients with epilepsy. Epilepsia 2002;43:768-772.

17. Lidgren L, Walloe A. Incidence of fracture in epileptics. Acta Orthop Scand 1977;48:356-361.

18. Souverein PC, Webb DJ, Weil JG, Van Staa TP, Egberts AC. Use of antiepileptic drugs and risk of fractures: case-control study among patients with epilepsy. Neurology 2006;66:1318-1324.

19. Souverein PC, Webb DJ, Petri H, Weil J, Van Staa TP, Egberts T. Incidence of fractures among epilepsy patients: a population-based retrospective cohort study in the General Practice Research Database. Epilepsia 2005;46:304-310.

20. Rodbro P, Christiansen C, Lund M. Development of anticonvulsant osteomalacia in epileptic patients on phenytoin treatment. Acta Neurol Scand 1974;50:527-532.

21. Andress DL, Ozuna J, Tirschwell D, Grande L, Johnson M, Jacobson AF, Spain W. Antiepileptic druginduced bone loss in young male patients who have seizures. Arch Neurol 2002;59:781-786.

22. Farhat G, Yamout B, Mikati MA, Demirjian S, Sawaya R, El-Hajj Fuleihan G. Effect of antiepileptic drugs on bone density in ambulatory patients. Neurology 2002;58:1348-1353.

23. Stephen LJ, McLellan AR, Harrison JH, Shapiro D, Dominiczak MH, Sills GJ, Brodie MJ. Bone density and antiepileptic drugs: a case-controlled study. Seizure 1999;8:339-342. 
24. Sato Y, Kondo I, Ishida S, Motooka H, Takayama K, Tomita Y, Maeda H, Satoh K. Decreased bone mass and increased bone turnover with valproate therapy in adults with epilepsy. Neurology 2001;57: 445-449.

25. Boluk A, Guzelipek M, Savli H, Temel I, Ozisik HI, Kaygusuz A. The effect of valproate on bone mineral density in adult epileptic patients. Pharmacol Res 2004;50:93-97.

26. Oner N, Kaya M, Karasalihoglu S, Karaca H, Celtik C, Tutunculer F. Bone mineral metabolism changes in epileptic children receiving valproic acid. J Paediatr Child Health 2004;40:470-473.

27. Pack AM, Morrell MJ, Marcus R, Holloway L, Flaster E, Doñe S, Randall A, Seale C, Shane E. Bone mass and turnover in women with epilepsy on antiepileptic drug monotherapy. Ann Neurol. 2005;57: 252-257.

28. Nissen-Meyer LS, Svalheim S, Taubøll E, Reppe S, Lekva T, Solberg LB, Melhus G, Reinholt FP, Gjerstad $\mathrm{L}$, Jemtland R. Levetiracetam, phenytoin, and valproate act differently on rat bone mass, structure, and metabolism. Epilepsia 2007;48:1850-1860.

29. Petty SJ, Paton LM, O'Brien TJ, Makovey J, Erbas B, Sambrook P, Berkovic SF, Wark JD. Effect of antiepileptic medication on bone mineral measures. Neurology 2005;65:1358-1365.

30. Kanis JA. Assessment of fracture risk and its application to screening for postmenopausal osteoporosis: synopsis of a WHO report. WHO Study Group. Osteoporos Int 1994;4:368-381.

31. Xu W, Perera S, Medich D, Fiorito G, Wagner J, Berger LK, Greenspan SL. Height loss, vertebral fractures, and the misclassification of osteoporosis. Bone 2011;48:307-311.

32. Angus RM, Eisman JA. Osteoporosis: the role of calcium intake and supplementation. Med J Aust. 1988;148:630-633.

33. Deckers CL, Hekster YA, Keyser A, Meinardi H, Renier WO. Reappraisal of polytherapy in epilepsy: a critical review of drug load and adverse effects. Epilepsia 1997;38:570-575.

34. Lyngstad-Brechan MA, Taubøll E, Nakken KO, Gjerstad L, Godang K, Jemtland R, Bollerslev J. Reduced bone mass and increased bone turnover in postmenopausal women with epilepsy using antiepileptic drug monotherapy. Scand J Clin Lab Invest 2008;68:759-766.

35. Beerhorst K, Schouwenaars FM, Tan IY, Aldenkamp AP. Epilepsy: fractures and the role of cumulative antiepileptic drug load. Acta Neurol Scand 2012;125:54-59.

36. Fitzpatrick LA. Pathophysiology of bone loss in patients receiving anticonvulsant therapy. Epilepsy Behav 2004;5 Suppl 2:S3-15.

37. Netherlands HCot. Towards an adequate intake of vitamin D2008; (2008/15).

38. CBO KvdG. Tweede herziene richtlijn osteoporose. Alphen aan de Rijn Van Zuiden Communications; 2002.

39. Lewiecki EM. In the clinic. Osteoporosis. Ann Intern Med 2011;155:ITC1--15; quiz ITC1-6. 


\section{Chapter}

Dual-energy X-ray absorptiometry versus quantitative ultrasonography in diagnosing osteoporosis in patients with refractory epilepsy and chronic antiepileptic drug use

K Beerhorst, J Tan, IY Tan, P Verschuure, AP Aldenkamp Therapeutic Advances in Musculoskeletal Disease 2013;5:59-66 


\section{Abstract}

\section{Objectives}

The aim of this study was to assess the feasibility of calcaneal quantitative ultrasonography (QUS) as a screening method for increased risk of osteoporosis in an unique population of people with chronic epilepsy, intellectual disability (ID), and chronic use of antiepileptic drugs.

\section{Methods}

205 patients from a long-stay care facility for people with epilepsy underwent dual-energy X-ray absorptiometry (DXA) and quantitative ultrasonography of the calcaneus. T-scores for both DXA and QUS were calculated and correlated.

\section{Results}

195 patients $(95,1 \%)$ were successfully measured with DXA and 204 (99,5\%) with QUS. High correlations were found between DXA and QUS T-scores: $r=0.666$ (QUS vs. T-score total femur), $r=0.631$ (QUS vs. T-score femur neck), and $r=0.485$ (QUS vs. T-score lumbar spine). All correlations were statistically significant $(p=0.01)$.

\section{Conclusion}

QUS showed a strong correlation with DXA and proved to be a feasible measuring method in a population with ID and epilepsy. Including osteopenia in the screening process increases the sensitivity of QUS to identify those patients at risk for the development of bone diseases. 


\section{Introduction}

Quantitative ultrasonography (QUS) methods are gaining ground as a reliable technique for measuring bone mineral status in the population. ${ }^{1,2}$ QUS has a number of advantages over the more commonly used dual-energy X-ray absorptiometry (DXA) scan: it is radiation free, relatively inexpensive, easy to use and portable., ${ }^{3,4}$ Furthermore it has the possibility of independently predicting fracture risk. QUS makes use of the alteration of travelling vibrations when passing through a medium. ${ }^{5}$ Information about bone density, structure and composition can be collected by measuring the change in velocity and amplitude when the sound waves travel through bone tissue. This makes the technique fast and easy to use, even for less mobile or less cooperative individuals. A relative disadvantage of QUS techniques measuring the heel bone, is the fact that bone density between left and right foot usually differs. ${ }^{4}$ However, Roux et al. found in a whole population no significant difference between QUS results of right and left feet. ${ }^{6}$ Often the non-dominant foot is measured, presuming it has the lowest value of bone density. However, in individuals with intellectual disabilities (ID) it can be difficult to determine which foot is dominant. Nevertheless, a study investigating feasibility of calcaneal QUS in people with ID concluded that it is a practical and non-stressful method for measuring bone status. ${ }^{4}$ Although feasibility has been ascertained, evidence with respect to validity and sensitivity has not been established for all kinds of populations. Some studies suggest QUS correlates strongly with DXA, holding the potency to independently diagnose osteoporosis. $^{7-10}$ Others find a weaker correlation and reject this potential, ${ }^{11-15}$ or propose QUS as a screening method in the absence of or prior to DXA. ${ }^{16-19}$ In one meta-analysis 25 articles were examined regarding QUS as identification method for osteoporosis. ${ }^{20}$ The authors concluded that the determined sensitivity and specificity of QUS were too low to diagnose DXA-determined osteoporosis.

There is an increasing body of evidence on the negative influence of AEDs on bone density. Patients on chronic AED therapy may have a reduced bone mineral density (BMD) and an increased risk of fractures ${ }^{21}$ even after correction for seizure-related fractures. $^{22,23}$ Irrespective of the population, DXA still is the gold standard for measurement of BMD. However screening a population of epileptic institutionalised patients with DXA demands a great piece of effort from patients and their care-takers. In this specific population many risk factors for low BMD exist. Moreover this is a population with frequent intellectual and physical co-morbidities and therefore would profit most from a portable and non-invasive method that would allow early screening and follow-up for the presence of osteoporosis and osteopenia. Also follow-up measurements for the evaluation of the effect of the implemented bone enhancing therapies (physical therapy with weight bearing exercise, calcium and vitamin D supplementation and sometimes also anti-resorptive bone therapy) is necessary. In the light of the repeated measurements a method of BMD measurement that is noninvasive, patient-friendly and without radiation load is obligatory. QUS could be a 
good candidate for screening for low BMD in this population, under the condition that it has a high sensitivity and specificity. To investigate this, we conducted a crosssectional study to determine the sensitivity and specificity of QUS in a high risk population consisting of patients with refractory epilepsy on chronic use of antiepileptic drugs, using DXA as gold standard.

\section{Materials and methods}

\section{Study population/subjects}

The study population consisted of patients living in a long-stay care facility for patients with epilepsy. 205 patients were adults of 18 years and older. Almost all patients had a history of refractory epilepsy for which in most patients treatment with several AEDs was necessary. Most of the patients also had some degree of intellectual disability.

A cross-sectional study was performed, measuring bone mineral density at lumbar spine and femur with DXA (Hologic) and using QUS of the calcaneus (Sahara, Hologic). Additionally, characteristics regarding lifestyle, epilepsy, medication use, history of AED use, fracture history and potential secondary causes of osteoporosis were recorded in a database. The study was approved by the local and regional Ethics Committee and was in accordance with the Code of Ethics (Declaration of Helsinki). Informed consent was obtained from each patient or his/her legal representative.

\section{Methods: BMD by DXA}

BMD of the lumbar spine and left femur was measured by dual-energy X-ray absorptiometry and expressed as the amount of mineral ( $\mathrm{g}$ ) divided by the area scanned $\left(\mathrm{cm}^{2}\right)$. All DXA measurements were performed by the same densitometer (Hologic, Discovery W [S/N 70991]) and were performed between 30 August and 29 September 2009. T-scores (number of standard deviations [SD] below peak bone mass) and Z-scores (number of SD below age- and sex-matched controls) were calculated for total lumbar spine, femoral neck and total femur using the manufacturers' reference database (reference values supplied by Hologic for the hip and lumbar spine as well as data from the National Health and Nutrition Examination Survey part III (NHANES III) dataset. Manufacturer specific reference population (Caucasian) was used to calculate T-scores). World Health Organisation (WHO) criteria $^{24}$ were used to classify bone mineral density and osteoporosis. A T-score of 1.0 and greater is considered normal, a T-score between -1.0 and -2.5 is considered low bone mass (osteopenia), and a T-score of -2.5 and less is considered osteoporosis. In patients aged 70 years and older also a Z-score of <-1.0 was considered osteoporosis, because of the increased fracture risk and the advice to consider 
treatment for osteoporosis in this specific age-group. ${ }^{25}$ The site with the lowest Tscore was included in the diagnosis osteoporosis.

\section{Methods: BMD by QUS}

Bone densitometry was performed by quantitative ultrasonography of the heel bone (Sahara, Hologic). Several devices using QUS are available, measuring at different parts of the body. A widely used measuring spot is the calcaneus. ${ }^{1,2}$ Two quantifiable variables are available: speed of sound (SOS) related to velocity of the ultrasound signal, and broadband ultrasound attenuation (BUA) related to the weakening of the ultrasound signal. ${ }^{4,5}$ In some techniques an additional variable, stiffness index (SI), can be assessed. Devices such as the Sahara (Hologic) require application of alcohol or gel to the foot, after which the foot can be placed in the device, measuring bone status within half a minute. The calcaneus of the left foot was measured to assess the lowest value of bone density. In 3 patients (1.5\%) the heel bone of the right foot was measured due to anatomical restrictions (severe clubfoot). Derived variables consisted of BUA, SOS, QUI/Stiffness and T-scores using manufacturers' database (Sahara Reference Ranges for Caucasian subjects). All QUS measurements were performed directly before or after the DXA measurements. A QUS T-score of -1.0 was taken as the cut-off value to distinguish between osteoporotic and non-osteoporotic patients. This value was based on data reported by Hologic, stating that $82-87 \%$ of people with a Sahara T-score less than -1 are diagnosed with osteoporosis as determined by DXA.

\section{Analysis and statistics}

Data are presented as means \pm standard deviations or as percentages. Tests determining the screening value of QUS in relation to DXA grouped osteopenia and osteoporosis together by using a cut-off value of -1.0 for DXA T-scores. This way not only patients with osteoporosis, but also patients in the risk group of low bone mass can be identified by a follow-up DXA scan. Correlation analysis was performed using a 2-tailed Pearson Correlation coefficient with a significance level of $p<0.05$. Furthermore a ROC curve and the area under the curve (AUC) was calculated to assess the correspondence of QUS with regard to the gold standard of DXA. AUC reflects the discriminatory value of a test; in this case the potential of QUS to discriminate between osteopenic/osteoporotic and non-osteopenic/osteoporotic patients as diagnosed by DXA. An AUC of 1 indicates a perfect discrimination and a AUC of .5 indicates a very poor discrimination. Additionally, discriminant analysis was used. This is a rotating procedure that stepwise searches the best solution to classify the patients according to a gold standard. We used the DXA T-score of the femur (total hip) as the gold standard with a cut-off value of -1.0, separating osteopenic and osteoporotic patients from the rest of the population. The QUS cut-off T -score of - 1 was then used to compare overlaps of classifications. Discriminant analysis gives outcomes for 
concordance: 'Hits' (same diagnosis with both techniques) and 'Correct rejections' (same rejection of diagnosis) and measures of disconcordance: 'Misses' (QUS T-score fails the DXA diagnosis) and 'False Alarms' (diagnosis with QUS T-score and not with DXA as gold standard). From a clinical perspective it is interesting to further examine the group of 'misses', because they are diagnosed as osteopenic or osteoporotic by DXA, but overlooked by QUS. Therefore, an additional analysis was done comparing the 'misses' with the rest of the population in order to find a possible explanation for the false rejection of these patients. All statistical analyses were done using SPSS for Windows (Rel. 18.0.2, 2010, Chicago:SPSS Inc.) and Excel 2003 (Microsoft, Seattle, USA).

\section{Results}

The study group consisted of 205 patients: 124 men (60.5 \%) and 81 women (39.5\%). Mean age was $47.0 \pm 16.8$ years, range $18-88$ years. $54.6 \%$ of patients was under the age of 50 years. Of the 205 patients 55 (26.8\%) were wheelchair-bound, 28 (13.7\%) walked with aid and 122 (59.5\%) walked without aid. The DXA scan of lumbar spine and/or femur was successfully performed in $195(95,1 \%)$ of the patients and QUS in $204(99,5 \%)$ of the patients. Mean and standard deviation of all QUS variables are shown in Table 5.1. Correlation analysis showed statistically significant correlations between QUS and the 3 different DXA T-scores of the lumbar spine, femur neck and total femur (Table 5.2). Correlations ranged from $r=0.485(p=0.01)$ for QUS T score with DXA T score lumbar spine to $r=0.666(p=0.01)$ for QUS-T score with DXA T-score Femur Total.

Table 5.1 Quantitative ultrasound parameters.

\begin{tabular}{lcccc}
\hline & BUA & SOS & T-score & QUI \\
\hline Number & 203 & 203 & 204 & 204 \\
Mean (SD) & $46.9(21.3)$ & $1514.6(30.9)$ & $-2.2(1.2)$ & $68.8(20.2)$ \\
\hline
\end{tabular}

$\mathrm{BUA}=$ broadband ultrasound attenuation, QUI=quantitative ultrasound index, $\mathrm{SD}=$ standard deviation, SOS=speed of sound.

Table 5.2 Correlation analysis QUS and DXA.

\begin{tabular}{lc}
\hline & QUS T-score \\
\hline DXA T-score lumbar spine & $* 0.485$ \\
DXA T-score femur total & $* 0.666$ \\
DXA T-score femur neck & $* 0.631$ \\
\hline
\end{tabular}

* Correlation is significant at the 0.01 level (2-tailed). DXA=dual-energy X-ray absorptiometry, QUS=quantitative ultrasonography. 
Results of the ROC analysis are shown in Figure 5.1 with the analysis showing an AUC (area under the curve) of .832. The strength of the relationship between DXA and QUS was additionally tested using discriminant analysis (Table 5.3 and Table 5.4). This shows a sensitivity of $90.3 \%$, as $90.3 \%$ of the patients diagnosed with osteoporosis or osteopenia based on DXA are also identified as osteoporotic or osteopenic by QUS. Specificity is lower, as $40.8 \%$ of the patients in whom the diagnosis was rejected with DXA were also rejected with QUS. In 15 cases the diagnosis of osteoporosis or osteopenia based on DXA could not be confirmed with QUS. Of these 15, 11 (73.3\%) were diagnosed as osteopenic and $4(26.7 \%)$ as osteoporotic.

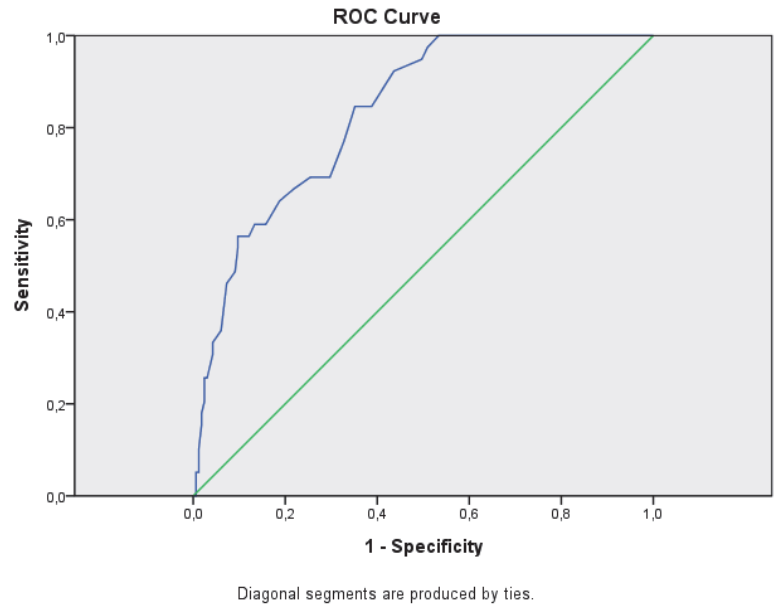

Figure 5.1 ROC curve using QUS T-score as the test variable and the diagnosis 'osteoporosis or osteopenia/no osteoporosis or osteopenia' based on DXA as the state variable. AUC $=.832$.

Table 5.3 Classification results for low bone mineral density (osteopenia and osteoporosis) as diagnostic outcome.

\begin{tabular}{lcc}
\hline & \multicolumn{2}{c}{ Predicted group membership (QUS T-score -1.0) } \\
\cline { 2 - 3 } & Osteopenia/osteoporosis & Normal \\
\hline DXA osteopenia/osteoporosis, $\mathrm{n}(\%)$ & $140(72.2)$ & $15(7.7)$ \\
DXA normal, $\mathrm{n}(\%)$ & $20(10.3)$ & $19(9.8)$ \\
\hline
\end{tabular}

The number of correct diagnoses for osteopenia/osteoporosis by QUS is 140 . The number of correct rejections is 19. 'False alarms' are found in 20 cases and 'false rejections' in $15.82 \%$ of the patients is correctly classified with QUS based on DXA diagnosis of osteopenia and osteoporosis. DXA=dual-energy X-ray absorptiometry, QUS=quantitative ultrasonography.

Table 5.4 shows demographic characteristics of the group classified as misses and the rest of the population. Factors that stand out are gender, number of fractures, drug load and the total duration of epilepsy. Of these variables the number of fractures $(t(170)=-1.48, p=.140)$, gender $\left(x^{2}(1, N=194)=3.12, p=.077\right)$. and the total duration of epilepsy $(t(183)=-1.70, p=.090)$ showed no significant effect. Drug load, expressed in 
presence of epilepsy in years $x$ the number of prescribed AEDs, showed a significant effect $(t(183)=-2.16, p=.032)$ with the group of misses having a smaller drug load than the remainder of the population.

Table 5.4 Demographic table: misses and rest.

\begin{tabular}{|c|c|c|c|c|}
\hline & \multicolumn{2}{|r|}{ Misses } & \multicolumn{2}{|r|}{ Rest } \\
\hline & $\mathrm{n}$ & Mean (SD) or $\%$ & $\mathrm{n}$ & Mean (SD) or \% \\
\hline Age at screening (years) & 15 & $40.53(17.75)$ & 179 & $47.89(16.64)$ \\
\hline $18-39$ & 8 & 53.3 & 56 & 31.3 \\
\hline $40-49$ & 2 & 13.3 & 40 & 22.3 \\
\hline $50-59$ & 2 & 13.3 & 35 & 19.6 \\
\hline $60-69$ & 2 & 13.3 & 32 & 17.9 \\
\hline $70-79$ & 1 & 6.7 & 13 & 7.3 \\
\hline $80-89$ & 0 & 0 & 3 & 1.7 \\
\hline \multicolumn{5}{|l|}{ Gender } \\
\hline Male & 6 & 40 & 113 & 63.1 \\
\hline Female & 9 & 60 & 66 & 36.9 \\
\hline Body mass index (BMI), kg/m² & 15 & $23.4(3.2)$ & 179 & $25.2(4.4)$ \\
\hline Barthel index & 15 & $11.3(6.4)$ & 178 & $12.1(6.3)$ \\
\hline \multicolumn{5}{|l|}{ Ambulatory status } \\
\hline Wheelchair-bound & 3 & 20.0 & 44 & 24.6 \\
\hline Walk with aid & 2 & 13.3 & 24 & 13.4 \\
\hline Walk without aid & 10 & 66.7 & 111 & 62 \\
\hline \multicolumn{5}{|l|}{ Intellectual Disability (IQ score) } \\
\hline Normal & 0 & 0 & 2 & 1.1 \\
\hline Mild (70-55) & 5 & 33.3 & 50 & 27.9 \\
\hline Moderate (40-55) & 4 & 26.7 & 66 & 36.9 \\
\hline Severe $(25-40)$ & 4 & 26.7 & 54 & 30.2 \\
\hline Profound $(<25)$ & 2 & 13.3 & 7 & 3.9 \\
\hline \multicolumn{5}{|l|}{ DXA T-scores } \\
\hline T-score lumbar spine & 14 & $-1.36(0.99)$ & 175 & $-0.95(1.65)$ \\
\hline T-score femur neck & 15 & $-1.28(0.93)$ & 175 & $-1.73(1.07)$ \\
\hline T-score total femur & 15 & $-1.12(0.62)$ & 175 & $-1.39(1.20)$ \\
\hline QUS T-score & 15 & $-0.33(0.84)$ & 179 & $-2.29(1.08)$ \\
\hline \multicolumn{5}{|l|}{ FRAX } \\
\hline Major osteoporotic & 7 & $5.72(2.05)$ & 119 & $10.03(9.66)$ \\
\hline Hip & 7 & $0.91(0.83)$ & 118 & $4.09(8.51)$ \\
\hline Total duration epilepsy (years) & 15 & $34.7(17.5)$ & 170 & $42.18(16.1)$ \\
\hline Drugload (years x no. of AEDs) & 15 & $83.8(59.4)$ & 170 & $116.1(55.1)$ \\
\hline \multicolumn{5}{|l|}{ Falls per month } \\
\hline Seizure related & 12 & $1.4(2.9)$ & 152 & $1.7(7.5)$ \\
\hline Seizure unrelated & 12 & $2.0(3.6)$ & 143 & $0.9(3.0)$ \\
\hline \multicolumn{5}{|l|}{ History of fractures } \\
\hline Yes & 8 & 57.1 & 115 & 68.9 \\
\hline No & 6 & 42.9 & 46 & 27.5 \\
\hline Unknown & 0 & 0 & 6 & 3.6 \\
\hline Number of fractures & 13 & $0.8(0.9)$ & 159 & $1.6(1.9)$ \\
\hline \multicolumn{5}{|l|}{ Smoking } \\
\hline Never smoked & 13 & 86.7 & 133 & 74.3 \\
\hline Past smoker & 0 & 0 & 25 & 14 \\
\hline Current smoker & 2 & 13.3 & 21 & 11.7 \\
\hline
\end{tabular}

AEDs=antiepileptic drugs, DXA=dual-energy X-ray absorptiometry, $I Q=$ intelligence quotient, QUS=quantitative ultrasonography. 


\section{Discussion}

The goal of this study was to assess the validity of QUS as a screening method for osteoporosis in a population with chronic epilepsy and antiepileptic drug use. The results show a strong and positive correlation between T-scores measured by DXA and QUS. Furthermore, this study demonstrates QUS as a feasible method for measuring bone density in a population with intellectual disabilities and epilepsy. For 10 (4.9\%) patients it was impossible to perform DXA due to anatomical or behavioural restrictions; for 1 patient QUS could not be performed due to the history of fractures in both feet. In 3 patients QUS of the right calcaneus was performed because of anatomical deformities of left foot (foot clubbing). Though feasible, using a DXA scanner in this specific population turned out to be a high effort undertaking, consuming a lot of time in preparation, instruction and application. These results confirm the advantages of QUS over DXA, regarding mobility and ease of use.

The manufacturers of the Sahara QUS device (Hologic) report that $80-82 \%$ of patients with DXA determined osteoporosis will score below -1.0 in the Sahara T-score. 5-10\% with non-osteoporotic or non-osteopenic DXA results will score lower than -1 on the Sahara T-score and 6-9\% with DXA determined osteoporosis will score above 0 on the Sahara T-score. Our results, including osteopenia as a diagnostic outcome, are marginally higher on the sensitivity level of the Sahara device in relation to DXA: $90.3 \%$ of patients with DXA determined osteoporosis or osteopenia fall under the QUS cut-off value of $T=-1.0$. The specificity was lower than the sensitivity: at a QUS cut-off T-score of $-1.0,40.8 \%$ of patients determined non-osteoporotic by DXA will be classified as non-osteoporotic by QUS.

The results show a strong correlation between QUS and DXA. However, the correlation is not strong enough to rule out any occurrence of false positives or false negatives when choosing a cut-off value for Sahara T-scores. Results show that when the cut-off value is high $(-1.0)$ there will be a large number of false hits, but when decreasing this T-value the number of false rejections steadily increases. Therefore, irrespective of the high correlation between DXA and QUS T-scores, using a single QUS measurement as a method for screening or diagnosing osteoporosis does not yet seem viable.

However, when screening with QUS, a relative higher number of false positives would be acceptable, given the follow-up examination performed by the gold standard of DXA. Especially in a specific population of people with epilepsy and ID the prevalence of osteoporosis is so high that, despite a low specificity, only a small percentage of patients will be falsely diagnosed with osteoporosis. The same argument is true for the falsely rejected cases, as only 4 of the 15 missed cases were diagnosed with osteoporosis by DXA.

Repeated measurements with QUS in this specific high risk population could greatly increase the validity of QUS as a reliable screening method as it allows follow-up procedures with a portable machine in a non-invasive and patient-friendly manner 
without involving radiation. Especially the chronic use of AEDs would make these patients eligible for follow-up screening with a six-monthly, yearly or two-yearly screening cycle. One way of approaching this method is repeated screening of a 'risk group' with a QUS T-score between -1 and 0 . This would lead to coverage of a large amount of the 15 patients that was falsely declared healthy in prior QUS measurements.

This study has a number of limitations. First of all we only measured the left foot in our population with QUS. Especially in a population with ID it is difficult to determine dominance and thereby higher bone density in a specific foot. Additionally, only the use of calcaneal QUS was explored in this research. A different study suggests that phalangeal QUS might be a better method to assess bone loss in epileptic patients. ${ }^{26}$ Another factor not taken into account in this study was the supplementation of Vitamin D. Pedrera et al. report that a group of patients using anticonvulsants regained normal bone status, measured by QUS, within a month after supplementation of high dosis vitamin D. ${ }^{27}$ Future studies might take this factor into account when trying to explain variability in measured bone status by QUS.

In conclusion, QUS is a feasible and a non-invasive method for measuring bone status in a population with ID and epilepsy. Moreover, future application of QUS as a screening method for the diagnosis of osteoporosis and osteopenia should be considered. Specifically in institutions with a population with epilepsy, chronic antiepileptic drug use and intellectual disability, the benefits of QUS as a screening method seem to outweigh the potential disadvantages. In a population with such a high prevalence of osteoporosis and osteopenia the actual number of misdiagnosed cases stays low. Also, its mobility and ease of use make it a suitable method for repeated measurements, thereby increasing its reliability. 


\section{References}

1 Glüer CC, Eastell R, Reid DM, Felsenberg D, Roux C, Barkmann R, Timm W, Blenk T, Armbrecht G, Stewart A, Clowes J, Thomasius FE, Kolta S. Association of five quantitative ultrasound devices and bone densitometry with osteoporotic vertebral fractures in a population-based sample: the OPUS Study. J Bone Miner Res 2004;19:782-793.

2 Hollaender R, Hartl F, Krieg MA, Tyndall A, Geuckel C, Buitrago-Tellez C, Manghani M, Kraenzlin M, Theiler R, Hans D. Prospective evaluation of risk of vertebral fractures using quantitative ultrasound measurements and bone mineral density in a population-based sample of postmenopausal women: results of the Basel Osteoporosis Study. Ann Rheum Dis 2009;68:391-396.

3 Economos CD, Sacheck JM, Wacker W, Shea K, Naumova EN. Precision of Lunar Achilles+ bone quality measurements: time dependency and multiple machine use in field studies. $\mathrm{Br} \mathrm{J}$ Radiol 2007;80: 919-925.

4 Mergler S, Lobker B, Evenhuis HM, Penning C. Feasibility of quantitative ultrasound measurement of the heel bone in people with intellectual disabilities. Res Dev Disabil 2010;31:1283-1290.

5 Baroncelli GI. Quantitative ultrasound methods to assess bone mineral status in children: technical characteristics, performance, and clinical application. Pediatr Res 2008;63:220-228.

6 Roux C, Lemonnier E, Kolta S, Charpentier E, Dougados M, Amor B, Viens-Bitker C. Ultrasound attenuation in calcaneus and bone density. Rev Rhum Ed Fr 1993;60:897-906.

7 Frost ML, Blake GM, Fogelman I. Quantitative ultrasound and bone mineral density are equally strongly associated with risk factors for osteoporosis. J Bone Miner Res 2001;16:406-416.

8 Huopio J, Kröger H, Honkanen R, Jurvelin J, Saarikoski S, Alhava E. Calcaneal ultrasound predicts early postmenopausal fractures as well as axial BMD. A prospective study of 422 women. Osteoporos Int 2004;15:190-195.

9 Jin N, Lin S, Zhang Y, Chen F. Assess the discrimination of Achilles InSight calcaneus quantitative ultrasound device for osteoporosis in Chinese women: compared with dual energy X-ray absorptiometry measurements. Eur J Radiol 2010;76:265-268.

10 Stewart A, Kumar V, Reid DM. Long-term fracture prediction by DXA and QUS: a 10-year prospective study. J Bone Miner Res 2006;21:413-418.

11 Dane C, Dane B, Cetin A, Erginbas M. The role of quantitative ultrasound in predicting osteoporosis defined by dual-energy X-ray absorptiometry in pre- and postmenopausal women. Climacteric 2008;11:296-303.

12 Dubois EF, van den Bergh JP, Smals AG, van de Meerendonk CW, Zwinderman AH, Schweitzer DH. Comparison of quantitative ultrasound parameters with dual energy X-ray absorptiometry in pre- and postmenopausal women. Neth J Med 2001;58:62-70.

13 Lochmuller EM, Muller R, Kuhn V, Lill CA, Eckstein F. Can novel clinical densitometric techniques replace or improve DXA in predicting bone strength in osteoporosis at the hip and other skeletal sites? J Bone Miner Res 2003;18:906-912.

14 El Maghraoui A, Morjane F, Mounach A, Ghazi M, Nouijai A, Achemlal L, Bezza A, Ghozlani I. Performance of calcaneus quantitative ultrasound and dual-energy $\mathrm{X}$-ray absorptiometry in the discrimination of prevalent asymptomatic osteoporotic fractures in postmenopausal women. Rheumatol Int 2009;29:551-556.

15 Shin MH, Kweon SS, Park KS, Heo H, Kim SJ, Nam HS, Jeong SK, Chung EK, Choi JS. Quantitative ultrasound of the calcaneus in a Korean population: reference data and relationship to bone mineral density determined by peripheral dual X-ray absorptiometry. J Korean Med Sci 2005;20:1011-1016.

16 lida T, Chikamura C, Aoi S, Ikeda H, Matsuda Y, Oguri Y, Ono Y, Katada K, Ishizaki F. A study on the validity of quantitative ultrasonic measurement used the bone mineral density values on dual-energy X-ray absorptiometry in young and in middle-aged or older women. Radiol Phys Technol 2010;3: 113-119.

17 Gemalmaz A, Discigil G, Sensoy N, Basak O. Identifying osteoporosis in a primary care setting with quantitative ultrasound: relationship to anthropometric and lifestyle factors. J Bone Miner Metab 2007;25:184-192. 
18 Marin F, Lopez-Bastida J, Diez-Perez A, Sacristan JA. Bone mineral density referral for dual-energy Xray absorptiometry using quantitative ultrasound as a prescreening tool in postmenopausal women from the general population: a cost-effectiveness analysis. Calcif Tissue Int 2004;74:277-283.

19 Trimpou P, Bosaeus I, Bengtsson BA, Landin-Wilhelmsen K. High correlation between quantitative ultrasound and DXA during 7 years of follow-up. Eur J Radiol 2010;73:360-364.

20 Nayak S, Olkin I, Liu H, Grabe M, Gould MK, Allen IE, Owens DK, Bravata DM. Meta-analysis: accuracy of quantitative ultrasound for identifying patients with osteoporosis. Ann Intern Med 2006;144: 832-841.

21 Jancar J, Jancar MP. Age-related fractures in people with intellectual disability and epilepsy. J Intellect Disabil Res 1998;42:429-433.

22 Desai KB, Ribbans WJ, Taylor GJ. Incidence of five common fracture types in an institutional epileptic population. Injury 1996;27:97-100.

23 Vestergaard P, Tigaran S, Rejnmark L, Tigaran C, Dam M, Mosekilde L. Fracture risk is increased in epilepsy. Acta neurologica Scandinavica 1999;99: 269-275.

24 Group WHOWW. Assessment of fracture risk and its application to screening for postmenopausal osteoporosis. World Health Organ Tech Rep Ser 1994;843:1-129.

25 CBO, K vd G. Tweede herziene richtlijn osteoporose. (Van Zuiden Communications, 2002).

26 Pluskiewicz W, Nowakowska J. Bone status after long-term anticonvulsant therapy in epileptic patients: evaluation using quantitative ultrasound of calcaneus and phalanges. Ultrasound Med Biol 1997;23:553-558.

27 Pedrera JD, Canal ML, Carvajal J, Postigo S, Villa LF, Hernández ER, Rico H. Influence of vitamin D administration on bone ultrasound measurements in patients on anticonvulsant therapy. Eur J Clin Invest 2000;30:895-899. 


\section{Chapter 6}

Biochemical markers of bone turnover for the prediction of fracture risk in patients with chronic epilepsy

K Beerhorst, IY Tan, P Verschuure, E van der Veer, AP Aldenkamp Submitted 


\section{Abstract}

\section{Purpose}

Chronic antiepileptic drug use is associated with increased fracture rate and low bone mineral density (BMD). The aim of this study was to gain insight into the bone turnover of a population with long-term antiepileptic drug use who are at risk for the development of bone mineral disorders.

\section{Methods}

A cross-sectional study was conducted in 155 patients from a residential unit of a tertiary epilepsy centre. BMD measurement was performed with dual-energy X-ray absorptiometry (DXA) scan of spine and hip. Laboratory evaluation of bone turnover including alkaline phosphatase, bone resorption marker serum C-telopeptides of type I collagen (sCTX), and bone formation marker procollagen type $1 \mathrm{~N}$-terminal peptide (P1NP) was performed. Based on DXA $\mathrm{T}$-scores, prevalences of bone mineral disorders (osteopenia and osteoporosis) were calculated. Correlations between DXA T-scores and bone turnover markers were explored. Biochemical evaluation of calcium and vitamin $D$ metabolism was performed by measurement of serum calcium, phosphate, 25-hydroxyvitamin D3 and parathormone.

\section{Results}

155 patients were included, 61\% was male. Mean age was 44.7 years (SD 16.4). More than half of the patients (58.1\%) had a history of fractures. $72 \%$ had low BMD of which $49 \%$ had osteopenia and $23 \%$ had osteoporosis. A history of fractures was correlated with several demographic and clinical variables: (age $(r=.24)$, duration of epilepsy $(r=.21)$, cumulative drug load $(r=.31)$ and ambulatory status $(r=-.18)$ ). The same factors were found for confirmed vertebral fractures. A regression analysis identified cumulative drug load as the strongest predictor. Of the bone markers 25-OH vitamin D3 ( $r=-.17)$, parathormone $(r=.18)$ and net bone formation ( $r=-.16)$ were predictors for fractures with net bone formation having the highest contribution. These variables combined, however, explained a mere $4 \%$ of the variance.

Patients with osteoporosis and osteopenia had increased SCTX-scores. Patients with osteoporosis had lower P1NP and net bone formations Z-scores (P1NP minus SCTX). The net bone formation Z-score was a significant predictor for low BMD, though it explained only $12 \%$ of the variance.

\section{Conclusion}

In patients with epilepsy and long-term AED use there is a high prevalence of fractures and low BMD (osteopenia and osteoporosis). In patients with osteopenia and osteoporosis bone resorption is increased, in patients with osteoporosis bone turnover is increased. Increased bone turnover was a significant predictor of fractures. However, in our study the BTMs P1NP and SCTX do not qualify as early predictors for identifying those patients with normal BMD at risk for developing low BMD. For fracture prediction age and cumulative drug load explained a larger percentage of the variance than BTMs or BMD. 


\section{Introduction}

In patients with epilepsy and antiepileptic drug (AED) use, bone turnover is often increased, ${ }^{1-6}$ although not all investigations could confirm these findings. ${ }^{7,8}$ Patients with epilepsy have a 2-6 times greater risk of fractures in comparison to the general population, and a reduction in bone mineral density (BMD) can be detected as early as 1-5 years after commencing treatment. ${ }^{9}$

Osteoporosis is a common health hazard that greatly increases fracture risk. Diagnosis of osteoporosis is performed by dual-energy X-ray absorptiometry (DXA). A DXA scan assesses BMD resulting in a T-score. Individuals with a T-score of -2.5 and less are diagnosed with osteoporosis. Even though a DXA scan is the gold standard for the diagnosis of osteoporosis, its use has some disadvantages: it uses potentially harming radiation, although at a very low dose, the equipment is relatively expensive and its use is restricted to specialised settings. Recently, the focus has shifted to a potential alternative method for predicting fracture risk: bone turnover markers (BTMs). BTMs are biochemical products related to the metabolic activity of bone. BTMs can be measured by analyzing samples of blood or urine. This method has a number of advantages over DXA such as being less invasive, easily executable and allowing a variety of assays. ${ }^{10}$ Furthermore, BTMs have the potential to detect changes in bone metabolism earlier than changes in bone density as assessed with a DXA scan. ${ }^{11,12} \mathrm{~A}$ recent meta-analysis of the reference markers of bone turnover for prediction of fracture concluded that there was a modest but significant association between BTMs and risk of future fractures in untreated middle-aged or older men and women. ${ }^{13}$ Currently no single serum marker is available for the detection of bone disease in patients with epilepsy, but a combination of the measurements is used (e.g. calcium, phosphorus, vitamin $\mathrm{D}$ and parathormone) to detect disturbances in bone and mineral metabolism. $^{14}$

In this study we investigated the association between fractures, BMD and BTMs in a cohort of patients with chronic epilepsy and long-term AED use, and thus a group at high risk for developing bone mineral disorders.

\section{Methods}

\section{Study population/ subjects}

The study population consisted of residents living in a long-stay care facility for patients with refractory epilepsy. Almost all patients had a history of refractory epilepsy for which in most patients treatment with several AEDs was necessary. Most of the patients also had some degree of intellectual disability.

A cross-sectional study was performed, measuring BMD at lumbar spine and femur with DXA. In addition, characteristics regarding life-style, epilepsy, medication use, 
history of antiepileptic (AED) use, fracture history and potential secondary causes of osteoporosis were recorded in a database.

The study was approved by the local and regional Ethics Committee and was in accordance with the Code of Ethics (Declaration of Helsinki). Informed consent was obtained from each patient or his/her legal representative.

\section{Methods: BMD by DXA}

BMD of the lumbar spine and left femur was measured by DXA and expressed as the amount of mineral $(\mathrm{g})$ divided by the area scanned $\left(\mathrm{cm}^{2}\right)$. All DXA measurements were performed by the same densitometer (Hologic, Discovery W [S/N 70991]) and were performed between 30 August and 29 September 2009. T-scores (number of standard deviations [SD] below peak bone mass) and Z-scores (number of SD below age- and sex-matched controls) were calculated for total lumbar spine, femoral neck and total femur using the manufacturers' reference database (reference values supplied by Hologic for the hip and lumbar spine as well as data from the National Health and Nutrition Examination Survey part III (NHANES III) dataset). Manufacturer specific reference population (Caucasian) was used to calculate T-scores. World Health Organisation (WHO) criteria $^{15}$ were used to classify bone mineral density and osteoporosis. A T-score of -1.0 and greater is considered normal, a T-score between -1.0 and -2.5 is considered low bone mass (osteopenia), and a T-score of -2.5 and less is considered osteoporosis.

\section{Methods: blood measurement}

For all subjects peripheral venous blood samples were collected in a non-fasting state between 8 and 11 a.m. All samples were collected between 12 September and 20 October 2009.

Serum levels of albumin, calcium, creatinine, inorganic phosphorus and alkaline phosphatase were determined using a routine chemistry analyzer (Cobas Integra 400, Roche Diagnostics). TSH and PTH were measured using routine immunochemistry analyzers (Access, Beckman Coulter and Immulite 2500, Siemens Healthcare, respectively). 25-Hydroxy vitamin D3 was measured by an automated chemiluminiscence assay (Liaison, Diasorin).

Bone turnover was studied by assessment of bone formation markers procollagen type $1 \mathrm{~N}$-terminal peptide (P1NP) and bone resorption marker serum C-telopeptides of type I collagen (sCTX). P1NP was measured by radioimmunoassay (Orion Diagnostica, Espoo, Finland; inter-assay coefficient of variation (CV) 9.0\%). SCTX was measured by electrochemiluminescence immunoassay (Elecsys Roche Diagnostics, Germany; CV 10.8\%).

Z-scores of BTMs were used to correct for the normal influence that age and gender have on bone turnover. Z-scores, the number of standard deviations (SD) from the 
normal mean for age and gender, were calculated using matched 10 -year-cohorts of a Dutch reference group (150 men or 350 women, checked for serum $25-\mathrm{OH}$ vitamin D levels $>50 \mathrm{nmol} / \mathrm{I}$ as well as for lumbar spine and hip BMD T-score $>-2.5$ after 50 years of age).

\section{Analysis and statistics}

Data are presented as mean \pm SD or as percentages.

Correlation analysis was performed using a two-tailed Pearson correlation coefficient with a significance level of $p<0.05$.

Group differences (normal BMD, osteopenia, osteoporosis) were tested with Anova and when this yielded statistical significance $(p<0.05)$, posthoc T-tests were used corrected by the Bonferroni correction for multiple testing. Non-parametric variables were tested with the Kruskall-Wallis with post-hoc Mann-Whitney U-tests.

Linear regression analysis was performed using a stepwise backward procedure.

All analyses were performed using SPSS (Statistical Package of Social Sciences, version 20, 2010 SPSS, Chicago, IL).

\section{Results}

A total of 155 patients were included in this study. In Table 6.1 the demographic characteristics are shown. In total, 94 of the 155 patients were male (61\%). The mean age was 44.7 years (SD 16.4). Body mass index was 25.0 (SD 4.5). The Barthel index was 12.5 (SD 6.3). The ambulatory status was satisfactory for the majority of the patients (67.7\%), whereas a large minority (32.2\%) had limited ambulatory possibilities. About one-third of the patients had a severe or profound intellectual disability (34.2\%). Most patients used coffee on a daily basis, but the vast majority never smoked neither used alcohol. Men and women did not differ significantly in demographic characteristics, except for a higher alcohol and coffee consumption in men (both $p=0.01$ ).

The epilepsy characteristics are shown in Table 6.2. Most patients have a chronic epilepsy with a duration over several decades; the epilepsy is still active in $88.4 \%$ of the patients who still have seizures. They have a symptomatic or probable symptomatic localisation-related epilepsy; they are treated with polytherapy antiepileptic treatment (on average 2.9 different antiepileptic drugs) and a cumulative drug load (number of current AEDs multiplied by the number of years with drug treatment; see Beerhorst et al., 2011) ${ }^{16}$ of 107.7 on average.

Based on the WHO criteria for osteoporosis $27.7 \%(n=43)$ of the patients are diagnosed with normal bone mineral density, $49 \%$ have osteopenia $(n=76)$ and $23.3 \%$ have osteoporosis $(n=36)$. 
Table 6.1 Demographic characteristics of study population $(n=155)$.

\begin{tabular}{|c|c|c|c|}
\hline Variable & $\mathrm{n}$ & mean (SD) or $\%$ & Range \\
\hline Sex male & 94 & $60.6 \%$ & \\
\hline Age & & $44.7(16.4)$ & $18-88$ \\
\hline \multicolumn{4}{|l|}{ Ethnicity } \\
\hline Caucasian & 152 & 98.1 & \\
\hline Asian & 2 & 1.3 & \\
\hline African-American & 1 & 0.6 & \\
\hline Body mass index, $\mathrm{kg} / \mathrm{m}^{2}$ & & $25.0(4.5)$ & \\
\hline Barthel index & & $12.5(6.3)$ & \\
\hline \multicolumn{4}{|l|}{ Ambulatory status } \\
\hline Wheelchair-bound & 34 & 21.9 & \\
\hline Walk with aid & 16 & 10.3 & \\
\hline Walk unassisted & 105 & 67.7 & \\
\hline \multicolumn{4}{|l|}{ Intellectual disability } \\
\hline None & 1 & 0.6 & \\
\hline Mild & 44 & 28.4 & \\
\hline Moderate & 57 & 36.8 & \\
\hline Severe & 47 & 30.3 & \\
\hline Profound & 6 & 3.9 & \\
\hline Exposure to sunlight, hours per month & 140 & $1.9(1.8)$ & \\
\hline \multicolumn{4}{|l|}{ Smoking } \\
\hline Never smoked & 119 & 76.8 & \\
\hline Past smoker & 36 & 23.2 & \\
\hline -Of which: current smoker & 20 & & \\
\hline \multicolumn{4}{|l|}{ Alcohol use } \\
\hline Nondrinker & 128 & 82.6 & \\
\hline Current drinker & 27 & 17.4 & \\
\hline \multicolumn{4}{|l|}{ Caffeine consumption } \\
\hline None & 35 & 22.6 & \\
\hline Current drinker & 120 & 77.4 & \\
\hline
\end{tabular}

Table 6.2 Clinical epilepsy characteristics of the study population $(n=155)$.

\begin{tabular}{lcc}
\hline Variable & $\mathrm{N}$ & mean (SD) or \% \\
\hline Total duration epilepsy in years & & $38.9(15.7)$ \\
Type of epilepsy & 84 & 54.2 \\
$\quad$ Symptomatic & 70 & 45.2 \\
$\quad$ Probable symptomatic & 1 & 0.6 \\
$\quad$ Idiopathic & & $88.4 \%$ \\
Seizures (i.e. not in remission) & 48 & $2.9(1.2)$ \\
Current number of AEDs & & $31 \%$ \\
Percentage on enzyme-inducing AEDs & & $2.6(1.3)$ \\
Current number AEDs & & $107.7(53.2)$ \\
Cumulative drug load & & \\
\hline
\end{tabular}


More than half $(58.1 \%)$ of the patients $(n=90)$ had a history of fractures with on average 1.2 fractures for the total group (SD 1.6). $21.3 \%(n=33)$ had a DXA confirmed vertebral fracture.

Both variables were first correlated with demographic and clinical variables. A history of fractures correlated statistically significant with age $(r=.24 ; p=<0.003)$ and duration of epilepsy ( $r=.21 ; p=.015)$. Age and duration of epilepsy, however, express the same variance as the correlation between age and duration of epilepsy is almost complete $(r=.92 ; p=<0.001)$. Other statistically significant correlations were found for cumulative drug load $(r=.31 ; p=<0.001)$ and ambulatory status $(r=-.18 ; p=0.026)$. For confirmed vertebral fractures statistically significant correlation was found for age $(r=.22$; $p=0.004)$, total duration of epilepsy $(r=.24 ; p=0.03)$ and for ambulatory status $(r=-.18$; $p=0.02$ ).

Statistically significant correlations with history of fractures were found for the following two variables: $25-\mathrm{OH}$ vitamin D3 $(r=-17 ; p=0.04)$ and parathormone $(r=.18$; $p=0.03$ ). For net bone formation (P1NP minus SCTX) a trend towards significance was found ( $r=-.16 ; p=0.06)$.

Linear regression analysis was performed with history of fractures as dependent and the two variables with significant correlation with fractures as predictors as well as net bone formation as a factor representing a trend. This shows that the three factors combined (25-OH vitamin D3, parathormone and net bone formation) explain $4 \%$ of the variance. Only when all 3 factors were included a statistical significant solution remained $(p=0.02)$ with net bone formation as the only variable that remained statistical significant as unique variable $(p=0.02)$.

When the 4 demographic and clinical variables that were significantly correlated with history of fracture are used as predictors than $12 \%$ of the variance is explained. Only when all factors combined were included, a statistical significant solution remained $(p=0.001)$ with cumulative drug load $(p=0.003)$ having the largest contribution.

No regression analysis was performed with confirmed vertebral fractures as dependent, due to the low correlation with the biochemical measurements.

In Table 6.3 laboratory assessment is summarised for the total group, and separately for the patients with a history of fractures and patients without fractures. This shows only a statistically significant difference for the net bone formation score, in which patients with a prior fracture had a lower net bone formation Z-score compared to patients without any fracture $(p=0.02)$.

In an additional analysis we also evaluated possible differences in BTMs when the group was divided based on DXA assessed BMD. Table 6.4 shows that patients with low BMD had a significantly higher alkaline phosphatase $(p<0.01)$, which is only statistically significant between the normal group and the group with osteoporosis. Also a higher Z-score sCTX $(p<0.002)$ was found in patients with osteopenia or osteoporosis compared to patients with normal BMD. The statistically higher Z-score P1NP $(p=0.02)$ is caused by differences between the groups with normal BMD and 
osteopenia with the group with osteoporosis. Finally the net bone formation (Z-score P1NP minus Z-score sCTX) was lower in the osteoporosis group compared to the normal BMD group. None of the BTMs showed a statistically significant difference between the normal BMD and the osteopenia group.

Consequently a linear regression analysis was performed with the outcome of the DXA scan as dependent variable and the four bone-markers that yielded statistical significance in the Anova's as predictors: 1) alkaline phosphatase, 2) Z-score sCTX, 3) Z-score P1NP and 4) net bone formation. A backward procedure was used. Although all 4 markers contributed significantly $(p<0.001)$, the procedure identified a two-factor solution as the strongest predictor $(p<0.001)$, with Z-score sCTX $(p<0.017)$ and alkaline phosphatase $(p=0.005)$. The two-factor solution explained $12 \%$ of the variance.

Table 6.3 Biochemical Markers of Bone Turnover for the total group and patients with or without fractures.

\begin{tabular}{lcccc}
\hline Variable & $\begin{array}{c}\text { Total Group } \\
(\mathrm{n}=155)\end{array}$ & $\begin{array}{c}\text { 2. Fractures } \\
(\mathrm{n}=90)\end{array}$ & $\begin{array}{c}\text { 3. No fractures } \\
(\mathrm{n}=47)\end{array}$ & $p$-values \\
\hline Alkaline Phosphatase (U/I) & $88.34(34.1)$ & $89.1(35.5)$ & $91.2(31.2)$ & 0.73 \\
Calcium (mmol/I) & $2.4(1.0)$ & $2.4(1.0)$ & $2.3(0.9)$ & 0.31 \\
Inorganic phosphorus (mmol/I) & $1.12(0.15)$ & $1.12(0.16)$ & $1.13(0.15)$ & 0.97 \\
25-OH vit D3 (nmol/I) & $43.1(22.7)$ & $41.1(22.2)$ & $48.2(27.0)$ & 0.76 \\
TSH (mU/I) & $1.6(0.9)$ & $1.6(1.0)$ & $1.5(0.9)$ & 0.49 \\
Z-score P1NP & $0.6(1.6)$ & $0.8(1.7)$ & $0.6(1.5)$ & 0.56 \\
Z-score sCTX & $1.2(2.3)$ & $1.5(2.6)$ & $0.7(1.5)$ & 0.06 \\
Albumin (g/l) & $43.3(3.5)$ & $42.9(3.4)$ & $44.1(3.7)$ & 0.07 \\
Parathormone (pmol/I) & $3.2(2.6)$ & $3.3(2.5)$ & $2.7(1.8)$ & 0.13 \\
Net bone formation (P1NP minus sCTX) & $-0.48(1.7)$ & $-0.73(1.7)$ & $-0.05(1.3)$ & 0.02 \\
MDRD clearance/ eGFR & $119.1(30.8)$ & $118.8(30.6)$ & $124.0(30.6)$ & 0.34 \\
\hline
\end{tabular}

Table 6.4 Biochemical assessment for the groups based on DXA BMD diagnosis.

\begin{tabular}{lcccc}
\hline Variable & 1. Normal & 2. Osteopenia & 3. Osteoporosis & p-values \\
\hline Alkaline Phosphatase (U/I) & $75.1(23.3)$ & $88.9(36.1)$ & $102.9(35.3)$ & $0.01(1-3)$ \\
Calcium (mmol/I) & $2.40(0.08)$ & $2.38(0.10)$ & $2.37(0.08)$ & 0.35 \\
Inorganic phosphorus (mmol/I) & $1.13(0.16)$ & $1.13(0.17)$ & $1.12(0.14)$ & 0.98 \\
25-OH vit D3 (nmol/I) & $43.8(19.5)$ & $42.3(22.4)$ & $43.8(27.0)$ & 0.92 \\
TSH (mU/I) & $1.5(0.8)$ & $1.7(1.0)$ & $1.6(1.0)$ & 0.62 \\
Z-score P1NP & $0.55(1.51)$ & $0.39(1.17)$ & $1.25(2.16)$ & $0.02(2-3)$ \\
Z-score sCTX & $0.49(1.86)$ & $1.02(2.26)$ & $2.29(2.64)$ & $0.002(1-3 ; 2-3)$ \\
Albumin (g/I) & $44.2(3.3)$ & $43.1(3.2)$ & $42.7(4.1)$ & 0.14 \\
Parathormone (pmol/I) & $2.7(1.2)$ & $3.2(2.7)$ & $3.8(3.5)$ & 0.17 \\
Net bone formation (P1NP minus sCTX) & $0.11(1.54)$ & $-0.63(1.63)$ & $-0.86(1.74)$ & $0.02(1-3)$ \\
MDRD clearance / eGFR & $110.6(26.2)$ & $122.2(34.1)$ & $122.9(30.8)$ & 0.10 \\
\hline
\end{tabular}

$\mathrm{DXA}=$ dual-energy $\mathrm{X}$-ray absorptiometry, $\mathrm{BMD}=$ bone mineral density. 


\section{Discussion}

In line with other studies we found higher fracture rates in patients with chronic epilepsy and low BMD. ${ }^{17-22}$ Of course, in this population, also general risk factors for osteoporosis are increased such as impaired ambulation and the presence of intellectual disability. However, in the regression analysis these factors did not significantly predict history of fractures nor low BMD.

Linear regression analysis showed that three characteristics combined $(25-\mathrm{OH}$ vitamin D3, parathormone and net bone formation) are significantly correlated with a history of fractures. Net bone formation has the strongest predictive value. However these variables explain a limited percentage $(4 \%)$ of the variance. Demographic and clinical variables explain a larger percentage (12\%) of the variance with cumulative drug load having the largest contribution. In a retrospective study on long-term AEDs use and fractures, cumulative drug load also was the only significant factor in predicting the number of fractures. ${ }^{16}$

When we divided our group into patients with normal BMD, patients with osteopenia and patients with osteoporosis, the osteoporosis group had increased bone turnover as reflected by lower net bone formation compared to the normal BMD group. The osteoporosis group also had lower bone formation compared to the normal BMD and osteopenia group. Patients with low BMD (osteopenia and osteoporosis) had increased bone resorption (SCTX Z-scores). Thus bone resorption is increased in patients with epilepsy, long-term AEDs treatment and low BMD.

However, no significant difference in BTM profile was found between patients with normal BMD and patients with osteopenia. Also, none of the BTMs differentiated the osteopenia group solely from the group with normal BMD. This is of course a disappointing result in the search for a biomarker that could support early detection and possible prevention of evolving low bone mass. Also the combined use of our BTMs only explained a mere $12 \%$ of the variance caused by dividing the population in the three aforementioned groups based on DXA BMD.

Increased bone turnover during AEDs therapy has been found by other investigators in adults and children on various AED monotherapies: $\mathrm{PHT},{ }^{5,23,24} \mathrm{VPA},{ }^{3,25,26} \mathrm{CBZ},{ }^{6,27,28}$ and $\mathrm{OXC}^{29}$. Guo et al. found that long-term VPA and LTG therapy in children, particularly when combined, was associated with low BMD and reduced bone formation. ${ }^{30}$ Sometimes increased bone turnover can be measured within a few weeks till 3 months of newly started AED treatment. ${ }^{29}$ However, not all studies could confirm increased bone turnover during AEDs therapy. ${ }^{5,7}$

Bone formation is a dynamic process with continuous bone formation and remodelling taking place. ${ }^{13}$ Theoretically, repeated measurement of BTMs over time could give more insight in the pathophysiologic mechanism of AED-induced low BMD and could help in better identifying those patients at risk of developing low BMD during AED-treatment when the process of bone formation and resorption is disturbed during AED use. 
There is a need to increase our knowledge of the pathophysiologic mechanism(s) of AED-induced low bone mass. Increased vitamin D metabolism resulting in secondary hyperparathyroidism is only one of the assumed mechanisms, but this mechanism certainly does not account for all patients. Several investigators found normal vitamin D levels in patients with epilepsy, AEDs use and low BMD. ${ }^{6,31}$ According to our study, another study also did not find an association between $25-\mathrm{OH}$ vitamin $\mathrm{D}$ and the measured bone markers. ${ }^{32}$ Variable pathophysiological mechanisms of AED-induced low BMD may require tailoring individual prevention and treatment strategies. ${ }^{29}$ Recently vitamin D receptor polymorphism $(\mathrm{VDR})^{33}$ and Bsml polymorphism in patients taking phenytoin were found to be associated with low bone mass. ${ }^{9}$

There are certain limitations of our present study to be acknowledged. First of all the cross-sectional design and the absence of a control group. A more powerful longitudinal design was not an option because of the necessary long follow-up. A strong aspect of our design is that almost all residents were included. Secondly, most patients used long-term AED polytherapy or had had polytherapy in the past. Therefore, no specific conclusions between individual AEDs or type of AEDs (enzymeinducing vs. non-enzyme-inducing AEDs) and BTMs could be drawn. Thirdly, most patients were chronic users of AEDs, only a few patients were recently started on AEDs, thus changes in BTMs in the first five years are not included in the analyses. Lastly, the number of fractures was based on recall and the medical records. This could have led to a wrong estimation of the life-time fracture rate, but an underestimation is more probable than an overestimation, making our finding even more sound.

In conclusion, in patients with epilepsy and long-term AED use there is a high prevalence of fractures and low BMD. In patients with osteopenia and osteoporosis bone resorption is increased. However, in our study the BTMs P1NP and SCTX do not qualify as early predictors for low BMD nor fractures. For fracture prediction age and cumulative drug load explain a larger percentage of the variance than BTMs or BMD. Further study is needed if repeated measurement of BTMs can be useful in identifying changes in the dynamic process of bone formation and bone resorption and give more insight in the pathophysiologic mechanisms. Thereby making it possible to tailor possible preventive and treatment strategies specified to the individual patient. 


\section{References}

1. Kulak CA, Borba VZ, Silvado CE, Paola Ld, Seibel MJ, Bilezikian JP, Boguszewski CL. Bone density and bone turnover markers in patients with epilepsy on chronic antiepileptic drug therapy. Arq Bras Endocrinol Metabol 2007;51:466-471.

2. Mintzer S, Boppana P, Toguri J, DeSantis A. Vitamin D levels and bone turnover in epilepsy patients taking carbamazepine or oxcarbazepine. Epilepsia 2006;47:510-515.

3. Sato Y, Kondo I, Ishida S, Motooka H, Takayama K, Tomita Y, Maeda H, Satoh K. Decreased bone mass and increased bone turnover with valproate therapy in adults with epilepsy. Neurology 2001;57: 445-449.

4. Välimäki MJ, Tiihonen M, Laitinen K, Tähtelä R, Kärkkäinen M, Lamberg-Allardt C, Mäkelä P, Tunninen R. Bone mineral density measured by dual-energy x-ray absorptiometry and novel markers of bone formation and resorption in patients on antiepileptic drugs. J Bone Miner Res 1994;9:631-637.

5. Pack AM, Morrell MJ, Marcus R, Holloway L, Flaster E, Doñe S, Randall A, Seale C, Shane E. Bone mass and turnover in women with epilepsy on antiepileptic drug monotherapy. Ann Neurol 2005;57: 252-257.

6. Verrotti A, Greco R, Latini G, Morgese G, Chiarelli F. Increased bone turnover in prepubertal, pubertal, and postpubertal patients receiving carbamazepine. Epilepsia 2002;43:1488-1492.

7. Koo DL, Joo EY, Kim D, Hong SB. Effects of levetiracetam as a monotherapy on bone mineral density and biochemical markers of bone metabolism in patients with epilepsy. Epilepsy research 2013;104:134-139.

8. Koo DL, Hwang KJ, Han SW, Kim JY, Joo EY, Shin WC, Lee HW, Seo DW, Hong SB. Effect of oxcarbazepine on bone mineral density and biochemical markers of bone metabolism in patients with epilepsy. Epilepsy research 2014;108:442-447.

9. Phabphal K, Geater A, Limapichart K, Sathirapanya P, Setthawatcharawanich S, Witeerungrot N, Thammakumpee N, Leelawattana R. The association between Bsml polymorphism and bone mineral density in young patients with epilepsy who are taking phenytoin. Epilepsia 2013;54:249-255.

10. Vasikaran $S$, Eastell $R$, Bruyère $O$, Foldes $A J$, Garnero $P$, Griesmacher $A$, McClung $M$, Morris $H A$, Silverman S, Trenti T, Wahl DA, Cooper C, Kanis JA; IOF-IFCC Bone Marker Standards Working Group. Markers of bone turnover for the prediction of fracture risk and monitoring of osteoporosis treatment: a need for international reference standards. Osteoporos Int 2011;22:391-420.

11. Wheater G, Elshahaly M, Tuck SP, Datta HK, van Laar JM. The clinical utility of bone marker measurements in osteoporosis. Journal of translational medicine 2013;11:201.

12. Burch J, Rice S, Yang H, Neilson A, Stirk L, Francis R, Holloway P, Selby P, Craig D. Systematic review of the use of bone turnover markers for monitoring the response to osteoporosis treatment: the secondary prevention of fractures, and primary prevention of fractures in high-risk groups. Health Technol Assess 2014;18:1-180.

13. Johansson H, Odén A, Kanis JA, McCloskey EV, Morris HA, Cooper C, Vasikaran S; IFCC-IOF Joint Working Group on Standardisation of Biochemical Markers of Bone Turnover. A meta-analysis of reference markers of bone turnover for prediction of fracture. Calcif Tissue Int 2014;94:560-567.

14. Svalheim S, Roste LS, Nakken KO, Tauboll E. Bone health in adults with epilepsy. Acta Neurol Scand Suppl 2011:89-95.

15. Kanis JA. Assessment of fracture risk and its application to screening for postmenopausal osteoporosis: synopsis of a WHO report. WHO Study Group. Osteoporos Int 1994;4:368-381.

16. Beerhorst K, Schouwenaars FM, Tan IY, Aldenkamp AP. Epilepsy: fractures and the role of cumulative antiepileptic drug load. Acta Neurol Scand 2012;125:54-59.

17. Souverein PC, Webb DJ, Petri H, Weil J, Van Staa TP, Egberts T. Incidence of fractures among epilepsy patients: a population-based retrospective cohort study in the General Practice Research Database. Epilepsia 2005;46:304-310.

18. Souverein PC, Webb DJ, Weil JG, Van Staa TP, Egberts AC. Use of antiepileptic drugs and risk of fractures: case-control study among patients with epilepsy. Neurology 2006;66:1318-1324.

19. Ensrud KE, Walczak TS, Blackwell TL, Ensrud ER, Barrett-Connor E, Orwoll ES. Antiepileptic drug use and rates of hip bone loss in older men: a prospective study. Neurology 2008;71:723-730. 
20. Vestergaard P. Epilepsy, osteoporosis and fracture risk - a meta-analysis. Acta Neurol Scand 2005;112:277-286.

21. Persson HB, Alberts KA, Farahmand BY, Tomson T. Risk of extremity fractures in adult outpatients with epilepsy. Epilepsia 2002;43:768-772.

22. Nicholas JM, Ridsdale L, Richardson MP, Grieve AP, Gulliford MC. Fracture risk with use of liver enzyme inducing antiepileptic drugs in people with active epilepsy: cohort study using the general practice research database. Seizure 2013;22:37-42.

23. Lyngstad-Brechan MA(1), Taubøll E, Nakken KO, Gjerstad L, Godang K, Jemtland R, Bollerslev J. Reduced bone mass and increased bone turnover in postmenopausal women with epilepsy using antiepileptic drug monotherapy. Scand J Clin Lab Invest 2008;68:759-766.

24. Pack AM, Morrell MJ, Randall A, McMahon DJ, Shane E. Bone health in young women with epilepsy after one year of antiepileptic drug monotherapy. Neurology 2008;70:1586-1593.

25. Ecevit C, Aydogan A, Kavakli T, Altinoz S. Effect of carbamazepine and valproate on bone mineral density. Pediatr Neurol 2004;31:279-282.

26. Rauchenzauner M, Griesmacher A, Tatarczyk T, Haberlandt E, Strasak A, Zimmerhackl LB, Falkensammer G, Luef G, Högler W. Chronic antiepileptic monotherapy, bone metabolism, and body composition in non-institutionalized children. Dev Med Child Neurol 2010;52:283-288.

27. Verrotti A, Greco R, Morgese G, Chiarelli F. Increased bone turnover in epileptic patients treated with carbamazepine. Ann Neurol 2000;47:385-388.

28. Verrotti A, Agostinelli S, Coppola G, Parisi P, Chiarelli F. A 12-month longitudinal study of calcium metabolism and bone turnover during valproate monotherapy. Eur J Neurol 2010;17:232-237.

29. Bauer S, Hofbauer LC, Rauner M, Strzelczyk A, Kellinghaus C, Hallmeyer-Elgner S, Oertel WH, Rosenow F. Early detection of bone metabolism changes under different antiepileptic drugs (ED-BoM-AED)--a prospective multicenter study. Epilepsy Res 2013;106:417-422.

30. Guo CY, Ronen GM, Atkinson SA. Long-term valproate and lamotrigine treatment may be a marker for reduced growth and bone mass in children with epilepsy. Epilepsia 2001;42:1141-1147.

31. Tsukahara H, Kimura K, Todoroki Y, Ohshima Y, Hiraoka M, Shigematsu Y, Tsukahara Y, Miura M, Mayumi M. Bone mineral status in ambulatory pediatric patients on long-term anti-epileptic drug therapy. Pediatr Int 2002;44:247-253.

32. Nettekoven S, Ströhle A, Trunz B, Wolters M, Hoffmann S, Horn R, Steinert M, Brabant G, Lichtinghagen R, Welkoborsky HJ, Tuxhorn I, Hahn A. Effects of antiepileptic drug therapy on vitamin D status and biochemical markers of bone turnover in children with epilepsy. Eur J Pediatr 2008;167:1369-1377.

33. Lambrinoudaki I, Kaparos G, Armeni E, Alexandrou A, Damaskos C, Logothetis E, Creatsa M, Antoniou A, Kouskouni E, Triantafyllou N. Bsml vitamin D receptor's polymorphism and bone mineral density in men and premenopausal women on long-term antiepileptic therapy. Eur J Neurol 2011;18:93-98. 


\section{Chapter 7}

General discussion 
Chapter 7 


\section{General discussion}

In our study we found a high prevalence of low bone mineral density (BMD) (osteopenia and osteoporosis combined $80 \%$ ) in a cohort of residents of a long-stay department of a tertiary referral centre for patients with refractory epilepsy. Also the prevalence of fractures was high: $62 \%$ of the patients had at least one fracture in the past. $28 \%$ of the patients showed signs of a vertebral fracture on vertebral fracture assessment (VFA) of DXA scan. In most residents these vertebral fractures were new and not already accounted for in their fracture history (Chapter 4).

The prevalence of $80 \%$ in our study population with low BMD (32\% osteoporosis, $48 \%$ osteopenia) was somewhat higher than found in other studies. ${ }^{1-6}$ Lado et al. found a prevalence of $55 \%$ of low BMD (osteopenia and osteoporosis). In a Norwegian prospective study in postmenopausal women with epilepsy using antiepileptic drugs (AEDs) $62 \%$ had osteoporotic T-values in one or more regions, compared to $27 \%$ in the control group. Coppola et al. found in $58 \%$ of their patients a low BMD (osteopenia and osteoporosis). ${ }^{4}$ Phabphal et al. 2009 found 36\% had osteopenia and $4 \%$ had osteoporosis in a group of 123 patients. ${ }^{5}$ The higher prevalence of low BMD in our population could be the result of the systematic evaluation of the total population. Also the chronic use of AEDs and use of antiepileptic drug (AED) polytherapy in most patients could have contributed to the higher prevalence of low BMD in our group.

During the last decades accumulating evidence has linked epilepsy with osteoporosis. Osteoporosis in patients with epilepsy is a multifactorial condition, related to the type of epilepsy, habitus, family history and to the presence of conditions affecting bone metabolism. ${ }^{7}$ Amongst other risk factors, AEDs use may be one additional cause of osteoporosis. Long-term AED therapy seems to be an independent risk factor for reduced bone mineral density. In addition, AED users have an increased risk for fractures, which can be an important cause of morbidity and mortality. ${ }^{8}$ The fracture risk of the epileptic population is approximately twice that of the general population, independent of seizure-related falls. ${ }^{8}$

The inducers of the CYP450 are most commonly associated with bone alterations, because they accelerate the catabolism of active vitamin $D$ into inactive polar metabolites. Decreased biologically active vitamin D leads to decreased absorption of calcium in the gut. This results in hypocalcaemia and increased circulating parathormone leading to secondary hyperparathyroidism, and subsequently increased bone turnover. ${ }^{8}$ Data, however, are still contradictory. Recent studies demonstrate different results regarding the effect of carbamazepine, an enzyme-inducer of the CYP450, on bones. ${ }^{9-13}$ Interestingly, valproate on the other hand, an inhibitor of the CYP450, has recently been associated with increased bone resorption. ${ }^{8,14}$ Furthermore, Ensrud et al. found an independent association between the use of nonenzyme-inducing AEDs and the rate of bone loss in the hip whilst in a large cohort of elderly men the use of enzyme-inducing AEDs had no significant effect on hip bone loss and BMD. 8,15 
There is a substantial body of evidence that AEDs use is associated with a higher risk of fractures, especially when older AEDs are used. ${ }^{16}$ It is estimated that patients with epilepsy have a 2-6 times higher hip or vertebral fracture rate compared to the general population. ${ }^{17}$

A more recent study showed that treatment with enzyme-inducing AEDs for 1 year was estimated to result in 48 extra fractures per 10000 women treated $(95 \% \mathrm{Cl}$ : 26-71), including 10 additional hip fractures (95\% Cl: 3-20). There was a number needed (NN) to harm of 209 (140-383) for any fracture and 962 (507-3116) for hip fracture in women. In women aged 50 years and over, one year of treatment with enzyme-inducing AEDs was estimated to result in 88 extra fractures per 10000 women treated (95\% Cl: 40-142) in comparison to treatment with non-enzyme-inducing AEDs, yielding NN to harm $113(70-252){ }^{18}$

Measurement of BMD is the most commonly used predictor of fracture risk. However, a number of other important risk factors also contribute to low BMD and increased fracture risk. Of these, the most important factors are older age, female sex, low body weight, history of fracture after age 50 years, excess alcohol intake, cigarette smoking, family history of fracture, and glucocorticoid treatment. ${ }^{8}$ Furthermore there are several epilepsy-related risk factors which have been suggested to contribute to low BMD in patients with epilepsy: polytherapy, ${ }^{19-23}$ older age ( $>50$ years), ${ }^{3,24}$ use of AED therapy for more than two years or longer duration of AED therapy, ${ }^{3,5,19,20,24-26}$ generalised seizures, ${ }^{19}$ and use of enzyme-inducing AEDs. $3,6,20,25,27$

In our population it was difficult to separate the effect of long-term AED therapy from the many hypothetically confounding variables in institutionalised patients such as inadequate diet, lack of exercise and sunlight exposure. However the vast majority of our population (75\%) was ambulant and had a mean exposure to sunlight of 1.8 hours per day (SD +/-1.7 h) (Chapter 4).

Most of our residents had some degree of intellectual disability. In patients with an intellectual disability the prevalence of osteoporosis is higher compared to the general population. ${ }^{4,6,28}$ However, in a study with children with cerebral palsy Henderson et al. found that besides severity of neurologic impairment (as graded by Gross Motor Functional Classification level) also use of AEDs independently contributed to significantly lower BMD Z-scores in the femur. ${ }^{29}$

In our study population low BMD correlated significantly with age, intellectual disability, BMI, ambulatory status, total duration of epilepsy, cumulative drug load, history of fractures, number of fractures, $F R A X^{\circledR}$ major osteoporotic fracture and FRAX ${ }^{\circledR}$ hip fracture (Chapter 4). The strongest predictor of low BMD in our population was BMI, followed by cumulative drug load and age, with cumulative drug load being the only significant epilepsy-related parameter. In a prospective study of 81 ambulant young men (age 25-45 year) also age and time receiving AEDs were two important risk factors associated with low femoral neck BMD. ${ }^{24}$ In contrast to what is found in the general population alcohol consumption and smoking were not correlated with low 
BMD in our population. Probably these findings could be explained by the relatively low prevalence of smoking (12\%) and alcohol consumption $(20 \%)$ in our population (Chapter 4).

Of striking notice was the relatively young age and male predominance in patients with osteopenia and osteoporosis in our study (Chapter 4). 156 of the included 195 patients (80\%) had low BMD. In both low BMD groups more than $60 \%$ of the patients were male. In the osteopenia group almost $60 \%$ was below the age of 50 and in the osteoporosis group $40 \%$ was below the age of 50 years. So low BMD is accelerated in this group in addition to the normal ageing processes.

When focusing on fractures in our study population (Chapter 3 and 6), again the clinical parameter cumulative drug load was a significant predictor (Chapter 3). Our findings have been confirmed by others. Vestergaard et al. found a trend towards more fractures with increasing number of AEDs. ${ }^{30}$ Tsiropoulos et al. confirmed in a case-control study that polytherapy (and thus higher drug load) was associated with higher fracture risk than monotherapy. ${ }^{31}$ Other studies, though, could not confirm such association. ${ }^{32,33}$

In our population of 205 residents of the long-stay department of a tertiary epilepsy centre the increased risk of fractures was already clinically apparent: $62 \%$ of the patients sustained a fracture in the past with another $28 \%$ who had evidence of a vertebral fracture on the vertebral fracture assessment of the DXA scan. The absolute number of fractures in these patients ranged from zero to a maximum of 13 fractures in one patient (Chapter 4). The increased risk of fractures in the future was also expressed in the high WHO FRAX ${ }^{\circledR}$ scores for major osteoporotic facture and for hip fracture. The WHO FRAX ${ }^{\circledR}$ Risk Assessment tool (FRAX ${ }^{\circledR}$ ) has been developed to evaluate the fracture risk of patients aged between 40 and 90 years. For patients below the age of 40 years, the program computes probabilities at age 40 years. The FRAX ${ }^{\circledR}$ is based on individual patient models that integrate the risks associated with clinical risk factors as well as BMD at the femoral neck. The output of FRAX ${ }^{\circledR}$ is the 10-year probability of a major osteoporotic fracture (hip, clinical spine, humerus or wrist fracture) and the 10-year probability of hip fracture. ${ }^{34}$

In our population the mean 10 year probability of major osteoporotic fracture and hip fracture was 8.6 and 3.4, respectively. The WHO FRAX ${ }^{\circledR}$ for major osteoporotic fracture correlated significantly with age, number of fractures, total duration of epilepsy, Barthel index (negative correlation), serum calcium (negative correlation) and parathormone. As already seen with low BMD, again age and total duration of epilepsy and therefore indirect also drug load were positively correlated with increased risk of future fractures.

There is still much debate about enzyme-inducing versus non-enzyme inducing AEDs and the effects on bone health. Most of our patients were on AED polytherapy or had polytherapy in the past. Most patients were treated with enzyme-inducing and nonenzyme inducing AEDs in the past. Therefore, in our studies no definite conclusion 
could be drawn between individual or type of AEDs (enzyme-inducing versus nonenzyme inducing), bone mineral density, fracture risk and bone turnover.

Of striking notice was the high prevalence of vitamin $D$ deficiency in our population (Chapter 4 ). $65 \%$ of the patients had a vitamin D deficiency, $24 \%$ had insufficient vitamin D levels. However, only $12 \%$ of the patients had increased parathormone levels compatible with secondary hyperparathyroidism. Similar to other studies ${ }^{19,24}$ we also found no correlation between vitamin D level and DXA BMD. Hypovitaminosus D and secondary hyperparathyroidism therefore seem not to be the only mechanism explaining low BMD and increased fracture risk. Furthermore, the high prevalence of hypovitaminosus $D$ in our patients could also partly be the result of institutionalisation as in Dutch residents of care homes a prevalence of hypovitaminosus D up to $85 \%$ was reported. ${ }^{35}$ Besides increased catabolism of vitamin $D$ there are several other mechanisms postulated by which AEDs can induce osteoporosis such as a direct negative effect of AEDs on bone cells, impaired calcium absorption leading to low serum calcium levels, resistance to parathyroid hormone eventually leading to hypocalcaemia, and calcitonin deficiency which results in higher osteoclast mediated bone resorption and thus increased bone turnover. ${ }^{36}$ Recently vitamin $D$ receptor polymorphism (VDR) and Bsml polymorphism in patients taking phenytoin, ${ }^{37}$ oxcarbazepine, valproate and levetiracetam ${ }^{8}$ were found to be associated with low bone mass. ${ }^{8,37}$ In a mouse model which investigated the effect of valproic acid (VPA) on bone mineral content, mouse strains sensitive and resistant to the adverse bone effect of chronic VPA treatment were identified. This strain-specific effect strongly suggests a role of genetic factors in the pathogenesis of AED-induced bone disease. ${ }^{38}$ Less is known about the effect of newer AEDs on bone. Gabapentin therapy may cause bone loss at the hip and lumbar spine according to previous studies. ${ }^{15,24,25,39,40}$ LTG monotherapy may not have osteopenic effects or significant impact on bone metabolism according to some investigators. ${ }^{24,40-43}$ Oxcarbazepine (OXC) seems to be associated with reduced 25-OH vitamin D3 levels and elevated biochemical markers enhancing bone turnover, especially in long-term treatment. ${ }^{11,40,44-46}$ However, not all studies could confirm this finding. ${ }^{47}$ One study on topiramate (TPM) in premenopausal women with epilepsy demonstrated that treatment with TPM could have adverse effects on bone. ${ }^{48}$ In an animal model treatment with zonisamide (ZNS) increased bone resorption without affecting bone formation and resulted in a lower BMD in the ZNS-treated group. ${ }^{49}$

\section{DXA versus QUS}

The current diagnostic criteria for management of osteoporosis, proposed by the WHO, are based on measurement of BMD assessed by dual-energy X-ray absorptiometry (DXA). ${ }^{50,51}$ Quantitative ultrasonography (QUS) is in vitro capable of measuring aspects of structural and mechanical properties of bone that are 
dependent of bone density. Clinical studies indicated that the discriminative ability of QUS between normal and osteoporotic subjects is comparable to that of conventional bone density measurements using radiographic absorptiometry. ${ }^{52-54}$ QUS is an attractive method for bone mineral status, because it is portable, inexpensive, without ionising radiation, has a short examination time and is available in areas of the world where central DXA is not readily accessible or available. ${ }^{50}$ According to several meta-analyses quantitative ultrasound of the calcaneus can also be reliably used to predict risk of different types of fracture in women and men, independent of the risk estimates from DXA measures. ${ }^{50,55}$

In our population we found a high correlation between DXA T-scores and all QUS parameters (Chapter 5). With a QUS cut-off T-score of $<-1.0,82 \%(n=159)$ of the residents was correctly classified, $10.3 \%(n=20)$ of the residents was misclassified as low BMD with a normal DXA T-score (false positive) and $7.7 \%(n=15)$ was classified as normal BMD while having low BMD on their DXA scan (false negative). In theory when using QUS, one would not want to miss any patient with osteopenia or osteoporosis, but in reality this is not feasible. In clinical practice QUS of the calcaneus is a very patient-friendly non-invasive examination, which in a population of epileptic institutionalised patients with many risk factors for low BMD, is a promising candidate to be used concurrently after an initial DXA scan in the follow-up and evaluation of the effect of the implemented bone enhancing measures and in selected patients. Also, it could be used as first screening method for the presence of bone disease and assessment of fracture risk in patients who cannot undergo a DXA scan (Chapter 5).

\section{Bone turnover markers (BTMs)}

Osteoporosis is diagnosed based on measurement of BMD by DXA scan. There are no standard laboratory markers for the diagnosis osteoporosis. BMD is the result of a dynamic process between bone formation and bone resorption. This dynamic process can be measured by bone markers. Markers of bone formation include procollagen markers, bone-specific alkaline phosphatase, and osteocalcin. Procollagen type I molecules are secreted by osteoblastic cells. Subsequent cleavage of the aminoterminal and carboxy-terminal domains creates extension peptides. The C-terminal extension peptide of type I procollagen (P1CP) is a putative serum marker of bone formation, and significant elevations are described in persons taking some AEDs. Specific markers of bone resorption can be measured in the urine and serum. Cross-linked carboxy-terminal telopeptide of human type I collagen (SCTX) is a serum marker of bone degradation. This marker is elevated in patients with epilepsy receiving long-term AED therapy and after recent initiation of therapy. ${ }^{56}$ However, BTMs still have limited clinical utility and it is not routinely recommended to use BTMs to select those at risk of fractures. Nevertheless baseline measurements of 
resorption markers are useful before commencement of anti-resorptive treatment and can be checked three to six months later to monitor response and adherence to treatment. Similarly, formation markers can be used to monitor bone forming agents. Recent recommendations by the Bone Marker Standards Working Group propose to standardise research and include a specific marker of bone resorption (sCTX) and bone formation (P1NP) in all future studies. ${ }^{57}$

In our study population patients with low BMD (osteopenia and osteoporosis) had increased bone resorption. The patients with osteoporosis, thus the group with the lowest BMD, also had reduced bone formation and increased bone turnover (Chapter 6). Our study results confirm the general opinion that increased bone turnover is a predictor of fractures, ${ }^{34}$ though the contribution of increased bone turnover in our population together with $25-\mathrm{OH}$ vitamin $\mathrm{D}$ level and parathormone to the total variance was quite low (4\%).

Unfortunately, based on the BTMs profile in our study population there was no clear distinction between patients with normal BMD and patients with osteopenia. Therefore based on a single measurement of the BTMs alone it is not possible to identify those patients at risk of low BMD and fractures. However, it is currently not routinely recommended to use BTMs to select those at risk of fractures. ${ }^{57}$

There is certainly a potential for BTMs in patients with epilepsy and AEDs use. To gain more insight in the pathophysiology of AED-induced osteoporosis baseline measurements of formation and resorption markers are necessary before the commencement of AED therapy, with repeated measurements during AED therapy. In this way changes in bone formation and resorption during treatment with specific AED therapy can be detected in an earlier manner. The pattern of eventual changes in BTM profile in combination with the timeframe in which the changes take place, can give understanding in which AEDs are culprit and by which mechanism(s) they are causing osteopenia and osteoporosis. BTMs can also be useful during monitoring the response of anti-resorptive treatment during follow-up.

\section{And what now......treatment, screening and follow-up}

Because of the increasing evidence of the negative influence of AEDs on bone metabolism, it is justified to screen patients with chronic epilepsy and long-term AEDs use for bone mineral disorders. NICE and MHRA guidelines advice blood tests for measuring bone metabolism and vitamin D supplementation for patients at risk, treated with enzyme-inducing AEDs and VPA. The Dutch epilepsy guideline advices life-style counselling concerning good bone health practice and supplementation of vitamin $D$ if insufficient or deficient in patients $>50$ years of age using enzymeinducing AEDs (PHT, PB, CBZ, and primidone) and VPA. ${ }^{58}$ Measurement with DXA is indicated if more risk factors for osteoporosis are present, as defined in the Dutch 
Guideline Osteoporosis $2011 .^{59}$ It has been shown that in adults and children with epilepsy and AEDs use vitamin D supplementation increases BMD significantly. ${ }^{60,61}$ Supplementation of $800 \mathrm{IU}$ vitamin D in combination with calcium has proven to be effective in the reduction in fracture risk, especially hip fractures. ${ }^{62,63}$ Use of bisphosphonate therapy in AED-induced osteoporosis is still under debate, especially in pediatric and adolescent patients because of inadequate long-term efficacy and safety data. For this reason treatment and follow-up of AED-induced osteoporosis should be done by a (pediatric)-endocrinologist.

Based on expert-opinion when reviewing the literature on AEDs and bone health, the clinician should take into consideration the following points (Chapter 2):

- All patients with epilepsy and AED treatment should be given lifestyle advices regarding prevention of osteoporosis such as regular weight-bearing exercise, nonsmoking, mild alcohol intake and sufficient/regular exposure to sunlight. ${ }^{56}$

- Baseline measurement of calcium, phosphate, alkaline phosphatase, parathormone and vitamin $D$ levels should be taken in patients starting on AED treatment, but also in patients already on AED treatment. These measurements should be repeated every 6-12 months. ${ }^{64,65}$

- Advise sufficient daily intake of calcium (1200 mg) and vitamin D (400 IU) or start supplementation. $^{42,66}$

- Consider fracture risk analysis with FRAX ${ }^{\circledR} .^{64}$

- Consider a DXA scan in patients treated with AED(s) for 2-5 year. ${ }^{56,65}$

- If low BMD is confirmed by DXA scan, consider referral of the patient to an internist-endocrinologist for further differential diagnosis and treatment. ${ }^{65}$

- Consider a baseline DXA scan for baseline BMD-measurement in postmenopausal women who are going to start with an AED..$^{56,65}$

- In epileptic patients with other risk factors for osteoporosis such as long duration of AED therapy, post-menopausal status, refractory epilepsy, non-ambulatory or institutionalised patients, low BMI, family history of osteoporosis, previous fracture history and/or intake of other bone-reducing medications prescribing enzymeinducing AEDs should be restricted to those patients in which no other alternatives are possible. In those patients already on enzyme-inducing AEDs counselling of bone health should also contain the topic switching to 'newer' non-enzyme inducing AEDs (except for VPA). In some patients switching from phenytoin to levetiracetam results in an increase of BMD of lumbar spine and femur and higher vitamin D level. ${ }^{67}$

- Re-assess bone health periodically, especially in adults and children. Children and adolescents have not reached their peak bone mass yet. If during adolescence the peak bone mass is less than biologically predicted because of the negative effect of AEDs, as a consequence during the rest of their life they have an increased risk of low BMD and increased fracture risk, because of their lower peak bone mass. Every standard deviation loss in BMD T-score is associated with a doubled fracture risk. $^{68,69}$

- Other secondary causes of osteoporosis need to be excluded. ${ }^{65}$ 


\section{Conclusions}

Patients with epilepsy and chronic AED use are at risk of developing bone mineral disorders. Those treated with enzyme-inducing AEDs are more at risk than those treated with non-enzyme inducing AEDs. In our population of institutionalised patients with refractory epilepsy $80 \%$ had low BMD of which $48 \%$ had osteopenia $(60 \%)$ and $32 \%$ had osteoporosis (40\%). More than half of these patients were below the age of 50. Cumulative drug load was the dominant factor determining low BMD and the occurrence of fractures. It is the presence of multiple risk factors for low BMD such as age, limited ambulation, and chronic antiepileptic medication use which made our population particularly vulnerable for the development of low BMD and its clinical sequelae, fractures. This high risk profile justifies early active screening for bone disease and warrants special attention of the treating physician with careful guidance of lifestyle factors (promote physical weight bearing exercise, stop smoking, intake of sufficient calcium and vitamin $D$, etc.).

Of the possible pathophysiologic mechanisms hypovitaminosus D was very common in our population (almost 90\%), though secondary hyperparathyroidism was far less common (12\%). On biochemical level patients with osteopenia and osteoporosis had increased bone turnover (sCTX Z-scores). Unfortunately, the combined use of the BTMs only explained a mere $12 \%$ of the variance and none of the bone turnover markers differentiated the osteopenia group from the normal BMD group.

There was no association between $25-\mathrm{OH}$ vitamin $\mathrm{D}$ level and the measured bone turnover markers.

In the diagnostic process of bone disease DXA is still the gold standard. QUS of the calcaneus has a strong correlation with DXA and is a feasible measuring method. The sensitivity of QUS of the calcaneus (cut-off point of $\mathrm{T}<-1.0$ ) in our population was $90.3 \%$, its specificity was lower, $40.8 \%$. Theoretically repeated measurements with QUS could increase the validity of QUS as reliable screening method. In our study population with intellectual disability and chronic epilepsy the benefits of QUS as screening method seem to outweigh the potential disadvantages.

\section{Future perspective}

Although the association between AEDs use and osteoporosis has been known for a long time, not all the questions are answered. The enzyme-inducing AEDs have the strongest association with osteopenia and osteoporosis, but also some non-enzyme inducing AEDs are culprit. However, from the newer AEDs there is less information about their effect on bone mineral metabolism.

Even of more importance is to gain complete insight in the different pathophysiologic mechanisms by which the individual AEDs cause osteopenia and osteoporosis. Repeated measurements of bone turnover makers can help to understand the 
changes in the dynamic process of bone formation and resorption. With this knowledge it is possible to tailor advices concerning bone health and bone metabolism to the specific individual patient with the opportunity to take preventive measures.

More data are necessary about bisphosphonate therapy in AED-induced osteoporosis. Paradoxically, in some patients bisphosphonate use increases the risk of atypical fractures. ${ }^{70,71}$ The current recommendations with regard to bisphosphonate therapy are mainly based on research data of osteoporosis in postmenopausal women. In AED-induced osteoporosis both men and women are affected as well as adolescents and even young children. Data on long-term safety and efficacy of bisphosphonates are still lacking.

In an attempt to get answers to the above questions, longitudinal prospective studies are warranted to assess the effects of specific AEDs on BMD, BTMs and fracture risk and also to assess the effects of calcium and vitamin $D$ supplementation and antiresorptive bone therapy in this specific population.

Till then screening patients with epilepsy and AED use for bone disease is necessary and helps in identifying those patients at risk for or already having osteoporosis. Based on expert opinion guidelines for treatment and follow-up are already available. Development of further guidelines for screening and treatment of bone disease in this specific vulnerable patient group is needed. 


\section{References}

1. Ray JG, Papaioannou A, loannidis G, Adachi JD. Anticonvulsant drug use and low bone mass in adults with neurodevelopmental disorders. Qjm 2002;95:219-223.

2. Swanton J, Simister R, Altmann D, Watts H, Keen R, Duncan JS, Koepp MJ. Bone mineral density in institutionalised patients with refractory epilepsy. Seizure 2007;16:538-541.

3. Lado F, Spiegel R, Masur JH, Boro A, Haut SR. Value of routine screening for bone demineralization in an urban population of patients with epilepsy. Epilepsy Res 2008;78:155-160.

4. Coppola G, Fortunato D, Auricchio G, Mainolfi C, Operto FF, Signoriello G, Pascotto A, Salvatore M. Bone mineral density in children, adolescents, and young adults with epilepsy. Epilepsia 2009;50:2140-2146.

5. Phabphal K, Geater A, Leelawattana R, Sathirapunya P, Sattawatcharawanich S, Limapichat K. Prevalence and risk factors of low bone mineral density and 25-hydroxyvitamin $D$ status in young healthy epileptic adult patients in a tropical Asian country taking antiepileptic drug. Bone 2009;45:232-237.

6. Srikanth R, Cassidy G, Joiner C, Teeluckdharry S. Osteoporosis in people with intellectual disabilities: a review and a brief study of risk factors for osteoporosis in a community sample of people with intellectual disabilities. J Intellect Disabil Res 2011;55:53-62.

7. Pack AM, Morrell MJ, Randall A, McMahon DJ, Shane E. Bone health in young women with epilepsy after one year of antiepileptic drug monotherapy. Neurology 2008;70:1586-1593.

8. Lambrinoudaki I, Kaparos G, Armeni E, et al. Bsml vitamin D receptor's polymorphism and bone mineral density in men and premenopausal women on long-term antiepileptic therapy. Eur J Neurol 2011;18:93-98.

9. Voudris K, Moustaki M, Zeis PM, Dimou S, Vagiakou E, Tsagris B, Skardoutsou A. Alkaline phosphatase and its isoenzyme activity for the evaluation of bone metabolism in children receiving anticonvulsant monotherapy. Seizure 2002;11:377-380.

10. Voudris KA, Attilakos A, Katsarou E, Garoufi A, Dimou S, Skardoutsou A, Mastroyianni S. Early alteration in bone metabolism in epileptic children receiving carbamazepine monotherapy owing to the induction of hepatic drug-metabolizing enzymes. J Child Neurol 2005;20:513-516.

11. Babayigit A, Dirik E, Bober E, Cakmakci H. Adverse effects of antiepileptic drugs on bone mineral density. Pediatr Neurol 2006;35:177-181.

12. Bramswig S, Zittermann A, Berthold HK. Carbamazepine does not alter biochemical parameters of bone turnover in healthy male adults. Calcif Tissue Int 2003;73:356-360.

13. Akin R, Okutan V, Sarici U, Altunbas A, Gokcay E. Evaluation of bone mineral density in children receiving antiepileptic drugs. Pediatr Neurol 1998;19:129-131.

14. Verrotti A, Agostinelli S, Coppola G, Parisi P, Chiarelli F. A 12-month longitudinal study of calcium metabolism and bone turnover during valproate monotherapy. Eur J Neurol 2010;17:232-237.

15. Ensrud KE, Walczak TS, Blackwell TL, Ensrud ER, Barrett-Connor E, Orwoll ES. Antiepileptic drug use and rates of hip bone loss in older men: a prospective study. Neurology 2008;71:723-730.

16. Lee $\mathrm{RH}$, Lyles $\mathrm{KW}$, Colon-Emeric $\mathrm{C}$. A review of the effect of anticonvulsant medications on bone mineral density and fracture risk. Am J Geriatr Pharmacother 2010;8:34-46.

17. Vestergaard P. Epilepsy, osteoporosis and fracture risk - a meta-analysis. Acta Neurol Scand 2005;112:277-286.

18. Nicholas JM, Ridsdale L, Richardson MP, Grieve AP, Gulliford MC. Fracture risk with use of liver enzyme inducing antiepileptic drugs in people with active epilepsy: cohort study using the general practice research database. Seizure 2013;22:37-42.

19. Farhat G, Yamout B, Mikati MA, Demirjian S, Sawaya R, El-Hajj Fuleihan G. Effect of antiepileptic drugs on bone density in ambulatory patients. Neurology 2002;58:1348-1353.

20. Hoikka V, Savolainen K, Karjalainen P, Alhava EM, Sivenius J. Treatment of osteomalacia in institutionalized epileptic patients on long-term anticonvulsant therapy. Ann Clin Res 1982;14:72-75.

21. Keck E, Gollnick B, Reinhardt D, Karch D, Peerenboom H, Kruskemper HL. Calcium metabolism and vitamin D metabolite levels in children receiving anticonvulsant drugs. Eur J Pediatr 1982;139:52-55.

22. Lee JJ, Lyne ED, Kleerekoper M, Logan MS, Belfi RA. Disorders of bone metabolism in severely handicapped children and young adults. Clin Orthop Relat Res 1989:297-302. 
23. Sotaniemi EA, Hakkarainen HK, Puranen JA, Lahti RO. Radiologic bone changes and hypocalcemia with anticonvulsant therapy in epilepsy. Ann Intern Med 1972;77:389-394.

24. Andress DL, Ozuna J, Tirschwell D, Grande L, Johnson M, Jacobson AF, Spain W. Antiepileptic druginduced bone loss in young male patients who have seizures. Arch Neurol 2002;59:781-786.

25. El-Hajj Fuleihan G, Dib L, Yamout B, Sawaya R, Mikati MA. Predictors of bone density in ambulatory patients on antiepileptic drugs. Bone 2008;43:149-155.

26. Feldkamp J, Becker A, Witte OW, Scharff D, Scherbaum WA. Long-term anticonvulsant therapy leads to low bone mineral density--evidence for direct drug effects of phenytoin and carbamazepine on human osteoblast-like cells. Exp Clin Endocrinol Diabetes 2000;108:37-43.

27. Salimipour H, Kazerooni S, Seyedabadi M, Nabipour I, Nemati R, Iranpour D, Assadi M. Antiepileptic treatment is associated with bone loss: difference in drug type and region of interest. J Nucl Med Technol 2013;41:208-211.

28. Jaffe JS, Timell AM, Elolia R, Thatcher SS. Risk factors for low bone mineral density in individuals residing in a facility for the people with intellectual disability. J Intellect Disabil Res 2005;49:457-462.

29. Henderson RC, Lark RK, Gurka MJ, Worley G, Fung EB, Conaway M, Stallings VA, Stevenson RD. Bone density and metabolism in children and adolescents with moderate to severe cerebral palsy. Pediatrics 2002;110:e5.

30. Vestergaard P, Rejnmark L, Mosekilde L. Fracture risk associated with use of antiepileptic drugs. Epilepsia 2004;45:1330-1337.

31. Tsiropoulos I, Andersen M, Nymark T, Lauritsen J, Gaist D, Hallas J. Exposure to antiepileptic drugs and the risk of hip fracture: A case-control study. Epilepsia 2008.

32. Stephen LJ(1), McLellan AR, Harrison JH, Shapiro D, Dominiczak MH, Sills GJ, Brodie MJ. Bone density and antiepileptic drugs: a case-controlled study. Seizure 1999;8:339-342.

33. Kulak CA, Borba VZ, Bilezikian JP, Silvado CE, Paola L, Boguszewski CL. Bone mineral density and serum levels of $25 \mathrm{OH}$ vitamin $\mathrm{D}$ in chronic users of antiepileptic drugs. Arq Neuropsiquiatr 2004;62:940-948.

34. Kanis JA, Hans D, Cooper C, Baim S, Bilezikian JP, Binkley N, Cauley JA, Compston JE, Dawson-Hughes B, El-Hajj Fuleihan G, Johansson H, Leslie WD, Lewiecki EM, Luckey M, Oden A, Papapoulos SE, Poiana C, Rizzoli R, Wahl DA, McCloskey EV; Task Force of the FRAX Initiative. Interpretation and use of FRAX in clinical practice. Osteoporos Int 2011;22:2395-2411.

35. Weggemans RM, Schaafsma G, Kromhout D. Towards an adequate intake of vitamin D. An advisory report of the Health Council of the Netherlands. Eur J Clin Nutr 2009;63:1455-1457.

36. Fitzpatrick LA. Pathophysiology of bone loss in patients receiving anticonvulsant therapy. Epilepsy \& behavior : E\&B 2004;5 Suppl 2:S3-15.

37. Phabphal K(1), Geater A, Limapichart K, Sathirapanya P, Setthawatcharawanich S, Witeerungrot N, Thammakumpee $\mathrm{N}$, Leelawattana $\mathrm{R}$. The association between Bsml polymorphism and bone mineral density in young patients with epilepsy who are taking phenytoin. Epilepsia 2013;54:249-255.

38. Senn SM, Kantor S, Poulton IJ, Morris MJ, Sims NA, O'Brien TJ, Wark JD. Adverse effects of valproate on bone: defining a model to investigate the pathophysiology. Epilepsia 2010;51:984-993.

39. Vestergaard P. Changes in bone turnover, bone mineral and fracture risk induced by drugs used to treat epilepsy. Curr Drug Saf 2008;3:168-172.

40. Koo DL, Joo EY, Kim D, Hong SB. Effects of levetiracetam as a monotherapy on bone mineral density and biochemical markers of bone metabolism in patients with epilepsy. Epilepsy Res 2013;104: 134-139.

41. Kim SH, Lee JW, Choi KG, Chung HW, Lee HW. A 6-month longitudinal study of bone mineral density with antiepileptic drug monotherapy. Epilepsy Behav 2007;10:291-295.

42. Pack AM, Morrell MJ, Marcus R, Holloway L, Flaster E, Doñe S, Randall A, Seale C, Shane E. Bone mass and turnover in women with epilepsy on antiepileptic drug monotherapy. Ann Neurol 2005;57: 252-257.

43. Sheth RD, Hermann BP. Bone mineral density with lamotrigine monotherapy for epilepsy. Pediatr Neurol 2007;37:250-254.

44. Babacan O, Karaoglu A, Vurucu S, Yesilkaya E, Yesilyurt O, Cayci T, Gulgun M, Unay B, Akın R, Ozcan O. May long term oxcarbazepine treatment be lead to secondary hyperparathyroidism? J Clin Neurol 2012;8:65-68. 
45. Cansu A, Yesilkaya E, Serdaroğlu A, Hirfanoğlu TL, Camurdan O, Gülbahar O, Gücüyener K, Cinaz P. Evaluation of bone turnover in epileptic children using oxcarbazepine. Pediatr Neurol 2008;39: 266-271.

46. Mintzer S, Boppana P, Toguri J, DeSantis A. Vitamin D levels and bone turnover in epilepsy patients taking carbamazepine or oxcarbazepine. Epilepsia 2006;47:510-515.

47. Cetinkaya Y, Kurtulmus YS, Tutkavul K, Tireli H. The effect of oxcarbazepine on bone metabolism. Acta Neurol Scand 2009;120:170-175.

48. Heo K, Rhee Y, Lee HW, Lee SA, Shin DJ, Kim WJ, Song HK, Song K, Lee BI. The effect of topiramate monotherapy on bone mineral density and markers of bone and mineral metabolism in premenopausal women with epilepsy. Epilepsia 2011;52:1884-1889.

49. Takahashi A, Onodera K, Kamei J, Sakurada S, Shinoda H, Miyazaki S, Saito T, Mayanagi H. Effects of chronic administration of zonisamide, an antiepileptic drug, on bone mineral density and their prevention with alfacalcidol in growing rats. J Pharmacol Sci 2003;91:313-318.

50. Moayyeri A, Adams JE, Adler RA, Krieg MA, Hans D, Compston J, Lewiecki EM. Quantitative ultrasound of the heel and fracture risk assessment: an updated meta-analysis. Osteoporos Int 2012;23:143-153..

51. Kanis JA. Assessment of fracture risk and its application to screening for postmenopausal osteoporosis: synopsis of a WHO report. WHO Study Group. Osteoporos Int 1994;4:368-381.

52. Heaney RP, Avioli LV, Chesnut CH, 3rd, Lappe J, Recker RR, Brandenburger GH. Ultrasound velocity, through bone predicts incident vertebral deformity. J Bone Miner Res 1995;10:341-345.

53. Schott AM, Weill-Engerer S, Hans D, Duboeuf F, Delmas PD, Meunier PJ. Ultrasound discriminates patients with hip fracture equally well as dual energy X-ray absorptiometry and independently of bone mineral density. J Bone Miner Res 1995;10:243-249.

54. Pluskiewicz W, Nowakowska J. Bone status after long-term anticonvulsant therapy in epileptic patients: evaluation using quantitative ultrasound of calcaneus and phalanges. Ultrasound Med Biol 1997;23:553-558.

55. Marin F, Gonzalez-Macias J, Diez-Perez A, Palma S, Delgado-Rodriguez M. Relationship between bone quantitative ultrasound and fractures: a meta-analysis. J Bone Miner Res 2006;21:1126-1135.

56. Pack AM, Morrell MJ. Epilepsy and bone health in adults. Epilepsy Behav 2004;5 Suppl 2:S24-29.

57. Wheater G, Elshahaly M, Tuck SP, Datta HK, van Laar JM. The clinical utility of bone marker measurements in osteoporosis. J Transl Med 2013;11:201.

58. 'Epilepsie' Wr. Richtlijn Epilepsie NVN. 2013; Available from: http://epilepsie.neurologie.nl. 2013.

59. CBO. Richtlijn Osteoporose en Fractuurpreventie, derde herziening. Utrecht2011.

60. Mikati MA, Dib L, Yamout B, Sawaya R, Rahi AC, Fuleihan Gel H. Two randomized vitamin D trials in ambulatory patients on anticonvulsants: impact on bone. Neurology 2006;67:2005-2014.

61. Pedrera JD, Canal ML, Carvajal J, Postigo S, Villa LF, Hernández ER, Rico H. Influence of vitamin D administration on bone ultrasound measurements in patients on anticonvulsant therapy. Eur J Clin Invest 2000;30:895-899.

62. LeBlanc E, Chou R, Zakher B, Daeges M, Pappas M. Screening for Vitamin D Deficiency: Systematic Review for the US Preventive Services Task Force Recommendation. Rockville (MD)2014.

63. Cranney A, Horsley T, O'Donnell S, Weiler H, Puil L, Ooi D, Atkinson S, Ward L, Moher D, Hanley D, Fang M, Yazdi F, Garritty C, Sampson M, Barrowman N, Tsertsvadze A, Mamaladze V. Effectiveness and safety of vitamin D in relation to bone health. Evid Rep Technol Assess (Full Rep) 2007:1-235.

64. Panday K, Gona A, Humphrey MB. Medication-induced osteoporosis: screening and treatment strategies. Ther Adv Musculoskelet Dis 2014;6:185-202.

65. Valsamis HA, Arora SK, Labban B, McFarlane SI. Antiepileptic drugs and bone metabolism. Nutr Metab (Lond) 2006;3:36.

66. Mattson RH, Gidal BE. Fractures, epilepsy, and antiepileptic drugs. Epilepsy Behav 2004;5 Suppl 2:S3640.

67. Phabphal K, Geater A, Limapichat K, Sathirapanya P, Setthawatcharawanich S, Leelawattana R. Effect of switching hepatic enzyme-inducer antiepileptic drug to levetiracetam on bone mineral density, 25 hydroxyvitamin D, and parathyroid hormone in young adult patients with epilepsy. Epilepsia 2013;54:e94-98.

68. Marshall D, Johnell O, Wedel H. Meta-analysis of how well measures of bone mineral density predict occurrence of osteoporotic fractures. BMJ 1996;312:1254-1259. 
69. Kanis JA, McCloskey EV, Johansson H, Strom O, Borgstrom F, Oden A; National Osteoporosis Guideline Group. Case finding for the management of osteoporosis with FRAX--assessment and intervention thresholds for the UK. Osteoporos Int 2008;19:1395-1408.

70. Gedmintas L, Solomon DH, Kim SC. Bisphosphonates and risk of subtrochanteric, femoral shaft, and atypical femur fracture: a systematic review and meta-analysis. J Bone Miner Res 2013;28:1729-1737.

71. Lenart BA, Neviaser AS, Lyman S, Chang CC, Edobor-Osula F, Steele B, van der Meulen MC, Lorich DG, Lane JM. Association of low-energy femoral fractures with prolonged bisphosphonate use: a case control study. Osteoporos Int 2009;20:1353-1362. 
Summary \& Samenvatting 


\section{Summary}

The use of antiepileptic drugs (AEDs) is associated with alterations in bone metabolism and an increased fracture risk. The strongest association between low bone mineral density (BMD) and antiepileptic drug use is with the older enzymeinducing antiepileptic drugs. However also the non-enzyme inducing AEDs are associated with low BMD. Some studies report a prevalence rate of low BMD as high as $40 \%$ to $62 \%$, depending on the population studied.

From observations we noticed that residents of the long-stay department of a tertiary referral centre for refractory epilepsy experienced many fractures, sometimes after minimal or low-energy trauma. Evaluation of these patients by an internistendocrinologist revealed in most patients osteoporosis or osteopenia, even in relative young male patients. In this thesis, we aimed at investigating the prevalence of osteopenia and osteoporosis in a high-risk population of patients with epilepsy and long-term antiepileptic drug (AED) use at the long-stay department of a tertiary referral centre for epilepsy. In addition we also evaluated risk factors, diagnostic procedures and some etiological factors.

In chapter 2 results of previous studies on bone mineral disorders and fractures in patients with epilepsy are presented. Relative risk values of the occurrence of fractures, osteopenia and osteoporosis are calculated if possible. General and specific risk factors for osteopenia and osteoporosis in patients with epilepsy are discussed and also the contributing role of specific AEDs on bone metabolism. The possible pathophysiologic mechanisms of antiepileptic drug-induced bone disease are discussed. The advices based on expert-opinion on screening, prevention and treatment of bone disease during AED treatment are summarised.

We found relative risk values of 1.7-6.1 for the occurrence of fractures, 1.3-3.8 for the occurrence of osteopenia and 1.7-2.4 for the occurrence of osteoporosis in patients with epilepsy.

In chapter $\mathbf{3}$ we investigated patient characteristics and possible predicting factors for fractures in a group of patients with epilepsy and AEDs use already diagnosed with osteoporosis and treated with a bisphosphonate. Most of these patients used enzyme-inducing AEDs (94\%) either in monotherapy or polytherapy. Carbamazepine was most frequent used, followed by lamotrigine and oxcarbazepine.

Also we tried to semi-quantify the antiepileptic drug amount by defining cumulative drug load as 'total duration of epilepsy multiplied by the current number of AEDs'. Regression analysis showed that cumulative drug load was the only significant variable predicting the number of fractures in this specific population. 
For the subsequent studies a new patient group was investigated consisting of residents with epilepsy on the long-stay department of a tertiary referral centre for refractory epilepsy with or without a diagnosis of osteoporosis.

In chapter 4 we describe the results of the screening for bone mineral disorders of the patients of the long-stay department of a tertiary referral centre. BMD was measured with dual X-ray absorptiometry (DXA) with vertebral fracture assessment (VFA), biochemical measurements were done for calcium, 25-OH vitamin $\mathrm{D}$, alkaline phosphatase and parathormone. The aim of this study was to determine the prevalence of bone mineral disorders in this high-risk cohort.

We found a very high prevalence of low BMD: $80 \%$ of the patients had low BMD $(48 \%$ osteopenia and $32 \%$ osteoporosis). $52 \%$ of the patients with low BMD was between 18 and 50 years old and both men and women were affected. $28 \%$ of the patients had signs of one or more vertebral fractures on VFA. Vitamin D deficiency was very common in this cohort: $65 \%$ had a deficiency, $24 \%$ had an insufficient $25-\mathrm{OH}$ vitamin D level. Secondary hyperparathyroidism was not common (12\%).

Our analyses showed that not only general risk factors for low BMD played a role, such as age, body mass index (BMI) and ambulatory status, but also epilepsy-related parameters such as duration of epilepsy and cumulative drug load were significantly correlated with low BMD (low DXA T-scores). Multiple regression analysis showed that cumulative drug load was the only significant epilepsy-related parameter predicting low BMD of the femur together with BMI and age.

In chapter $\mathbf{5}$ we investigated the feasibility of calcaneus quantitative ultrasonography (QUS) as a screening method for BMD and determined the sensitivity and specificity of QUS to diagnose osteoporosis. Currently the gold standard for BMD measurement is DXA. QUS has a number of advantages over DXA because it is radiation free, relatively inexpensive, easy to use and portable. In our study population of patients with refractory epilepsy often in combination with intellectual and physical comorbidities, a more easy, portable and patient-friendly measurement of BMD compared to DXA would make screening for low BMD more easy.

In our study population 10 patients could not undergo a DXA scan because of lack of cooperation and/or anatomical restrictions versus 1 patient that could not undergo a QUS of the calcaneus because of anatomical restrictions. We found a strong and positive correlation between DXA T-scores and QUS T-scores. At a cut-off value of QUS T-score of <-1.0 we found a high sensitivity of $90.3 \%$ for osteoporosis and osteopenia. The specificity was lower with $40.8 \%$. Therefore using a single QUS measurement as a method for screening or diagnosing osteoporosis seems not viable. However, when combining QUS and DXA by confirming all the QUS-suspected osteoporosis cases with DXA -scanning, the low specificity and therefore false hits is corrected. 
In chapter 6 we investigated the biochemical markers of bone metabolism and we looked for the association with fractures and BMD. Bone turnover markers (BTMs) are biochemical products related to the metabolic activity of bone and are categorised as markers of bone formation such as P1NP and markers of bone degradation such as SCTX. BTMs can also be used in the prediction of fracture risk.

We investigated the same patient population as in chapter 4 and 5 , but patients with a recent fracture and/or bisphosphonate use were excluded, because of the influence of these factors on the BTMs.

We found increased bone resorption in patients with osteopenia and osteoporosis with increased net bone turnover in the patients with osteoporosis, compared to patients with normal BMD. We did not identify differences in BTMs between the group with normal BMD and the group with osteopenia. Net bone formation had the strongest predictive value for a history of fractures, but together with parathormone and $25-\mathrm{OH}$ vitamin $\mathrm{D}$ it only explained a limited percentage of the variance. Alkaline phosphatase and SCTX together significantly predicted low BMD, but also with a low percentage of variance. Therefore a single measurement of the BTMs SCTX and P1NP does not qualify as early predictor for low BMD nor fractures.

In Chapter $\mathbf{7}$ the main findings of this thesis were discussed. Furthermore it addresses the possibilities for future research. 


\section{Samenvatting}

Het gebruik van anti-epileptica is geassocieerd met het optreden van veranderingen in het botmetabolisme en een verhoogd risico op fracturen. De sterkste associatie tussen een verlaagde botmineraaldichtheid (BMD) en het gebruik van anti-epileptica is van toepassing op de oudere enzym-inducerende anti-epileptica. Echter ook het gebruik van niet-enzym-inducerende anti-epileptica wordt geassocieerd met een verlaagde BMD. Bepaalde onderzoeken vinden een prevalentie van verlaagde BMD tussen de 40 tot $62 \%$, afhankelijk van de onderzoekspopulatie.

Vanuit observaties merkten we dat bewoners van de verblijfafdeling van een tertiair epilepsiecentrum voor patiënten met refractaire epilepsie veel fracturen opliepen, soms na een minimaal trauma of een trauma met lage impact. Evaluatie van deze patiënten door een internist-endocrinoloog toonde in de meeste patiënten osteoporose of osteopenie aan, zelfs bij relatief jonge mannelijke patiënten. In dit proefschrift hadden we als doel om de prevalentie van osteopenie en osteoporose te onderzoeken in een hoog-risico populatie van patiënten met epilepsie en langdurig gebruik van anti-epileptica binnen de lang-verblijfsafdeling van een tertiair centrum voor epilepsie. Daarnaast evalueren we ook de risicofactoren, diagnostische procedures en enkele etiologische factoren.

In hoofdstuk 2 worden de resultaten gepresenteerd van voorgaande studies over patiënten met epilepsie en botmineraal stoornissen en fracturen. Relatieve risico waarden van het optreden van fracturen, osteopenie en osteoporose worden indien mogelijk, berekend. Algemene en specifieke risicofactoren voor osteopenie en osteoporose bij patiënten met epilepsie worden besproken alsook de bijdragende rol van specifieke anti-epileptica op het botmetabolisme. De mogelijke pathofysiologische mechanismen van anti-epileptica geïnduceerde botziekten worden besproken. De adviezen die gebaseerd zijn op expert-opinion ten aanzien van screening, preventie en behandeling van botziekten tijdens anti-epileptica gebruik, worden samengevat.

Wij vonden relatieve risico's tussen de 1.7 en 6.1 voor het optreden van fracturen, 1.3-3.8 voor het optreden van osteopenie en 1.7-2.4 voor het optreden van osteoporose bij patiënten met epilepsie.

In hoofdstuk 3 onderzochten we de patiënt-kenmerken en de mogelijke voorspellende factoren voor fracturen in een groep patiënten met epilepsie en antiepileptica gebruik, bij wie de diagnose osteoporose al gesteld was en die reeds behandeld werden met een bisfosfonaat. De meeste patiënten gebruikten enzyminducerende anti-epileptica (94\%) ofwel als monotherapie of polytherapie. Carbamazepine werd het meeste gebruikt, gevolgd door lamotrigine en oxcarbazepine. 
We hebben ook geprobeerd om de hoeveelheid anti-epileptica te semi-kwantificeren door het definiëren van cumulatieve drug load als 'de totale duur van epilepsie vermengvuldigd met het huidige aantal anti-epileptica'. Regressie analyse toonde dat cumulatieve drug load de enige significante variabele was die het aantal fracturen in deze specifieke populatie voorspelde.

Voor de volgende studies werd een nieuwe patiëntengroep onderzocht die bestond uit bewoners van de lang-verblijfsafdeling van een tertiair verwijscentrum voor patiënten met refractaire epilepsie met of zonder de diagnose osteoporose.

In hoofdstuk 4 beschrijven wij de resultaten van de screening op botmineraal aandoeningen bij patiënten van de lang-verblijfsafdeling van een tertiair verwijscentrum. De botmineraaldichtheid (BMD) werd gemeten met dual-energy X-ray absorptiometrie (DXA) met bepaling van wervelfracturen (VFA), biochemische metingen werden gedaan in de vorm van calcium, 25-OH vitamine D3, alkalisch fosfatase en parathormoon. Het doel van deze studie was om de prevalentie van botmineraalstoornissen te bepalen in dit hoog-risico cohort.

We vonden een zeer hoge prevalentie van verlaagde botmineraaldichtheid: $80 \%$ van de patiënten had een te lage BMD ( $48 \%$ had osteopenie en $32 \%$ had osteoporose). $52 \%$ van de patiënten met een lage BMD was tussen de 18 en 50 jaar oud en zowel mannen als vrouwen waren aangedaan. $28 \%$ van de patienten had aanwijzingen voor één of meerdere wervelfracturen op de VFA. Vitamine $D$ deficientie kwam veel voor in dit cohort: $65 \%$ had een deficiëntie, $24 \%$ had een insufficiënte $25-\mathrm{OH}$ vitamine D spiegel. Secundaire hyperparathyreoidie kwam niet vaak voor (12\%).

Uit onze analyses kwam naar voren dat niet alleen de algemene risicofactoren voor een lage BMD, zoals leeftijd, body mass index (BMI) en ambulatoire status een rol speelden, maar ook dat epilepsie-gerelateerde parameters zoals duur van epilepsie en cumulatieve drug load significant gecorreleerd waren met een lage BMD (lage DXA Tscores). Multipele regressie analyse toonde dat cumulatieve drug load de enige significante epilepsie-gerelateerde parameter was die lage BMD van de femur voorspelde tezamen met BMI en leeftijd.

In hoofdstuk 5 onderzochten we de uitvoerbaarheid van de kwantitatieve echografie van de calcaneus als screeningsmethode voor de BMD en we bepaalden de sensitiviteit en specificiteit van kwantitatieve echografie voor de diagnose osteoporose. De huidige gouden standaard voor meting van de BMD is DXA. Kwantitatieve echografie heeft een aantal voordelen ten opzichte van DXA: er wordt geen gebruik gemaakt van röntgenstraling, het is relatief goedkoop, gemakkelijk in gebruik en draagbaar. In onze onderzoekspopulatie bestaande uit patiënten met refractaire epilepsie vaak in combinatie met een geestelijke handicap en lichamelijke beperkingen, zou een eenvoudige, draagbare en patiënt-vriendelijke manier van BMD meting screening op lage BMD in vergelijking met DXA, makkelijker maken. 
In onze onderzoekspopulatie konden 10 patiënten geen DXA scan ondergaan vanwege beperkte patiënt-coöperatie/medewerking en/of anatomische beperkingen versus 1 patiënt die geen kwantitatieve echo van de calcaneus kon ondergaan vanwege anatomische beperkingen. We vonden een sterke positieve correlatie tussen DXA T-scores en QUS T-scores. Bij een afkappunt waarde van de echografie T-score van $<-1.0$ vonden we een hoge sensitiviteit van $90.3 \%$ voor osteoporose en osteopenie. De specificiteit was lager met een waarde van $40.8 \%$. Derhalve is het gebruik van een enkele echografie meting als screening op osteoporose of voor de diagnose osteoporose niet haalbaar. Echter indien echografie en DXA gecombineerd gebruikt worden door alle op basis van echografie-verdachte osteoporose patiënten ook met DXA te scannen, dan worden de vals-positieven gecorrigeerd en daarmee ook de lage specificiteit.

In hoofdstuk 6 onderzochten we de biochemische markers van het botmetabolisme en keken we naar de associatie met fracturen en botmineraaldichtheid. Botturnover markers (BTMs) zijn biochemische producten die gerelateerd zijn aan de metabole activiteit van bot. Ze zijn onder te verdelen in markers van de botopbouw zoals P1NP en markers van de botafbraak zoals SCTX. BTMs kunnen ook gebruikt worden bij het voorspellen van het risico op fracturen.

We vonden verhoogde botresorptie bij patiënten met osteopenie en osteoporose met verhoogde netto botturnover bij patiënten met osteoporose in vergelijking met patiënten met een normale BMD. We vonden geen verschil in BTMs tussen de groep met normale BMD en de groep met osteopenie.

Netto botformatie had de sterkste voorspellende waarde voor fracturen in het verleden, maar voorspelde samen met het parathormoon en $25-\mathrm{OH}$ vitamine D slechts een beperkt percentage van de variantie. Alkalische fosfatase en SCTX tezamen voorspelden significant een lage BMD, echter ook met een laag percentage variantie. Derhalve is een enkele meting van de BTMs SCTX en P1NP niet geschikt als vroege voorspeller voor lage BMD noch fracturen.

In hoofdstuk 7 worden de belangrijkste bevindingen van dit proefschrift besproken. Ook worden mogelijkheden voor toekomstig wetenschappelijk onderzoek besproken. 
Dankwoord 


\section{Dankwoord}

En dan is het klaar! Na jaren werk zit het er nu bijna op. Veel mensen hebben een belangrijke bijdrage geleverd aan de totstandkoming van dit proefschrift en die wil ik dan ook graag bedanken. Allereerst een woord van dank aan mijn promotieteam.

Prof. dr. A.P. Aldenkamp, beste Bert. Het heeft even geduurd, maar nu is het dan toch eindelijk af. Het afronden van $m^{\prime} n$ promotie in combinatie met $m^{\prime} n$ werk in Heerlen als neuroloog was geen gemakkelijke opgave. Patiëntenzorg ging bij mij altijd voor. Gelukkig had je hier alle begrip voor en bleef je geduldig informeren naar mijn vorderingen, ook als deze volledig stil lagen, terwijl ik op een berg zat in Frankrijk, Kirgizië of Tibet, of ik hard aan het trainen was voor $m^{\prime} n$ marathons. Onze besprekingen waren voor mij altijd erg zinvol. Van je statistische kennis heb ik veel opgestoken en dankbaar gebruik van kunnen maken. Je bleef altijd opbouwende kritiek geven en je kon als ik door de bomen het bos even niet meer zag, feilloos knopen doorhakken en me weer de goede kant op sturen. Dank voor je fijne begeleiding en geduld.

Prof. dr. R. van Oostenbrugge, beste Robert. Dank voor het faciliteren van mijn promotie-traject tijdens mijn opleiding neurologie in het azM. Ook toen ik in 2009 koos om in het Atrium Medisch Centrum Parkstad ziekenhuis aan de slag te gaan als neuroloog, ben je de mogelijkheden om mijn promotie af te ronden, samen met Bert, blijven faciliteren.

Dr. P. Verschuure, beste Pauline. Als klinisch chemicus was je onmisbaar tijdens de opzet en de uitvoering van het laboratorium-technische stuk van het onderzoek bij de bewoners van Providentia. Dank voor je hulp bij de analyse van de botmarkers.

Drs. I.Y. Tan, beste Francis. Jij was één van de drijvende krachten achter het osteoporose-onderzoek bij de bewoners van Providentia/ Kempenhaeghe. Het relatief vaak voorkomen van botbreuken bij de bewoners van Providentia, vaak na een relatief klein trauma, was het onderwerp van onze eerste retro-spectieve studie. We hadden toen nog geen idee dat het vóórkomen van een te lage botmineraaldichtheid onder de bewoners van Providentia bijna endemische vormen aan zou nemen. Jouw inzet, enthousiasme en betrokkenheid zijn cruciaal geweest voor het slagen van ons onderzoek.

Prof. em. Dr. W.O. Renier, beste Willy. U stond aan het begin van mijn medische carrière. Als student geneeskunde kwam ik op de Reinier Postlaan in Nijmegen solliciteren naar de wetenschappelijke stage over het Lyell syndroom (toxische epidermale necrolyse) bij lamotrigine gebruik. Uiteindelijk leidde dit onderzoek tot mijn eerste wetenschappelijke publicatie. Na afronding van deze stage in 2002 gaf $u$ 
aan dat het u was opgevallen dat een aantal patiënten met epilepsie (zowel kinderen als volwassenen) makkelijk fracturen op liepen. $U$ had al langer het idee om hier verder onderzoek naar te doen. Uiteindelijk is het tijdens mijn opleiding in het Canisius-Wilhelmina ziekenhuis niet gelukt om financiële middelen te werven om dit onderzoek van de grond te krijgen. Toen Maastricht me de mogelijkheid bood om wetenschappelijk onderzoek te combineren met mijn opleiding tot medisch specialist, heb ik niet lang hoeven nadenken. Dank voor uw steun en adviezen die u mij gegeven heeft tijdens $\mathrm{m}$ 'n prille carrière als co-assistent en anios neurologie.

'Trial-nurse' mevr. P. van Mierlo, beste Petra. Dankzij jouw organisatie talent is het onderzoek voor de bewoners van Providentia goed verlopen. Samen met Francis organiseerde jij de informatie-bijeenkomsten voor de bewoners van Providentia en hun wettelijk vertegenwoordigers. Het verkrijgen van toestemming voor deelname aan het onderzoek was slechts een kleine moeite in vergelijking met de logistieke 'nachtmerrie' om 205 bewoners van Providentia, inclusief de buitenhuizen binnen 1 maand voor een DXA scan en hielecho in te plannen. Mede dankzij jouw inzet is het gelukt om de hele logistiek gladjes te laten verlopen. Ook je hulp bij het opzetten van een excel- en SPSS database en het aansturen van de hulptroepen bij het invoeren van alle data, is van groot belang geweest. Dank voor je inzet. Zonder jouw hulp was het niet gelukt. Zoals een collega het al eens verwoordde: jij bent goud waard!

Dr. E. van der Veer, beste Eveline. Jouw kennis over de botmakers was onontbeerlijk om dit deel tot een goed einde te volbrengen. Stukken waar wij soms al tevreden over waren, riepen bij jou soms wel enkele vraagtekens op. Dank voor je kritische blik en kennis.

Dr. M.C.F.T.M. de Krom, beste Marc. Jij was degene die samen met Wim Verhagen het plan had opgevat om mij onderzoek te laten doen in Maastricht. Dat ik hiervoor van opleidingsplek moest wisselen van Nijmegen naar Maastricht, was een klein detail. Toen ik kwam kennismaken in het azM werd ik hartelijk ontvangen door jou en Bert Aldenkamp. De beslissing om van opleidingsplek te wisselen was voor mij geen moeilijke. Tijdens onze onderzoeksbesprekingen op jouw kamer in het Oxford-gebouw was er altijd tijd voor een goed kopje koffie uit je eigen Nespresso apparaat. Je was de tijd van George Clooney ver vooruit! Mede dankzij jouw inspanningen konden wij als assistenten mee naar congressen (ECE Helsinki, Colloquium on Status Epilepticus Londen, ENS Brussel). Samen hadden we diverse posters op internationale congressen over epilepsie-gerelateerde onderwerpen. Niet alleen was je geïnteresseerd in het werk, maar ook in de persoon. De zwembad-borrels die je organiseerde in jullie achtertuin, samen met Ellen en je kinderen, zijn daar een goed voorbeeld van. Dank voor je betrokkenheid en meedenken aan het uiteindelijk uitgevoerde onderzoeksprotocol. 
Dr. W.I.M. Verhagen, beste Wim. De dag dat ik uitgenodigd werd voor de sollicitatie in het Canisius-Wilhelmina Ziekenhuis staat in m'n geheugen gegrift. In 2003 tijdens m'n vakantie in Noorwegen belde je mij om me uit te nodigen om op sollicitatiegesprek te komen voor een agio plek. Ik was bereid om eerder van vakantie terug te komen, maar uiteindelijk kon ik vanaf Schiphol rechtstreeks door naar het CWZ voor het sollicitatiegesprek. Aldaar vertelde ik dat ik eigenlijk 4 dagen later zou beginnen als agnio bij de neurologie in het Radboud ziekenhuis, maar op zoek was naar een opleidingsplek. De rest is geschiedenis. Mijn interesse in de epilepsie en de wens om onderzoek te doen waren bij jou en de overige leden van de vakgroep bekend. Omdat vanwege financiële redenen het niet mogelijk was om dit onderzoek in het CWZ te verrichten, overlegde je tijdens een congres met Mark de Krom. Toen je terugkwam legde je mij de optie voor. Lang heb ik er niet over na hoeven denken. Na ruim 2 jaar opleiding in het CWZ kon ik mijn opleiding neurologie verder voortzetten in Maastricht. Ik wil de vakgroep neurologie van het CWZ bedanken voor de brede en solide eerste 2 jaar opleiding die ze mij gegeven heeft en het creëren van deze mogelijkheid voor mij.

Prof. dr. P. Geussens, beste Piet. Tijdens het onderzoek hebben we diverse besprekingen in het azM gehad over osteoporose bij epilepsie-patiënten. $U$ had hierbij altijd nuttige tips en adviezen. Bedankt voor uw bijdrage aan het onderzoek.

Ik ben de leden van de beoordelingscommissie, Prof. dr. J.E. Wildberger, Prof. dr. K. Vonck, Prof. dr. O. Bekers, Prof. dr. Ir. W.H. Backes, en dr. A. de Louw erkentelijk voor de bereidheid om het manuscript kritisch te beoordelen en van commentaar te voorzien.

Drs. F.M. Snoeijen-Schouwenaars, beste Francesca. Jouw wetenschappelijke stage bij Francis Tan was de basis voor onze eerste wetenschappelijke publicatie. Dank voor je inzet en betrokkenheid. Veel succes met het afronden van je eigen promotieonderzoek!

Joost Tan en Sylvie van de Kruijs. Dank voor het meedenken en meeschrijven van de artikelen.

De vakgroep neurologie van het MUMC: na 2 jaar opleiding in het CWZ, een perifere opleidingskliniek, was het leuk en goed voor algemene ontwikkeling en mijn beeldvorming om eens een kijkje in de academische keuken te hebben. Bedankt voor de mooie opleidingsjaren.

De vakgroep neurologie van het voormalige Atrium Medisch Centrum Parkstad (huidige Zuyderland Medisch Centrum, locatie Heerlen). Tijdens mijn sollicitatiegesprek werd gezegd dat promoveren een pré was, maar geen vereiste. Gaande weg 
werd duidelijk dat het veel belangrijker was of de persoon wel in de groep paste. De drukke perifere praktijk combineren met promotie was zeker in het eerste jaar, toen ik nog full-time werkte, een onmogelijke combinatie. Dank voor de ruimte die jullie mij nadien gegeven hebben om mijn onderzoek tot een goed einde te brengen. Ook dank voor de mogelijkheid die jullie mij gegeven hebben om een sabbatical op te nemen voor mijn 'gekke' bergavonturen.

Uiteraard ben ik veel dank verschuldigd aan de bewoners van Providentia, die hebben deelgenomen aan deze studie alsook hun wettelijk vertegenwoordigers. Dat zoveel bewoners mee zouden doen, hadden we van te voren nooit durven hopen. Zonder jullie was dit onderzoek nooit een succes geworden.

Medewerkers van Providentia. Dank voor jullie hulp bij het begeleiden van de bewoners naar de DXA scan en hiel-echo. Petra van Mierlo had alle schema's mooi opgezet, maar jullie moesten met de bewoners naar de mobiele DXA scan. Mede doordat de onderzoeken op het eigen terrein van Providentia verricht konden worden met hierbij begeleiding door voor de bewoners vertrouwde mensen, is het gelukt om bij alle patiënten de geplande metingen te kunnen verrichten. Ook jullie hulp is van essentieel belang geweest bij het slagen van deze logistieke operatie.

Medewerkers van Kempenhaeghe, dank aan de neurologen en huisartsen Monique Veendrick en Sjef de Vocht voor het informeren en motiveren van hun patiënten voor deelname aan dit onderzoek. Richard Lazeron en Theo Rentmeester bedankt voor het meedenken over het onderzoeksprotocol.

Medewerkers van het klinisch chemisch laboratorium van Kempenhaeghe, dank voor het afnemen van bloed bij alle bewoners. Ook dit was een grote logistieke operatie. Fijn dat het mogelijk was om op de woonunits van de bewoners het bloed af te nemen.

Kitty Verwoerdt. Bedankt voor het vrij maken van onderzoekstijd tijdens mijn opleiding in het azM. Het is bewonderenswaardig hoe je rekening houdend met een ieders opleidingsschema, vaak toch wel ruimte wist te creëren. Onze wegen kruisen zich binnenkort weer, als je aan de slag gaat als secretaris van onze vakgroep neurologie in het Zuyderland Medisch Centrum. Fijn dat je onze vakgroep komt versterken.

De ATAKK -, Peak Lenin-, en de Cho Oyu klimgroepen. De bergen hebben mij altijd een welkome afleiding gegeven. Of het nu een gewone bergwandeling is, een verticale kilometer wedstrijd of een expeditie, ik geniet alleen al van 'het in de bergen zijn'. Dat samen te delen met gelijkgestemden maakt het alleen nog maar mooier. 
Peter-Paul Andriessen, jouw oproep in 2010 om voor de stichting 'Vrienden van de Sahel' in 2011 de Mont Blanc (4810 m) te beklimmen wakkerde het bergbeklim-virus in mij aan. Dank voor deze wake-up call! Ondertussen hebben we er alweer 3 ATAKKedities op zitten en wordt er nagedacht over de bestemming van de 4 editie.

Doede Wessels en Clara Wilken. Kirgizië was voor ons alle drie de eerste kennismaking met expeditie-klimmen op serieuze hoogte. Jullie warme persoonlijkheid en open karakter vielen mij meteen op. Ik heb goede herinneringen aan onze gezellige tijd in de kleine groene tentjes op de flanken van Peak Lenin. Toen ik enigszins gehavend terugkeerde in het basiskamp, stonden jullie voor me klaar. Ik ben blij dat jullie mij willen bijstaan als paranimf.

Lieve Marc, mijn grote broer. We zien elkaar af en toe, maar het is altijd gezellig en het voelt als thuis. Samen met Irma, is nu met Noah en Roos jullie mooie gezin compleet. Onze mening over de geneeskunde verschilt soms, maar er is altijd wederzijds respect. Op spiritueel vlak kan ik nog veel van je leren. Ik heb grote bewondering voor je doorzettingsvermogen.

Lieve papa en mama. Jullie hebben me altijd alle ruimte gegeven om mij te ontwikkelen en mijn eigen keuzes te maken en hebben mij onvoorwaardelijk gesteund in de beslissingen die ik nam. Dank voor jullie liefde en vertrouwen.

Lieve Myrthe, jij bent ons zonnetje in huis. Jouw vrolijkheid en onbezorgdheid doen mij realiseren dat er veel meer is in het leven dan alleen maar werken en promoveren.

Lieve Danny, je geeft mij alle ruimte om mij 'mijn ding' te laten doen. De bergen vind jij ook mooi, maar dat rennen en klimmen laat je liever aan mij over. Onze karakters en hobby's lopen uiteen, maar dat is juist ook wat ons een heel sterk team maakt. Dank voor de onvoorwaardelijke steun en je liefde. 
118 
List of publications 


\section{List of publications}

Beerhorst K, Tan IY, De Krom M, Verschuure P, Aldenkamp AP. Antiepileptic drugs and high prevalence of low bone mineral density in a group of inpatients with chronic epilepsy. Acta Neurol Scand 2013;128:273-80.

Beerhorst K, Tan J, Tan IY, Verschuure P, Aldenkamp AP. Dual-energy X-ray absorptiometry versus quantitative ultrasonography in diagnosing osteoporosis in patients with refractory epilepsy and chronic antiepileptic drug use. Ther Adv Musculoskelet Dis 2013;5:59-66.

Beerhorst K, van der Kruijs SJ, Verschuure P, Tan IY, Aldenkamp AP. Bone disease during chronic antiepileptic drug therapy: general versus specific risk factors. J Neurol Sci 2013;331:19-25.

Beerhorst K, Schouwenaars FM, Tan IY, Aldenkamp AP. Epilepsy: fractures and the role of cumulative antiepileptic drug load. Acta Neurol Scand 2012;125:54-9.

Beerhorst K, Tan IY, Renier WO, Aldenkamp AP. Anti-epileptica en het risico op osteoporose. Tijdschr Neurol Neurchir 2010;111:239-44.

Beerhorst K, Huvers FC, Renier WO. Severe early onset osteopenia and osteoporosis caused by antiepileptic drugs. Neth J Med 2005;63:222-226.

Beerhorst K, Renier WO. Toxic epidermal necrolysis due to lamotrigine. Ned Tijdschr Geneeskd 2003;147:1128-31. 
Curriculum Vitae 


\section{Curriculum Vitae}

Kim Beerhorst werd op 18 augustus 1978 geboren in Seoul, Zuid-Korea. In 1996 behaalde zij het VWO-diploma aan het Christelijk Streeklyceum in Ede (Gelderland). Aansluitend begon zij haar studie geneeskunde aan de Radboud Universiteit Nijmegen. In haar vijfde studiejaar deed zij een co-schap interne geneeskunde in het Bezirksspital te Frutigen (Zwitserland). De interesse voor de neurologie werd gewekt tijdens het reguliere co-schap neurologie in het Rijnstate ziekenhuis te Arnhem (huidige Alysis Zorggroep) (supervisoren: dr. Q.H. Leijten en dr. R.H. Boerman). Aan het einde van haar studie deed zij onder begeleiding van prof. dr. W.O. Renier haar wetenschappelijke stage 'Toxische epidermale necrolyse bij gebruik van lamotrigine'. Prof. dr. W.O. Renier was tevens de grondlegger van het idee om onderzoek te doen naar osteoporose bij patiënten met epilepsie en anti-epileptica gebruik.

$\mathrm{Na}$ het behalen van het artsexamen in 2002 begon zij als AGNIO op de afdeling Neurologie van het Rijnstate Ziekenhuis te Arnhem. In augustus 2003 startte zij haar opleiding tot neuroloog in het Canisius Wilhelmina Ziekenhuis te Nijmegen (opleider dr. W.I.M. Verhagen). In december 2005 maakte zij vanwege de mogelijkheid om wetenschappelijk onderzoek te doen, de overstap naar de opleiding Neurologie van het Academisch Ziekenhuis Maastricht (huidige Maastricht Universitair Medisch Centrum) (opleiders: Prof. dr. M. Limburg, dr. W. Weber, dr. M. de Krom). Tijdens deze opleiding startte zij met het onderzoek naar osteoporose als gevolg van antiepileptica gebruik. Eind augustus 2009 werd de eerste patiënt van de onderzoekspopulatie die beschreven is in dit proefschrift, op de locatie Providentia onderzocht met een mobiele DXA-scan en hiel-echo.

Sinds 1 juni 2009 werkt ze als neuroloog in het Zuyderland Medisch Centrum (voormalig Atrium Medisch Centrum Parkstad) en combineerde ze het werken in de dagelijkse praktijk met het voltooien van haar proefschrift.

In haar vrije tijd loopt ze graag hard en wandelt ze in de bergen. In 2011 beklom ze met het 12-koppig artsenteam "ATAKK" de Mont Blanc $(4810 \mathrm{~m})$ onder leiding van Wilco van Rooijen. In 2012 bereikte ze de top van Peak Lenin (7134 m) in Kirgizië. In het voorjaar van 2014 nam ze een sabbatical om deel te nemen aan de 'Dutch Cho Oyu 2014 expedition' (documentaire Hemelbestormers, regisseur Geertjan Lassche). 25 Oktober 2014 werd ze bij de dames Nederlands Kampioen Verticale Kilometer in Fully (Zwitserland).

Ze woont samen met Danny Hilkman en heeft een bonusdochter Myrthe. 
Valorisation 
128 


\section{Valorisation}

\section{Relevance}

Worldwide about 65 million people are estimated to have epilepsy. ${ }^{1}$ In the Netherlands the prevalence of active epilepsy is approximately $84.000 .^{2}$ The majority of the patients diagnosed with epilepsy can expect to achieve good control of seizures with antiepileptic drugs. However, chronic use of antiepileptic drugs is not uncommon. A substantial minority of the patients will continue to experience seizures in spite of several antiepileptic drugs used in adequate doses over longer periods (sometimes decades).

Living with epilepsy is often a great burden for the patients themselves and those around them. Epilepsy sometimes results in significant disability, social exclusion and stigmatisation. People with epilepsy frequently encounter problems in several areas such as education, employment, driving, personal development, psychiatric and psychological aspects and social and personal relationships.,

In Europe, the annual cost of epilepsy is 15.5 billion. $^{5}$ In 2011 direct medical costs in the Netherlands were 248 million ( $0.3 \%$ of the health care budget). ${ }^{6}$ The three main cost drivers are health care professional visits and hospitalisation (122 million), followed by institutionalised patients ( 73.6 million) and cost of medication (36.5 million). ${ }^{6}$

Most patients with epilepsy need long-term treatment with anti-epileptic drug(s) (AEDs). Side-effects of antiepileptic drugs can be acute or chronic. The negative influence of antiepileptic drug (AED) use on bone health is classified as a chronic sideeffect. In the Dutch guideline on epilepsy 2006 active screening for possible sideeffects during antiepileptic drug therapy was advised. However, no specific advice was given for screening measures on bone health. In the update of the Dutch epilepsy guideline in 2011 advices concerning bone health are given. However, these advices are restricted to patients with epilepsy above the age of 50 years using enzymeinducing AEDs and/or valproate. Considering the body of evidence of the negative influence of AEDs on bone health in our population it seems not justified to restrict these advices to the older patients with epilepsy.

Till this thesis, in the Netherlands no data were available about the prevalence of osteopenia and osteoporosis nor of the vitamin D status in patients with refractory epilepsy. Probably more relevant are our data showing the effect of long-term AED use on the clinical end parameters bone mineral density and fractures. These data are obligatory to develop further guidelines for prevention of bone disease and to the development of protocols for surveillance and treatment of AED associated osteoporosis in the Netherlands.

Moreover, to date the Dutch Osteoporosis Foundation and the Dutch League against Epilepsy have not yet focused their attention on the prevention of metabolic bone disease as a result of chronic AED treatment. In the Netherlands, the estimated 
fracture incidence is about 5 pro mille, which means that in one year at least 420 to 500 patients with epilepsy have a bone fracture of any kind. It is not unlikely that, in agreement with a 2-6 times higher fracture risk in patients with epilepsy, ${ }^{7}$ the actual incidence of fractures is outnumbered in patients using chronic AEDs.

It has been shown that in adults and children with epilepsy and AEDs use vitamin D supplementation increases BMD significantly..$^{8,9}$ Supplementation of 800 IU vitamin D in combination with calcium has proven to be effective in the reduction of fracture risk, especially hip fractures. ${ }^{10,11}$ The annual costs of treatment with 1 dd 800 IE cholecalciferol and $1 \mathrm{dd} 1$ gram calcium are estimated at around $€ 90$ and just around $€ 54$ for vitamin D alone. The direct costs of a spontaneous fracture of a vertebrae or forearm fracture are estimated at around $€ 1000$ per year, for a hip fracture the direct costs are around $€ 12,000^{12}$ not counting the secondary costs due to loss of working capacity. Therefore, research and in the end development of guidelines for screening and treatment for metabolic bone disease in patients with epilepsy at high risk seems reasonable and cost effective. At this moment osteopenia and later on osteoporosis as a result of long-term AED use is an underestimated problem in patients of all ages, which theoretically can be quite easily prevented or treated.

\section{Target groups}

The results of this thesis are of interest for all physicians who have patients with epilepsy under their attendance. Not only neurologists and child neurologists but also general practitioners, physicians specialised in patients with intellectual disability, internist-endocrinologists and paediatricians. Also orthopaedic surgeons and emergency physicians, who are confronted with the clinical relevant aspects of low $B M D$, i.e. fractures, should know about the association between AED use and fractures. Nowadays antiepileptic drugs are also used in the psychiatric field and in the treatment of neuropathic pain. Therefore also psychiatrists and physicians specialised in pain-medicine should also be aware of the negative effects of AEDs use on bone health.

However, the results of this these are most relevant for patients with epilepsy themselves. They should be informed about the possible negative influence of AED use on their bone health. In most patients with epilepsy AED treatment is first choice treatment. Therefore monitoring bone health and discussing bone health promoting activities should be common clinical practice when starting AED treatment.

\section{Activities/products}

The research described in this thesis have led to the identification of low BMD in $80 \%$ of the patients and almost $90 \%$ prevalence of low $25-\mathrm{OH}$ vitamin D levels. All the patients with osteoporosis and vitamin D deficiency or insufficiency were treated. In all patients with low BMD (osteopenia and osteoporosis) bone health counselling was done by their treating physicians. 


\section{Innovation}

To our knowledge this is the first research done in the Netherlands in which a very large population of patients with refractory epilepsy and chronic AED use is screened for low BMD and is analysed for identification of risk factors for low BMD.

\section{Implementation}

There are plans to perform a new screening round for low BMD for all patients with AED use of the long-stay department of Providentia/Kempenhaeghe, in whom 5 years ago osteopenia or normal BMD was diagnosed. Patients with osteoporosis are already under follow-up of an internist-endocrinologist. 


\section{References}

1. Ngugi AK, Bottomley C, Kleinschmidt I, Sander JW, Newton CR. Estimation of the burden of active and life-time epilepsy: a meta-analytic approach. Epilepsia 2010;51:883-890.

2. Kotsopoulos IA, Evers SM, Ament AJ, de Krom MC. Estimating the costs of epilepsy: an international comparison of epilepsy cost studies. Epilepsia 2001;42:634-640.

3. Suurmeijer TP, Reuvekamp MF, Aldenkamp BP. Social functioning, psychological functioning, and quality of life in epilepsy. Epilepsia 2001;42:1160-1168.

4. Kobau R, Cui W, Kadima N, et al. Tracking psychosocial health in adults with epilepsy--estimates from the 2010 National Health Interview Survey. Epilepsy Behav 2014;41:66-73.

5. Pugliatti M, Beghi E, Forsgren L, Ekman M, Sobocki P. Estimating the cost of epilepsy in Europe: a review with economic modeling. Epilepsia 2007;48:2224-2233.

6. Kosten van ziekten in Nederland. In: RIVM, ed. Bilthoven2011.

7. Vestergaard P. Epilepsy, osteoporosis and fracture risk - a meta-analysis. Acta Neurol Scand 2005; 112:277-286.

8. Mikati MA, Dib L, Yamout B, Sawaya R, Rahi AC, Fuleihan Gel H. Two randomized vitamin D trials in ambulatory patients on anticonvulsants: impact on bone. Neurology 2006;67:2005-2014.

9. Pedrera JD, Canal ML, Carvajal J, et al. Influence of vitamin D administration on bone ultrasound measurements in patients on anticonvulsant therapy. Eur J Clin Invest 2000;30:895-899.

10. LeBlanc E, Chou R, Zakher B, Daeges M, Pappas M. Screening for Vitamin D Deficiency: Systematic Review for the US Preventive Services Task Force Recommendation. Rockville (MD)2014.

11. Cranney A, Horsley T, O'Donnell S, et al. Effectiveness and safety of vitamin D in relation to bone health. Evid Rep Technol Assess (Full Rep) 2007:1-235.

12. CBO KvdG. Tweede herziene richtlijn osteoporose. Alphen aan de Rijn Van Zuiden Communications, 2002. 